NBER WORKING PAPER SERIES

\title{
WHY IS MATH CHEAPER THAN ENGLISH? UNDERSTANDING COST DIFFERENCES
} IN HIGHER EDUCATION

\author{
Steven W. Hemelt \\ Kevin M. Stange \\ Fernando Furquim \\ Andrew Simon \\ John E. Sawyer \\ Working Paper 25314 \\ http://www.nber.org/papers/w25314 \\ NATIONAL BUREAU OF ECONOMIC RESEARCH \\ 1050 Massachusetts Avenue \\ Cambridge, MA 02138 \\ November 2018
}

We thank Tom Eleuterio, Xiaohang Zhao, and Ti Yan at the University of Delaware for their exceptional partnership and willingness to share generously of their deep knowledge of the Delaware Cost Study. Cassandra Baxter provided invaluable research assistance. The Smith Richardson Foundation provided critical financial support. This research was also supported in part by grant R305B150012 from the Institute of Education Sciences to the University of Michigan. Helpful comments were shared by numerous seminar participants. All errors and any opinions are our own. The views expressed herein are those of the authors and do not necessarily reflect the views of the National Bureau of Economic Research.

NBER working papers are circulated for discussion and comment purposes. They have not been peer-reviewed or been subject to the review by the NBER Board of Directors that accompanies official NBER publications.

(C) 2018 by Steven W. Hemelt, Kevin M. Stange, Fernando Furquim, Andrew Simon, and John E. Sawyer. All rights reserved. Short sections of text, not to exceed two paragraphs, may be quoted without explicit permission provided that full credit, including $\odot$ notice, is given to the source. 
Why is Math Cheaper than English? Understanding Cost Differences in Higher Education Steven W. Hemelt, Kevin M. Stange, Fernando Furquim, Andrew Simon, and John E. Sawyer NBER Working Paper No. 25314

November 2018

JEL No. I21,I22,I23

\begin{abstract}
$\underline{\text { ABSTRACT }}$
The private return to postsecondary investment varies widely by field, but the resources required by different fields are not well known. This paper establishes five new facts about college costs using novel department-level data. First, costs vary widely across field, ranging from electrical engineering (109 percent higher costs than English) to math (22 percent lower). Costs are generally higher in fields where graduates earn more and in pre-professional programs. Second, this pattern is explained statistically by differences in class size and faculty pay, though differences in production technology enable some fields to offset higher salaries with larger classes. Third, some STEM fields experienced steep declines in expenditures over the past fifteen years while others saw increases. Fourth, increases in class size and teaching loads alongside a shift in faculty composition toward contingent faculty explain these trends. Finally, online instruction is associated with a modest reduction in cost per student, but only for undergraduate instruction. Recent policy efforts to promote enrollment in high-earning fields will thus have important implications for postsecondary costs and the social return on investment in higher education.
\end{abstract}

Steven W. Hemelt

Department of Public Policy

University of North Carolina at Chapel Hill

Abernethy Hall, Campus Box 3435

Chapel Hill, NC 27599

hemelt@email.unc.edu

Kevin M. Stange

Gerald R. Ford School of Public Policy

University of Michigan

5236 Weill Hall

735 South State Street

Ann Arbor, MI 48109

and NBER

kstange@umich.edu

Fernando Furquim

University of Michigan

ffurquim@umich.edu
Andrew Simon

University of Michigan

735 S. State Street

Ann Arbor, MI 48109

arsimon@umich.edu

John E. Sawyer

327 Hullihen Hall

University of Delaware

Newark, DE 19716

sawyerj@udel.edu 


\section{Introduction}

Investment in education fosters human capital development, shapes long-term economic growth, and influences socioeconomic mobility (Goldin \& Katz, 2008; Autor, 2014). At the postsecondary level, the private return to this investment varies widely by field of study, with science and engineering fields generally having a higher labor market payoff than the humanities and social sciences (e.g., Altonji, Arcidiacono, \& Maurel, 2016; Kirkeboen, Leuven, \& Mogstad, 2016). These outcome differences have prompted policymakers to promote enrollment in highearning fields through various direct and indirect incentives to institutions and students, such as targeted scholarships and performance-based funding. However, we know very little about the economic cost of this investment or the resource consequences of steering more students into these fields.

In this paper we use novel, department-level data on costs (expenditures), outputs, and factors of production for a large and diverse sample of four-year institutions from 2000 to 2015 to provide a comprehensive descriptive analysis of instructional costs within institutions. We estimate differences in instructional costs by field, characterize associations between production factors such as class size and faculty workload and these cost differences, and document trends over time in field-specific costs. Prior work on college costs largely consists of institution-level analyses and case studies of elite private institutions, and thus cannot illuminate differences across fields for the institutions attended by most students.

We establish five new facts about college costs. First, there are substantial cost differences across fields of study. Using English as a benchmark, instructional costs per student credit hour (SCH) range from 109percent higher for electrical engineering to 22percent lower for math. The average English course with 20 students incurs approximately $\$ 12,500$ in instructional 
expenses, so these percentage differences reflect substantial levels of resources. Costs are generally higher in fields where graduates earn more and in pre-professional programs. These patterns of average cost differences also generally map to marginal cost differences. Second, most of the cross-discipline patterns can be explained statistically by large differences in class size and, to a lesser extent, differences in average faculty pay (itself a function of salaries and mix of faculty type/rank). Teaching loads and other (non-personnel) expenditures explain little of the instructional cost differences across fields. Further, some fields with highly paid faculty (like economics) offset high wages with large classes, resulting in costs that are comparable to English despite higher faculty pay. Differences in production technology that enable some departments to offset higher salaries with larger classes are thus a key determinant of cost differences in postsecondary education. Third, cost differences have evolved over time. Some STEM fields mechanical engineering, chemistry, physics, biology, and nursing - experienced steep declines in spending over the past fifteen years while others saw increases. Fourth, these trends are explained by large increases in class size (mechanical engineering, nursing) and increases in faculty teaching loads (chemistry, biology) alongside a shift in faculty composition toward contingent faculty. Finally, the extent of online instruction is associated with a modest reduction in cost per student in undergraduate, but not graduate, education.

A better understanding of cost differences across fields informs several policy domains. First, institutions and states could explicitly take the large cost differences across fields into account when setting prices and allocating resources. Many public institutions charge students differentially by college or field (Stange, 2015), and some states recognize cost differences in their appropriations formulas, but these cost differences are present even for states and institutions that do not use such practices. Second, the social return to investment in high-earning 
fields may be lower than wage premiums suggest because high-return fields also tend to be more costly to teach. This point was made in earlier work by Altonji and Zimmerman (2016), but we broaden the scope of institutions for which we now have evidence of this fact. This underscores the need for policymakers to consider the cost implications of changes in the mix of fields students study.

Finally, our analysis of cost drivers begins to inform how postsecondary institutions could temper cost escalation. College prices have grown by 40 percent between 2005 and 2015 (College Board, 2015), increasing the share of postsecondary costs shouldered by students and their families to nearly half (Desrochers \& Hurlburt, 2016) and shifting postsecondary enrollment away from four-year public universities and toward two-year colleges and less selective institutions (Hemelt \& Marcotte, 2016). Given these trends, a number of initiatives aim to “stretch the higher education dollar” (Kelly \& Carey, 2013). In Texas, some colleges answered Governor Rick Perry’s challenge to offer a \$10,000 college degree by creating programs that combine high school, community college, and four-year college instruction (Seligman, 2012). The expansion of online learning technology may also lower costs, at least among the least selective colleges (Deming, Goldin, Katz, \& Yuchtman, 2015; Bowen, 2012). In Wisconsin, Governor Scott Walker proposed increased faculty teaching loads as a way to control costs (DeFour, 2015). Our work suggests that differences in production technology enable some departments to take different approaches to cost management, from changing the mix of faculty ranks to increasing class sizes. This implies that a one-discipline-fits-all approach to addressing cost escalation is likely misguided and ineffective. An important caveat is that we focus on direct instructional expenditures and therefore abstract from other forms of expenditures by institutions that are shared across departments, such as student services or administration. 
The paper unfolds as follows. The next section situates our study within prior theoretical and empirical research on postsecondary costs, with a focus on work that goes below the institution-level. Section III describes our data and samples. Section IV presents cross-sectional cost differences by field of study, and Section V documents how these differences have evolved over time. In Sections VI and VII we dig more deeply into these patterns by exploring marginal cost and the role of instructor type and class size more specifically. Online instruction has been touted as one way that institutions can bend the cost curve. In Section VIII we describe the adoption of online instruction and its association with costs for a much larger and diverse sample than has been examined in prior work. We conclude with a discussion of the implications of our work in Section IX.

\section{Background}

\section{A. Theories of Costs and Implications for Cross-Field Differences}

Scholars have long noted the tendency for postsecondary costs to rise faster than economy-wide costs over the long term (Bowen, 2012). A range of explanations has been posited for this phenomenon, including the curse of "labor-intensive" industries in which the relative capacity to substitute capital for labor is low (Baumol \& Bowen, 1966) ${ }^{1}$, the proclivity of colleges to act like "revenue-maximizers" in effort to compete in the murkily defined race of prestige (Bowen, 1980), the temptation to spend on student amenities (Rubin, 2014; Jacob, McCall, \& Stange, 2018), and the expansion of unnecessary or duplicative administrative

1 This is often termed the "cost disease" theory, originally proposed in the context of performing arts (Baumol \& Bowen, 1966). Since higher education is labor-intensive and wages are set on a national market, instructional costs in higher education tend to rise faster than in other industries that can more easily substitute capital for labor. Productivity gains are not able to offset wage increases, holding down (or reducing) costs as they do in other industries, particularly manufacturing. The health care industry faces a similar challenge. 
positions (Campos, 2015). These theories tend to focus on macro-level phenomena and institutional behavior. However, they also provide insights relevant to the postsecondary unit chiefly responsible for instruction: the department. To understand differences across fields within institutions, we now sketch an informal economic model of decision-making for individual academic departments (programs), and then detail the implications of these broader theories of costs to the factors that shape education production at a department level.

Programs produce a set of outputs, such as quality-equivalent units of undergraduate instruction or research publications, using a large set of inputs, such as faculty of different types, classrooms, office space, technology, and laboratories. ${ }^{2}$ Programs choose inputs and how to combine them in order to maximize an objective function, which characterizes how much a department prioritizes different outputs. Programs’ maximization is done subject to a production function and department-level budget constraint, taking input prices as given. Programs will seek to equalize the marginal benefit of each input relative to its net cost. Variation in the cost of instruction per student across programs can thus be due to differences in production functions, budget constraints, input prices, or objective functions across programs. We discuss each of these in turn.

The production function that maps inputs to outputs likely varies across fields. Some subjects require intense interaction between students and faculty to produce a given level of instructional quality; others may require close supervision of students by faculty; and yet others may require costly laboratory sessions. Relatedly, some fields may be able to take

${ }^{2}$ We consider the quantity of instructional credits produced (e.g., how many classes students take) and the quality of those instructional credits (e.g., how much students learn) as separate outputs. The relative value placed on quantity versus quality likely varies across institutions (and possibly programs) and is determined by the objective function. 
advantage of economies of scale and scope. Some departments are charged with delivering general education courses for the entire institution, affecting the portion of the marginal and average cost curves faced by the department. ${ }^{3}$ Departments offering both undergraduate and graduate programs may experience scope economies, as they can tap graduate students as a pool of lower-cost instructors (e.g., Dundar \& Lewis, 1995). Such differences necessarily affect optimal class size, faculty mix, faculty teaching load, and non-personnel expenditures all of which determine costs per unit of instruction.

Budget constraints can also vary importantly by field and institution. On the revenue side, fields typically housed in separate schools such as Engineering or Business (compared to the College of Arts and Sciences) have different opportunities for revenue generation due to the use of differential pricing (Stange, 2015) or decentralized budgeting (often referred to as “responsibility centered management”). Both dictate how much of tuition revenue specific departments can keep. Some states, such as Ohio, Texas, and North Carolina, explicitly provide higher levels of appropriations for certain fields that are perceived to be more costly. Finally, given the large cross-major earnings differences among graduates, some fields will have greater opportunities to raise donations from alumni. ${ }^{4}$ These factors alter departments' incentives and potential for revenue generation which is used to fund investment. On the cost side of the budget constraint, programs may differ in the extent to which they internalize personnel and other expenses at the margin, again depending on institutional budgetary and cost-sharing practices.

${ }^{3}$ The data allow us to focus on average instructional costs, but we cannot observe marginal costs.

${ }^{4}$ Monks (2003) finds empirical supports for such differences. 
Though the "cost disease" theory refers to patterns of cost growth over time, its logic easily extends to cross-field differences. Higher input prices - most importantly the salaries that faculty command on the non-academic market - will make instruction of certain fields more expensive. However, the extent of substitutability of different inputs in the production process will determine how influential specific input prices are to overall cost differences. For instance, an ability to shift to larger classes without a meaningful reduction in quality in response to high wages would constrain cost differences across fields.

Finally, programs may differ in their objectives. In particular, programs may differ in the extent to which they value quality versus quantity of instruction and between undergraduate instruction, graduate training, research output, and public service. We do not take a stand on programs' particular objectives, but it is reasonable to assume that most programs strive to maximize something like the number of quality-adjusted degrees. ${ }^{5}$ However, we do not expect meaningful differences in objectives across fields in the same institution given that reputation, admissions, and faculty research expectations mostly operate at the level of the institution. For instance, tenure decisions are ultimately approved by university-wide committees or administrators specifically to enforce institution-wide quality

${ }^{5}$ There is some literature on the goals of universities. Rothchild and White (1995) assume colleges are profit maximizing while Epple and colleagues $(2006,2017)$ assume that colleges are quality maximizing. If universities and programs have similar objectives since they are part of the same organization, assuming programs maximize quality of instruction is consistent with previous research. However, given our data and the purposes of this article, we need not impose this assumption, but instead, we discuss how well it fits the findings that emerge. It is also worth noting that because of our data, we focus on instruction, but programs may also care about other outputs, like research and public service. 
standards. Throughout the paper, we attempt to tie relevant findings back to this simplified model of the academic department. ${ }^{6}$

\section{B. Prior Evidence on Costs in Higher Education}

Most prior work on costs in higher education uses institution-level measures from the Delta Cost Project (DCP) and IPEDS, documenting trends over time and differences by type of institution (e.g., Desrochers \& Hurlburt, 2016). ${ }^{7}$ For instance, Hoxby (2009) demonstrates that institutional spending became more stratified across institutions as the college market became more nationalized, with the most selective institutions increasing spending considerably more than the least selective institutions over the past forty years. ${ }^{8}$

This paper builds on very limited prior work on differences in costs across fields and within institutions, and is most closely related to three previous papers. Altonji and Zimmerman

${ }^{6}$ The department-level focus also ignores spillovers across departments and general equilibrium effects operating through overall student demand. For instance, students need a fixed number of classes to graduate so a reduction in course demand in one department will typically be offset by increased demand in another. Programs housed in separate schools may be less sensitive to this because they can more easily increase enrollments through their own admissions processes and demand is likely more inelastic since transferring (within a university) is costly.

${ }^{7}$ Desrochers and Hurlburt (2016) use DCP data to document changes in spending between 2003 and 2013. They find large increases in total expenditures at research-intensive universities, with smaller increases at public and private institutions less focused on research. Education and related expenses, which include expenditures on instruction, student services, and (prorated) administration and operation costs, range from almost \$38,000 per full-time equivalent (FTE) student at private research-intensive universities, to around $\$ 13,000$ per FTE at public master's institutions.

${ }^{8}$ Archibald and Feldman (2011) also use aggregate data to explore the numerous explanations for cost increases, concluding that the "cost disease" theory goes a long way toward explaining aggregate cost trends. Other explanations - such as administrative bloat and student amenities do not seem to hold up to scrutiny. They find that the apparent increase in number of administrative jobs at colleges is due to changes in how workers are classified in survey data and increased spending on amenities does not appear to be out of line with similar trends in residential spending. In the end, Archibald and Feldman (2011) tie the increasing costs of higher education much more strongly to "economy-wide" factors that affect higher education as well as other similar industries rather than to "dysfunctional economic behavior at colleges and universities” (p. 113). 
(2017) estimate the costs of producing graduates at the program level for the Florida State University System. They report, among other findings, substantive differences in costs by discipline, bookended by engineering and health sciences at the top (with spending of around \$450 per credit) and social science, math, business, and psychology at the bottom (with costs ranging from $\$ 200$ to $\$ 250$ per credit). ${ }^{9}$ These large cost differences cause the earnings differences across fields to be a misleading indicator of the social return on investment across fields.

Johnson and Turner (2009) document large differences in students per faculty across departments for several sets of institutions and the University of Virginia. They find that the number of faculty relative to undergraduate student demand is much higher in sciences and humanities than in core social science fields like economics and political science. While differences in salary, research output, and pedagogy likely explain some of these patterns, they conclude that political frictions constrain universities from dynamically reallocating resources across units in response to student demand. More recently, Courant and Turner (2017) examine how resources are allocated at the University of Michigan and the University of Virginia. They find that departments facing higher faculty salaries allow larger classes and more non-faculty teaching. Furthermore, higher-paid faculty within departments teach fewer undergraduates and specialize in graduate instruction.

${ }^{9}$ There are a few earlier studies that focused on a small sample of departments and institutions. Tierney (1980) found that the sciences (biology, chemistry) have costs per student that are 20 percent to 50 percent higher than programs in the social sciences or humanities in 24 liberal arts colleges. Examining 17 departments across 18 public research universities, Dundar and Lewis (1995) find economies of scale for engineering but not for physical sciences. They also found economies of scope in the social sciences, where offering graduate degrees enables departments to employ graduate students as teaching assistants, resulting in cost savings. 
Our study also builds on very detailed case studies of a small number of elite institutions. Clotfelter (1996) investigates Chicago, Duke, Harvard, and Carleton, concluding that the rise in costs during the 1980s was only partially attributable to increased prices of inputs such as faculty salaries and books. Increased spending was mostly explained by broad efforts to improve institutional quality, expand research output, and improve access via financial aid for needy students. Greater instructional costs were mostly driven by affirmative decisions by institutions to pay "for more and better units of the educational services that these institutions always had produced.” (Clotfelter, 1996, p. 13). A specific aspect of this is costly investments in new technology - such as computers and physics labs - which have benefited students and faculty and increased research output (Bowen, 2012). Examining Cornell University, Ehrenberg (2002) reaches a broadly similar conclusion: increasing costs reflect a desire to "be the best" on the part of elite research universities, which is consistent with revenue theory and quality maximization, broadly defined. This behavior is unconstrained by typical market forces, as non-profit and public entities do not profit-maximize since they cannot keep any residual surplus of revenue over cost as profit. Ehrenberg (2002) also notes several external and structural forces that fuel this behavior, such as colleges explicitly being rewarded for higher spending in college rankings and shared governance making substantial cost-cutting nearly impossible.

We build on this prior work to make four contributions. First, our focus on withininstitution, program-level costs is novel (with the few exceptions noted above) and reflects the reality that "departments constitute the fundamental organizational unit of colleges and universities” (Tierney, 1980, p. 454.) ${ }^{10}$ Second, we look at a much larger set of institutions

${ }^{10}$ Academic programs have a great deal of discretion in defining curricula, setting academic standards, and hiring and promoting faculty (Lattuca \& Stark, 2009) - all of which shape instructional costs. Adoption of differential tuition (Stange, 2015) and responsibility-centered 
across more sectors. It is not clear if the patterns seen in prior work generalize nationally or to other sectors. Third, using this broader sample, we examine the role of several factors of production such as class size, faculty workload, and online instruction in shaping departmentlevel costs. Finally, we look over a longer and more recent time period. Importantly, Johnson and Turner’s (2009) analysis ends before the Great Recession when many states cut higher education funding considerably.

\section{Data Sources and Samples}

\section{A. The Delaware Cost Study Data}

We use data from the National Study of Instructional Cost and Productivity from the University of Delaware (the Delaware Cost Study). Since 1998, the study has collected programlevel data from over 700 four-year public and private non-profit higher education institutions and some 22,000 programs (institution-CIP4). ${ }^{11}$ Each year, institutions report degrees awarded, fall semester instructional activity, and annual expenditure data for each of their academic programs, which are identified at the four-digit CIP code level. ${ }^{12}$ For degrees awarded, institutions report a three-year average by level: bachelors, master's, professional, and doctorate. Fall instructional activity is measured by faculty full-time equivalents (FTEs), student credit hours, and organized class sections. Institutions report overall and instructional FTEs by faculty type: tenured and tenure eligible, other regular, supplemental, credit-bearing teaching assistants, and non-creditbearing teaching assistants. They also disaggregate student credit hours and class sections by faculty/instructor type and the course level: lower-division undergraduate, upper-division

management (Priest, Becker, Hossler, \& St. John, 2002) lend further support to the importance of disaggregating measures of cost to the academic program level.

${ }^{11}$ Appendix Table A1 lists frequently participating institutions.

${ }^{12}$ Appendix Figure A1 provides a copy of the form used by institutions to report these data. 
undergraduate, and graduate. Finally, institutions report total direct expenditures for instruction, research, and public service and total undergraduate and graduate student credit hours for the entire academic year.

In this paper, we work with direct instructional expenditures per student credit hour as our main measure of costs, which include salaries, benefits, and non-personnel expenses. In 2015, the Delaware Cost Study added a component to the survey to capture information about online instruction. In that first year of data collection, 5,891 unique programs from 264 fields of study across 175 institutions completed the questions about online courses - over 94 percent of participants. The data contain information on online student credit hours by department at the undergraduate and graduate levels.

Institutions choose whether to report data to the Delaware Cost Study. Therefore, we assessed how well our sample matched the broader universe of public and private non-profit four-year institutions operating in the United States. ${ }^{13}$ We found that over a third of all institutions had participated in the Delaware Cost Study at least once (34.2percent) and that these institutions accounted for 60.1 percent of all the degrees awarded between 1998 and 2015. However, institutions do not participate every year and some fail to report data for all of their departments. Accounting for these gaps, we estimate that our sample represents 23.3 percent of all degrees awarded between 1998 and 2015. Coverage is higher for public institutions than private (32.2 percent versus 7.8 percent of degrees, respectively). Public research universities ranked as “competitive” or "very competitive” by Barron's have the highest rates of survey

${ }^{13}$ We defined the relevant universe as public or private non-profit bachelors, master's, and research-intensive doctoral institutions operating in the 50 states and the District of Columbia between 1998 and 2015, from the IPEDS Completions survey. The final universe includes 1,786 institutions that granted 34.9 million degrees. 
participation. Finally, we find no association between expenditures and participation, after controlling for sector, type, selectivity, size, and revenue, but we do find a positive association for both tuition (among privates) and enrollment (among publics) with survey participation. We use this participaption analysis to construct a set of analytical weights which adjusts our sample to resemble the universe of four-year institutions. Appendix B provides a detailed explanation of the coverage analysis and weighting procedure.

\section{B. Analytic Sample}

We limit the analytic sample to data collected between 2000 and 2015 from researchintensive, master's, and baccalaureate institutions in the United States. ${ }^{14}$ We exclude observations that were missing critical data or had outlying values for the main variables. ${ }^{15}$ Our analysis focuses on 20 core fields of study; they represent the largest fields in terms of student credit hours delivered or fields that are particularly salient for institutional leaders and policymakers. ${ }^{16}$ Our final sample contains 32,496 institution-year-CIP-4 observations representing 552 institutions, 20 disciplines, and 7,150 unique programs. We use the full sample for our longitudinal analyses and pool years 2013 to 2015 for cross-sectional analyses. The cross-sectional sample includes 7,245 institution-year-CIP-4 observations representing 314 institutions, 20 disciplines, and 3,950 unique programs. The online sample is restricted to the 2015 survey year and consists of 2,051 programs in 20 disciplines and 173 institutions.

\footnotetext{
${ }^{14}$ We use Carnegie Classification to identify institution type. We exclude 13 special-focus institutions due to small sample sizes. We also exclude 11 institutions outside the United States and the District of Columbia. Finally, we drop a small number of observations that did not pass a series of basic data validity checks (e.g., negative FTE values were provided).

${ }^{15}$ We define outliers as values greater than the $99^{\text {th }}$ percentile or lower than the $1^{\text {st }}$ percentile of all values grouped by Carnegie Classification and 2-digit Classification of Instructional Programs (CIP) codes.

16 These fields along with CIP codes are listed in Appendix Table A2.
} 
Using these data, we construct variables that measure costs, outputs, and inputs. Our primary outcome of interest is direct instructional spending per student credit hour, which we construct by dividing annual instructional costs by annual student credit hours. We also calculate this ratio for the personnel expenditures portion of costs. ${ }^{17}$ In terms of candidate cost drivers, we calculate faculty per student (overall and by faculty rank level), faculty teaching load (overall and by faculty rank level), and average class size (overall and by student level). Where necessary, we follow IPEDS guidelines for calculating FTEs for faculty and students. ${ }^{18}$ We construct a measure of faculty teaching load by dividing the total number of class sections by faculty FTE. To generate a measure of class size, we divide fall student credit hours (excluding individual instruction) by three, assuming the average class is three credits, and then divide this student count by the total number of course sections (excluding additional course sections, such as labs and discussion sections). ${ }^{19}$

\section{Descriptive Statistics}

Table 1 presents summary statistics for the main variables in the full sample, separately by Carnegie classification. ${ }^{20}$ All analyses, summary statistics, figures, and regressions are weighted by the product of the inverse probability of participating and student credit hours at the program level. This provides estimates that reflect the average student course enrollment in the country. Research-intensive institutions spend more per credit hour, on average, than do master's

${ }^{17}$ Before constructing these variables, we convert all cost data to 2015 dollars using the CPI-U. 18 The student FTE equals $1 / 3^{\text {rd }}$ of total adjusted part-time student count plus the count of fulltime students; faculty FTE equals $1 / 3^{\text {rd }}$ of total adjusted part-time instructional staff plus the count of full-time instructional staff.

${ }^{19}$ We calculated additional class size variables to use for robustness checks that assume the average course is four credits. Results are similar when we use this higher credit value.

${ }^{20}$ Appendix Table A3 presents the same statistics for the pooled, cross-sectional sample of 2013 to 2015. Patterns are similar. 
and baccalaureate institutions. The gap between institutions with the highest research activity and baccalaureate colleges is about $\$ 54$ per credit hour. This is a sizeable gap relative to the average for all institutions in the sample of about $\$ 222$ per credit hour. Teaching loads are also lower at research institutions. Compared to faculty at baccalaureate institutions, faculty at high and moderate research institutions teach about 1.2 and 0.7 fewer classes per semester. Smaller teaching loads may influence undergraduate class sizes, which are larger at high and moderate research institutions, respectively, compared to baccalaureate institutions. ${ }^{21}$

These differences likely reflect differences in objective functions. If instruction, rather than research, contributes more to a baccalaureate institution's objective, then holding the production function constant, theory predicts that departments will spend relatively more of their budgets on instructional quality through smaller classes. Similarly, we expect lower teaching loads where research output constitutes more to universities objectives.

Figure 1 depicts average instructional costs per student credit hour from 2000 to 2015, in 2015 dollars. Contrary to the narrative of soaring tuition prices, real instructional expenditures per student credit hour have remained quite flat over the past 15 years. As we show below, this steady, institution-level average obscures substantial variation in costs over time by field of study. Figure 2 shows cross-sectional variation in expenditures across different fields. Electrical engineering averages more than $\$ 475$ per student credit hour, about $\$ 300$ more than for math.

What drives these differences across fields? As a prelude to subsequent analyses, Figure 3 depicts variation in four key determinants of costs at a department level: class size, instructor salary, workload, and non-personnel expenses. There are clearly big differences in these factors of production across fields, particularly in class size (student credit hours per section) and

${ }^{21}$ Graduate classes are about the same size across institution type. 
average salary. Below we quantify the individual contribution of each factor to explaining the cross-field cost differences observed in Figure 2.

\section{Cross-sectional Differences}

\section{A. Cross-Field Differences in Instructional Costs}

Using a pooled sample from 2013 to 2015 as a single cross-section, we document differences in average direct instructional costs with the following econometric setup:

$$
\ln \left(y_{c i}\right)=\alpha+\delta_{c}+\varphi_{i}+\varepsilon_{c i}
$$

Here, $y_{c i}$ is direct instructional expenditures per student credit hour in 2015 dollars for discipline $c$ (i.e., CIP-4 code) at institution $i ; \delta_{c}$ are CIP-4 fixed effects; $\varphi_{i}$ are institution fixed effects; and $\varepsilon_{c i}$ is a stochastic error term. We use the most common discipline in our data, English, as the reference category. Thus, the coefficients on the vector of discipline fixed effects $\left(\delta_{c}\right)$ represent the average log difference in instructional costs per credit hour relative to English, controlling for fixed, time-invariant characteristics of institutions. ${ }^{22}$ Alternatively, we can think of these parameters as the across-field differences within institutions, averaged across institutions.

Figure 4 reports cross-sectional differences in costs across disciplines, after netting out institutional differences using equation (1). There is substantial variation across fields in average costs. For example, costs associated with each additional SCH are 109 percent (0.74 log points) higher for electrical engineering and 22 percent lower for math, relative to English. Most social science disciplines, math, and philosophy are relatively less costly whereas STEM fields and those with traditionally large pre-professional programs (e.g., nursing) are relatively more costly. This broad conclusion holds across institutions of different control, research intensity, and

${ }^{22}$ The inclusion of institution fixed effects does not materially alter our estimates of cross-field cost differences, as most institutions in the data offer a variety of disciplines and this is not systematically related to costs. 
selectivity. ${ }^{23}$ That is, a field like computer science is moderately more expensive than English no matter whether it resides in a private comprehensive institution or a public research-intensive institution. We therefore pool institutions going forward.

Which fields are more expensive? Table 2 catalogues a few characteristics of fields ordered by their relative cost. Though several of the more costly fields also tend to have high earnings (e.g., engineering and computer science), there are exceptions to this general pattern. For instance, education and fine/studio arts are among the most costly programs and also the lowest paid. Higher-earning fields being more costly to produce is generally consistent with the university equalizing the ratio of economic benefits and costs across fields, though these measures do not capture the full extent of costs and benefits, nor do they capture them at the margin.

More costly fields also are more likely to have access to additional revenue sources than English departments. In both revenue theory and quality maximization, we expect fields with access to larger budgets to have greater expenditures. Almost all of the most costly fields are typically housed in separate schools or colleges from English, permitting them to generate additional revenue through differential tuition or separate fund-raising efforts from alumni or industry. Finally, many of the more costly fields receive additional state appropriations in Texas and North Carolina, two states with large systems of public institutions for which we obtained detailed information on budgeting formulas. ${ }^{24}$

${ }^{23}$ Appendix Figures A2 and A3 show cost differences for public relative to private institutions and for institutions of varying levels of selectivity. The broad conclusions about field-specific costs are similar to what we see in the pooled sample.

${ }^{24}$ Note that the causal direction is unclear. States are aware of cost differences between fields and thus target additional resources to more costly fields. 


\section{B. Why Do Costs Differ Across Fields?}

To quantify how these cross-field differences can be explained, in a statistical sense, by individual factors of production, we develop an accounting identity in the spirit of Clotfelter (1996) and estimate its logged form. We replace the field fixed effects from equation (1) with terms that capture four cost components: ${ }^{25}$

$\ln \left(y_{c i}\right)=\varphi_{i}+\ln \left(\frac{\text { dir instr exp }}{\text { personnel }}\right)_{c i}+\ln \left(\frac{\text { personnel }}{\text { facFTE }}\right)_{c i}+\ln \left(\frac{\text { facFTE }}{\text { sections }}\right)_{c i}+\ln \left(\frac{\text { sections }}{S C H}\right)_{c i}+\varepsilon_{c i}(2)$

The first factor captures the importance of personnel expenses relative to all direct instructional expenditures. The second term represents average faculty salary, which is determined by the mix of faculty ranks (e.g., tenure-track faculty, fixed-term instructors, adjunct faculty) and average salary conditional on rank. The third term is an inverse measure of faculty workload (i.e., the inverse of class sections taught per FTE faculty member). Finally, the last term captures (the inverse of) class size. Differences in these four cost factors explain variation across programs in costs to deliver a credit hour, or an approximation of the production function. A given program may be more expensive than another because it employs more expensive faculty; because its faculty have a lower average teaching load; because its classes are smaller; or because the department incurs a greater level of other non-personnel instructional expenses (e.g., laboratory expenses in the sciences).

Since equation (2) is the log of an accounting identity, the coefficients on the cost drivers ought to be one and the constant zero. However, the time horizon over which the dependent

${ }^{25}$ Average direct instructional costs per student credit hour for any given program can be decomposed into four distinct components of cost:

$$
\left(\frac{\text { dir instr exp }}{S C H}\right)=\left(\frac{\text { dir instr exp }}{\text { personnel exp }}\right)\left(\frac{\text { personnel exp }}{\# \text { faculty FTE }}\right)\left(\frac{\# \text { faculty FTE }}{\# \text { sections }}\right)\left(\frac{\# \text { sections }}{S C H}\right)
$$


variable is measured differs from the horizon over which the components of the cost drivers are captured, so coefficients will not exactly equal one. ${ }^{26}$ Once the four cost drivers are included in the regression, the coefficients on those measures are indeed quite close to one. ${ }^{27}$ In all analyses, we cluster standard errors by institution and weight observations by the product of total student credit hours and the inverse probability of participating in the survey. This ensures that the sample is approximately representative of instruction across all institutions.

We determine the relative importance of each cost driver in explaining cost differences by field via a series of simulations. Continuing with English as the benchmark field, we predict costs for each of the 19 other disciplines by varying one cost driver at a time and holding the rest constant, at the values for English. Table 3 presents the results of this decomposition. The first column reproduces the unadjusted cost differences from Figure 4. Each subsequent column estimates the contribution of a particular cost driver to the overall cost difference between a given field and English. First consider economics, which is approximately 5 percent less expensive than English. Economics faculty are more highly paid than English, and thus if all cost drivers other than average pay were equalized between the two fields, economics would be 0.38 log points more expensive (column 2). On the other hand, economics classes tend to be much larger than English classes, so class size differences make economics 0.50 log points less expensive than English (column 4). Faculty workload is a little lighter in economics than English, so if that were the only difference, economics would be 7 percent more expensive than English. Putting these findings together, we see that economics departments are able to field

${ }^{26}$ Specifically, direct instructional expenditures is measured over the full academic year, but the four cost factors only capture the fall semester of an academic year. Appendix $\mathrm{C}$ works out the implications of these data realities for our estimating equation.

${ }^{27}$ Regression results are reported in Appendix Table A4. 
classes that are large enough to more than offset the higher salary and (slightly) lower workload of economics faculty, resulting in slightly lower average costs than English.

Mechanical engineering, which is 82 percent more expensive than English (or 0.60 log points), provides a counter example. Like economics, mechanical engineering professors also command higher wages and have lower teaching loads than English faculty. As a result, the average difference in faculty pay across these two fields contributes substantially to the overall cost difference. Unlike economics, however, classes are only modestly larger in mechanical engineering than in English. Class size differences are not large enough to offset the higher salary and lower teaching load, thus mechanical engineering remains much more expensive than English.

Though each field is slightly different, a few general patterns emerge. Economics, political science, accounting, and business have high salaries which are offset by large classes, though not completely for the latter two fields. Engineering and nursing are more expensive than English due to higher salaries and lower teaching loads without commensurately larger classes. Workload and non-personnel expenses are important for some of the sciences with laboratory components, namely biology and chemistry, but otherwise explain relatively little of the observed cost differences.

More generally, instructional cost differences across fields can mostly be explained by large differences in class size across disciplines and, to a lesser extent, differences in average faculty pay. Teaching loads and other (non-personnel) expenditures explain relatively little. Further, some fields with highly paid faculty (like economics) fully offset salaries via large 
classes, generating costs that are comparable to English despite the higher pay. ${ }^{28}$ One explanation is that these patterns reflect important differences across field in the production function of higher education - some fields are more amenable to the large, lecture-based format needed for large classes without a commensurate reduction in instructional quality. An alternative interpretation is that fields have different objectives dictating how they value instructional quality and other outputs. While possible, our within-institution analysis likely minimizes the role of preference differences as an explanation. Within institution, departments are overseen by common Provosts and Deans and also compete for students.

\section{Differences in Costs Over Time by Field of Study}

Figure 5 plots field-specific trends in instructional costs since 2000 and net of institutionby-field fixed effects. Several trends are noteworthy. First, there are appreciable declines in costs in several STEM fields - mechanical engineering, chemistry, physics, and biology - as well as in nursing. A few fields experienced growth in costs during this time period, including English, accounting, communication, and fine arts. Finally, several fields - mostly social sciences experienced declines in expenditures that recovered by the end of the sample period. These striking differences across fields are masked when one looks at the aggregate spending trend shown in Figure 1.

Though several fields experience unusual time patterns, we focus on cross-field differences in the linear time trend over the whole sample period, estimated with the following setup:

$$
\ln \left(y_{c i t}\right)=\varphi_{c i}+\beta_{1} \text { time }+\gamma_{d}\left(\text { time } * \delta_{c}\right)+\varepsilon_{c i}
$$

${ }^{28}$ It is worth recalling that these average pay differences already reflect instructor mix differences across fields, so they likely attenuate market-level pay differences across fields for instructors of a given rank. 
Here, $y_{\text {cit }}$ is the log of direct instructional expenditures per student credit hour in 2015 dollars for discipline $c$ (i.e., CIP-4 code) at institution $i$ in year $t$. This model includes fixed effects at the program level (field-by-institution, denoted $\varphi_{c i}$ ), controlling for time-invariant characteristics of academic programs. The coefficients of interest are the field-specific linear time trends in $\gamma_{d}$. They represent annualized changes in costs over the 15 year time period, relative to English. Thus, $\beta_{1}$ captures the annual time trend in costs for English departments. Instead of costs, the outcome $y_{\text {cit }}$ can also represent a particular cost driver, such as the log of average class size for discipline $c$ at institution $i$ in year $t$.

Figure 6 presents estimates from equation (3) of the average yearly changes in instructional costs and each of our four cost drivers. Each bar is equal to $\beta_{1}$ plus the fieldspecific $\gamma$; the average annual change for English is simply $\beta_{1}$. Panel A of Figure 6 arrays disciplines by the average annual percentage increase in direct instructional expenditures per SCH between 2000 and 2015. Panels B, C, and D array disciplines by average growth in cost drivers over the same period. Costs grew for many fields, especially Fine Arts and Education, while a subset of largely STEM-related fields saw real declines in costs. Changes over time in costs for most fields are quite linear; however, our approach will be a relatively poorer approximation of the experiences of fields with non-linear cost changes over time, such as electrical engineering and computer science. ${ }^{29}$ Focusing on one field across these panels allows one to tell a story about the drivers of field-specific cost changes over time. For example, in chemistry, the decline in costs over time of about 1.5 percent per year is explained by an increase

${ }^{29}$ Appendix Figures A4 to A7 show the full trends over time in instructional costs and cost drivers by field. 
in average class size and a large increase in average faculty workload, which together more than compensate for the modest rise in faculty salaries.

Table 4 decomposes the field-specific linear growth rates show in Figure 6 into the contribution made by changes in each of the four factors. Column (1) reports the average annual change in instructional costs for each of our 20 fields. The contribution to overall cost trend for each driver is reported in columns 2 to $5 .{ }^{30}$ The findings that emerge from this panel analysis largely concord with our cross-sectional analyses: across many fields, changes in faculty salaries and class sizes over time account for the bulk of changes in instructional costs between 2000 and 2015. For instance, mechanical engineering saw a 2.17 percent reduction in cost each year, which is more than fully explained by the 2.36 percent annual increase in class size. Costs for accounting rose by 0.83 percent annually, driven by faculty salary growth of 1.55 percent that outpaced offsetting increases in workload and class size. Some fields saw notable changes in faculty workload: Psychology, education, English, and media/communications studies all saw reductions in faculty workload over this period, which increased costs, while chemistry experienced a notable increase. For no field did changes in non-personnel expenditures increase costs, and for a few STEM fields there were appreciable declines in such expenditures - perhaps reflecting lower technology or lab-related costs.

For a handful of fields, the linear, annualized growth rates are poor approximations of actual, non-linear trends in costs. One of the clearest examples of such a field is electrical engineering. Appendix Figures A4 to A7 show the full trends in direct instructional expenditures

${ }^{30}$ For example, electrical engineering costs increased by 0.52 percent annually on average. Changes to salaries alone would have resulted in a 0.93 percent annual increase; reductions in workload would have resulted in a 0.87 percent increase. These are offset by reductions in cost due to increasing class sizes (-1.14 percent) and a modest decline in other expenses (-0.13 percent). Summing columns 2 to 5 equals the annual percentage change reported in column 1. 
and cost drivers over time by field. The inverted-U shaped cost curve visible in Figure 5 for electrical engineering tightly tracks the trends for average class size and teaching workload in Appendix Figures A4 and A6. The story for computer science is very similar: a decline in average class size alongside an increase in average faculty salaries over the first half of our time period pushed costs up, while an increase in average class size and decline in salaries over the second half accounts for the bulk of the decline in average instructional costs during those years. Thus, we encourage readers with particular interests in fields that have highly non-linear cost trajectories to consult the raw trends in costs and cost drivers available in these appendix figures.

\section{Average versus Marginal Cost}

Our focus so far has been on differences in average costs across fields and over time. Of additional relevance for institutions, however, is how total cost changes as they provide more (or less) instruction; marginal cost is highly relevant for decision-making. Providing an additional credit hour of instructional activity may be more costly for some fields than others due to differences in production functions. We test this by contrasting average and estimated marginal cost for each of the 20 fields. Average cost is more straightforward to assess, as it is directly observed (Figures 2 and 6 show unconditional and conditional estimates, respectively). Table 5 presents estimates of average and marginal cost by field. We assume marginal cost is constant and we estimate it as the coefficient on total credits when regressing total instructional cost on total credits, separately by field. ${ }^{31}$ Our preferred estimates include program-level fixed effects, correlating within-program changes in instructional output with changes in instructional cost. It should be noted that prior work estimating returns to scale relied on cross-sectional variation

${ }^{31}$ We explored several ways of relaxing this constant marginal cost (linear total cost) assumption. Estimates of field-specific piecewise linear total cost curves do not show obvious patterns of decreasing or increasing marginal cost for most fields. 
(column (2)), which is quite biased by unobserved factors that are correlated with scale and cost (comparing (2) to (3)).

Similar to average cost, we find large differences in marginal cost across fields. Patterns of average and marginal cost are similar, with some exceptions. Electrical engineering has both the highest estimated marginal cost (\$228) and average cost (\$410) and many of the lowest average cost programs (mathematics, sociology, psychology, and philosophy) have very low marginal cost. Chemistry, however, has the lowest estimated marginal cost of $-\$ 72$, meaning that Chemistry program expansion is actually associated with a decrease in total instructional cost in our data. This could be due extreme economies of scope as in Dunbar and Lewis (1995), changes in program quality, or changes in the level of other outputs (research or public service output of faculty) since our cost function estimates incorporate the endogenous responses by programs. Reductions in program quality (larger classes, less qualified instructors) could then have negative impacts on student performance.

We test for the possibility of scope economies by estimating the marginal cost functions separately by the presence of graduate education, shown in the last two columns. ${ }^{32}$ We find an estimated marginal cost of $-\$ 115$ for chemistry programs with graduate education, and \$115 for those without. This is consistent with a disproportionately greater use of graduate students as low-cost instructors when programs expand scale. We see a similar story in computer and information sciences, biology, physics, and psychology. In professional degree fields, like electrical engineering, nursing, education and business, the marginal cost is much larger when graduate education is present than in undergraduate-only programs. This is again consistent with

${ }^{32}$ Unfortunately our data do not separate costs between graduate and undergraduate instruction. 
the economies of scope explanation since large master degree programs in those fields do not typically generate more teaching assistants.

Our four cost drivers play a similar role for marginal cost as they do for average cost. Programs with high faculty workload, such as chemistry, biology, physics, and computer and information sciences, tend to have low marginal cost. In these fields, program expansion in

response to increased student demand can be accommodated by current faculty teaching more for the same salary, with modest increase in instructional cost and an unclear effect on the quality of instruction.

\section{Deeper Investigation of Faculty Salary and Class Size}

In this section, we further investigate the two factors that account for the bulk of crossfield differences in costs cross-sectionally and over time: faculty salary and class size.

At the department level, faculty salaries are a function of the mix of faculty (e.g., share tenure-track, share supplemental/adjunct) and average salary level conditional on type/rank. In our data, we cannot disaggregate compensation by faculty type; therefore we focus on faculty mix and its relationship to personnel expenditures. ${ }^{33}$ Figure 7 displays cross-sectional differences in faculty mix by field. There is quite a bit of variation in the share of tenure-track faculty by field, with only 40 percent of nursing faculty on the tenure track but nearly three-quarters of mechanical and electrical engineering faculty in tenure-track roles. English, communications, and math also have relatively low shares of tenure-track faculty. Thus greater use of tenure-track faculty, which are more expensive, is one explanation for higher personnel costs in engineering, economics, and the sciences. The greater use of such faculty could reflect a number of things,

33 This means that we cannot formally integrate our disaggregated explorations of this driver (nor the next) into the accounting identity that guided our decomposition analyses. 
including how different faculty types enter into the production function or differences in the availability of non-tenure-track instructors to draw on to teach. ${ }^{34}$

In Figure 8, we document trends in faculty mix over time by field. The majority of fields experienced a clear decline in the share of tenure-track faculty between 2000 and 2015 alongside offsetting increases in shares of contingent faculty. This drop was especially pronounced for nursing, where by 2015 the typical nursing program had roughly equal shares of tenure-track and “other” faculty and a relatively large share of "supplemental” faculty. This change in faculty rank mix is reflected in the salary trend for nursing, where we see a modest decline. For example, if tenure-track faculty in nursing became more expensive over this time, programs may have chosen less expensive faculty types to combat cost growth and satisfy their budget constraints. The shift in nursing faculty may also reflect changes to nursing instruction itself, toward RN-toBSN programs with greater reliance on contingent faculty.

In economics, the shares of tenure-track, other, and supplemental faculty remained relatively stable between 2000 and 2015 while average expenditures on faculty salaries trended upward. This suggests that in economics, changes in salary expenditures were largely related to increases in salary conditional on rank (likely rising salaries for tenure-track positions) rather than changes in the mix of faculty types. Costs also increased during this time period, implying that economics departments must have been able to secure larger budgets or adjust other cost drivers such as class size, faculty workload, or faculty mix to accommodate higher faculty salaries, conditional on rank. In panel C of Figure 6, we see a moderate increase in average class size over this period for economics. In contrast, psychology saw a notable decline in the share of

${ }^{34}$ The share of tenure-track faculty will also relate to the program's desire for research productivity, which we do not examine. 
tenure-track faculty from 2000 to 2015 and an increase in the share of non-tenure-track instructors; yet, average expenditures on psychology faculty salaries increased on par with other fields over this period. There could be several explanations for such a pattern - from stagnating salaries for tenure-track faculty in psychology to a smaller gap between tenure-track salaries and non-tenure-track salaries relative to other fields.

We now turn to the second key cost driver, class size. Differences in class size are a function of the mix of course types offered (i.e., lower-level undergraduate, upper-level undergraduate, and graduate) as well as the average class size conditional on type of course. Figure 9 shows substantial differences in the mix of course types offered, with relatively fewer lower-division courses in professional fields like nursing, education, and business, and many lower division courses in the sciences (physics and chemistry) and mathematics. Fields with relatively little undergraduate instruction, like engineering and nursing, tend to be more expensive.

Figure 10 presents trends in average class size by course type for each field (Panel A) as well as trends in the mix of course types by field (Panel B). Pairing findings from these figures with the overall trends in class size by field yields deeper field-specific insights. For example, the marked increase in average class size for nursing was partially driven by a decrease in the share of credits that were lower-division undergraduate and an increase in the share of graduatelevel credit hours. Average class sizes for all types of nursing courses, undergraduate and graduate, also trended upward over time. In contrast, consider the uptick in overall average class size for mechanical engineering documented earlier. Figure 10 shows that this increase was driven by an increase in class sizes among all levels of undergraduate courses, rather than by a large shift in the mix of courses taught. 


\section{Is Online Instruction Cost-Saving?}

In recent years, the adoption of online instruction has commanded sustained interest from policymakers and institutional leaders as a possible means of counteracting the growth in postsecondary prices (e.g., Deming, Goldin, Katz, \&Yuchtman, 2015). Using a new online survey component that was added to the Delaware Cost Study in $2015,{ }^{35}$ we compute the share of total credits delivered online by discipline, which are displayed in Figure 11 for undergraduate and graduate instruction. There is substantial variation in the prevalence of online instruction, ranging from essentially zero (undergraduate engineering) to as much as a third of all credits (graduate nursing). Table 6 shows descriptive statistics for programs divided into five groups: no online enrollment, and (conditional on any online instruction) the quartiles of online shares. In the 20 disciplines we study, 48 percent of programs have no online enrollment. Online offerings, as well as exclusively online programs, are more prevalent in graduate education. Private institutions, those with larger shares of undergraduate credits, and those with larger shares of tenure-track faculty all have less online enrollment.

To better understand the relationship between online offerings and costs, we present estimates from regression models in Table 7. The outcome across all columns is the log of direct instructional expenditures per credit hour in 2015. Estimates come from our preferred specification, which includes institution and field fixed effects as well as a distantly lagged

${ }^{35}$ A wide range of programs and institutions responded to the new online survey component. Indeed, over 95 percent of the 2,158 programs across 173 institutions and 20 fields of study that completed the main survey in 2015 also completed the new online section. The remaining 107 programs come from 11 institutions, with 9 of those not completing the online portion for any of their programs in our sample. Non-respondents were more likely to be private institutions with moderate levels of research activity. 
measure of direct instructional expenditures. ${ }^{36}$ Since online instruction is relatively new and nearly non-existent more than 10 years ago, controlling for lagged costs allows us to interpret the regression coefficients as the within field and institution correlation between change in costs and the change in online instruction. ${ }^{37}$ Taken together, the fixed effects and lagged cost variable account for many first-order concerns related to selection bias. However, we caution the reader against a causal interpretation of these findings.

The results in columns 1 and 2 reveal that the presence of any online instruction is associated with a modest reduction in costs for undergraduate courses. However, column 3 suggests that the intensive margin of online education matters more than the extensive margin. That is, the mere presence of a few online courses may be unlikely to meaningful alter average costs, but a program that is substantially online may reduce costs, which is consistent with online instruction having its own large fixed costs. This is also reflected in column 6 , where we find that only the largest undergraduate online programs have statistically significantly lower costs. Indeed, the findings in column 3 imply that a fully online program is 29 percent less costly than a fully in-person program. The estimates in columns 4 to 6 further suggest that this may be especially true for undergraduate education. We find much less evidence that the presence or intensity of online instruction in graduate education reduces instructional costs. Contrast this finding with the fact that online instruction tends to be more prevalent among graduate

${ }^{36}$ We compute this lagged control variable of direct instructional expenditures per SCH by averaging over the available program data from 2000-2005 based on prior survey participation so that the baseline is at least 10 years ago. When data are missing, we include an indicator to maintain the full sample. Results are similar in specifications where we drop programs with missing data. In addition, estimates from unweighted models reveal a similar pattern of findings, though estimates are a bit more precise.

37 The regression thus approximates a first-difference approach with field- and institutionspecific trends. However, the coefficient on the lagged costs is much less than 1 so it is not precisely a first difference. 
coursework (Table 6). While most point estimates are statistically insignificant, most specifications suggest that greater online enrollment is associated with lower costs. Finally, we note that there is only one program in our sample that is fully online, and the median program is 5 percent online. Thus, the relevant range of "intensity” observed in our sample is modest, which ought to temper any proclivity to overgeneralize these findings.

The returns to the adoption of new technology such as online courses will depend on a field's production function, and how online education alters it; moving to online instruction may decrease quality-adjusted output for some fields more than others. Indeed, recent evidence suggests that online instruction may harm the performance of lower-achieving students (Bettinger \& Loeb, 2017; Dynarski, 2018). Similarly, some fields may find online education a more useful tool than others in lowering costs without compromising quality. Better understanding this element of fields' production functions is a productive path for future research.

\section{Conclusions}

In this paper we use detailed data on costs, outputs, and factors of production to provide a comprehensive descriptive analysis of field-level instructional costs in higher education. This analysis reveals appreciable variation in the cost of delivering a unit of teaching across fields: relative to English, costs range from 109 percent higher for electrical engineering to 22 percent lower for math. This variation in costs is a function of large differences in class size and, to a lesser extent, differences in average faculty pay. We observe different stories across fields in terms of the trade-offs implied by the cost drivers. Some fields, like economics, offset high wages with large classes, resulting in costs that are comparable to English despite higher faculty pay. Other fields, such as mechanical engineering and computer science, do not offset high 
faculty pay with large classes, resulting in costs that are much greater than English. Still others, like physics, partially offset higher faculty salaries with heavier faculty workloads, resulting in costs that are moderately higher than English.

Over the past 15 years, we find that average instructional costs per credit hour have barely budged. However, this relatively flat trend in average costs obscures variation in such cost trends by field of study. Some STEM fields experienced steep declines in spending over this time period as classes became larger and faculty workloads increased. Other fields like nursing also saw declining costs that reflect a shift in the composition of faculty, with greater reliance on nontenure track staff. Yet other fields, like business and accounting, have experienced escalating costs driven by rapid growth in faculty salaries. For all its promise, online education, arguably the highest profile change to the delivery of higher education over this time period, is associated with only a modest reduction in instructional costs, and only for undergraduate instruction.

The cross-sectional findings highlight the fact that costs associated with instructional activity vary greatly across disciplines. Analyses of costs at the institution level mask this heterogeneity. Variation in costs by discipline has important implications for institutional leaders facing decisions such as differential tuition pricing or the appropriate level of centralization for managing academic units and budgets (e.g., the adoption of responsibility centered management). Cost differences by discipline also have implications for institutional or governmental efforts to encourage student enrollments in certain high-cost disciplines (e.g., the numerous initiatives aimed at increasing attainment in STEM), and for the distribution of state appropriations to public universities. The panel analysis suggests ways in which universities and departments may have sought to manage costs. Institutions have little control over the prevailing market wages for faculty, but changes in faculty workload, class size, and mix of course types 
(i.e., undergraduate versus graduate, and in-person versus online) across disciplines show some of the ways that costs might be kept in check. However, changes along these margins are also likely to shape other departmental outputs, such as research productivity and the capacity for public service. Thus, changes aimed at reducing instructional costs must balance potential effects on other valued outputs of academic departments.

Many of our findings highlight the fact that the production function in higher education is likely to differ meaningfully by field. Thus, these results highlight the need for additional research that sheds light on the effects of inputs on field-specific outcomes, including measures of quality such as student performance and success after college completion. For example, perhaps the adoption of online instruction reduces average instructional costs without impinging quality in mathematics, but a similar reliance on online education in chemistry reduces quality. It is imperative to consider the effect that resource allocation decisions have on learning, instructional quality, and student outcomes and how this differs by field - especially in light of recent evidence that ties increases in spending to higher rates of degree completion (Deming \& Walters, 2018). This next step would allow policymakers and institutional leaders to use the findings related to discipline-specific cost drivers from this paper in a manner most likely to reduce costs while upholding the quality of postsecondary educational delivery. 


\section{References}

Altonji, J.G., Arcidiacono, P., \& Maurel, A. (2016). The analysis of field choice in college and graduate school: Determinants and wage effects. In E. Hanushek, S. Machin, and L.Woessmann, eds., Handbook of the Economics of Education, Vol. 5, pp. 305 - 396. London, UK: Elsevier.

Altonji, J.G., \& Zimmerman, S.D. (2017). The costs of and net returns to college major. NBER Working Paper No. 23029.

Autor, D.H. (2014). Skills, education, and the rise of earnings inequality among the "other 99 percent”. Science, 344(6186), 843-851.

Bettinger, E., \& Loeb, S. (2017). Promises and pitfalls of online education. Evidence Speaks Reports, 2(15). Washington, DC: Brookings Institution.

Bowen, H.R. (1980). The costs of higher education. Hoboken, NJ: Jossey-Bass.

Bowen, W.G. (2012). The cost disease in higher education: Is technology the answer? The Tanner Lectures Stanford University.

Bowen, W.G. (2013). Higher education in the digital age. Princeton, NJ: Princeton University Press.

Campos, P. (2015, April 4). The real reason college tuition costs so much. The New York Times.

Clotfelter, C.T. (1996). Buying the best: Cost escalation in elite higher education. Princeton, NJ: Princeton University Press.

College Board. (2015). Trends in college pricing. Washington, DC: Author.

Courant, P. N., \& Turner, S. (2017). Faculty deployment in Research Universities. NBER Working Paper No. w23025.

DeFour, M. (2015, January 29). Gov. Scott Walker to UW faculty: Consider teaching one more class per semester. Wisconsin State Journal.

Deming, D.J., Goldin, C., Katz, L.F., \& Yuchtman (2015). Can online learning bend the higher education cost curve? American Economic Review: Papers \& Proceedings, 105(5), 496501.

Deming, D. J., \& Walters, C. R. (2017). The impact of price caps and spending cuts on US postsecondary attainment. NBER Working Paper No. w23736.

Desrochers, D.M., \& Hurlburt, S. (2016). Trends in college spending: 2003-2013. Washington, DC: Delta Cost Project. 
Dundar, H., \& Lewis, D.R. (1995). Departmental productivity in American universities: Economies of scale and scope. Economics of Education Review, 14(2), 119-144.

Dynarski, S. (2018, January 19). Online courses are harming students who need the most help. The New York Times, Economic View.

Ehrenberg, R. G. (2002). Tuition rising. Boston, MA: Harvard University Press.

Epple, D., Romano, R., \& Sieg, H. (2006). Admission, tuition, and financial aid policies in the market for higher education. Econometrica, 74(4), 885-928.

Epple, D., Romano, R., Sarpça, S., \& Sieg, H. (2017). A general equilibrium analysis of state and private colleges and access to higher education in the US. Journal of Public Economics, 155, 164-178.

Goldin, C., \& Katz, L.F. (2008). The race between education and technology. Boston: Harvard University Press.

Hemelt, S. W., \& Marcotte, D. E. (2016). The changing landscape of tuition and enrollment in American public higher education. RSF: The Russell Sage Foundation Journal of the Social Sciences, 2(1), 42-68.

Hoxby, C. M. (2009). The changing selectivity of American colleges. Journal of Economic Perspectives, 23(4), 95-118.

Johnson, W.R., \& Turner, S. (2009). Faculty without students: Resource allocation in higher education. Journal of Economic Perspectives, 23(2), 169-189.

Kelly, A., \& Carey, K. (2013). Stretching the higher education dollar: How innovation can improve access, equity, and affordability. Boston: Harvard Education Press.

Kirkebøen, L., Leuven, E., \& Mogstad, M. (2016). Field of study, earnings and self-selection. Quarterly Journal of Economics 131(3), 1057-1111.

Lattuca, L.R., \& Stark, J.S. (2009). Shaping the college curriculum: Academic plans in context. Hoboken, NJ: John Wiley and Sons.

Monks, J. (2003). Patterns of giving to one's alma mater among young graduates from selective institutions. Economics of Education Review, 22(2), 121-130.

National Association of State Budget Officers. (2013). Improving postsecondary education through the budget process: Challenges \& opportunities. Washington, DC: Author. 
Rothschild, M., \& White, L. (1995). The analytics of the pricing of higher education and other services in which the customers are inputs. Journal of Political Economy, 103(3), 573586.

Seligman, L. (2012, November). Did Texas just discover the cure for sky-high tuition? The Atlantic.

Stange, K. (2015). Differential pricing in undergraduate education: Effects on degree production by field. Journal of Policy Analysis and Management, 34(1), 107-135.

Stange, K., Jacob, B., \& McCall, B. (forthcoming). College as country club: Do colleges cater to students’ preferences for consumption? Journal of Labor Economics.

State Higher Education Executive Officers Association. State higher education finance: FY2016. Boulder, CO: Author.

Tierney, M.L. (1980). An estimate of departmental cost functions. Higher Education, 9(4), 453468. 
Figure 1. Average Instructional Cost per Student Credit Hour

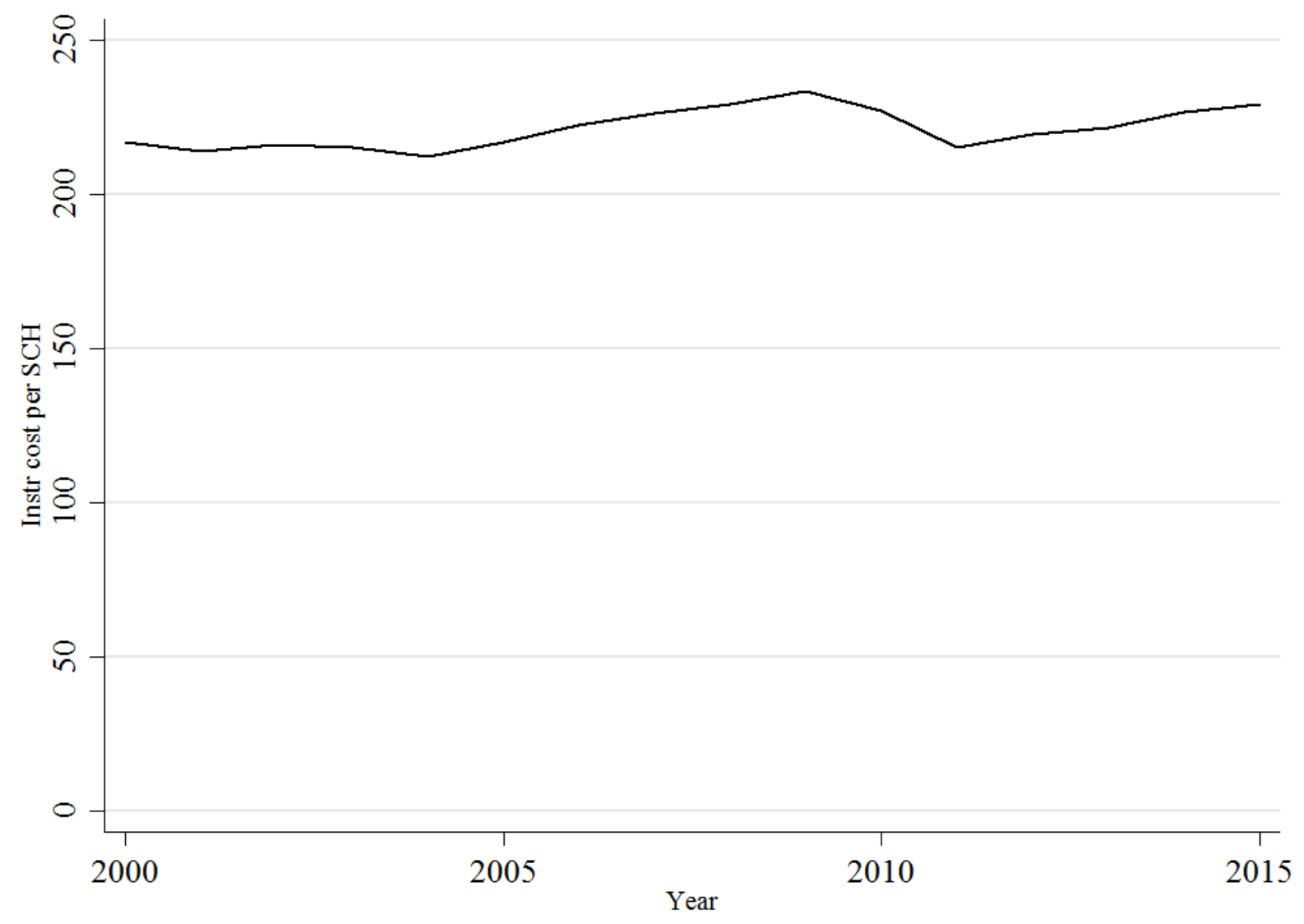

Notes: Cost refers to direct instructional expenditures per student credit hour. Sample includes public and private institutions participating in the Delaware Cost Study between 2000-2015. Only departments in the 20 fields listed in Table A1 are included. A small number of observations with missing or outlier data are excluded. Program-level observations are weighted by number of student credit hours multiplied by the inverse of the probability of being included in the sample (estimated at the institution-year level). Costs are in 2015 dollars. 
Figure 2. Average Instructional Cost by Field

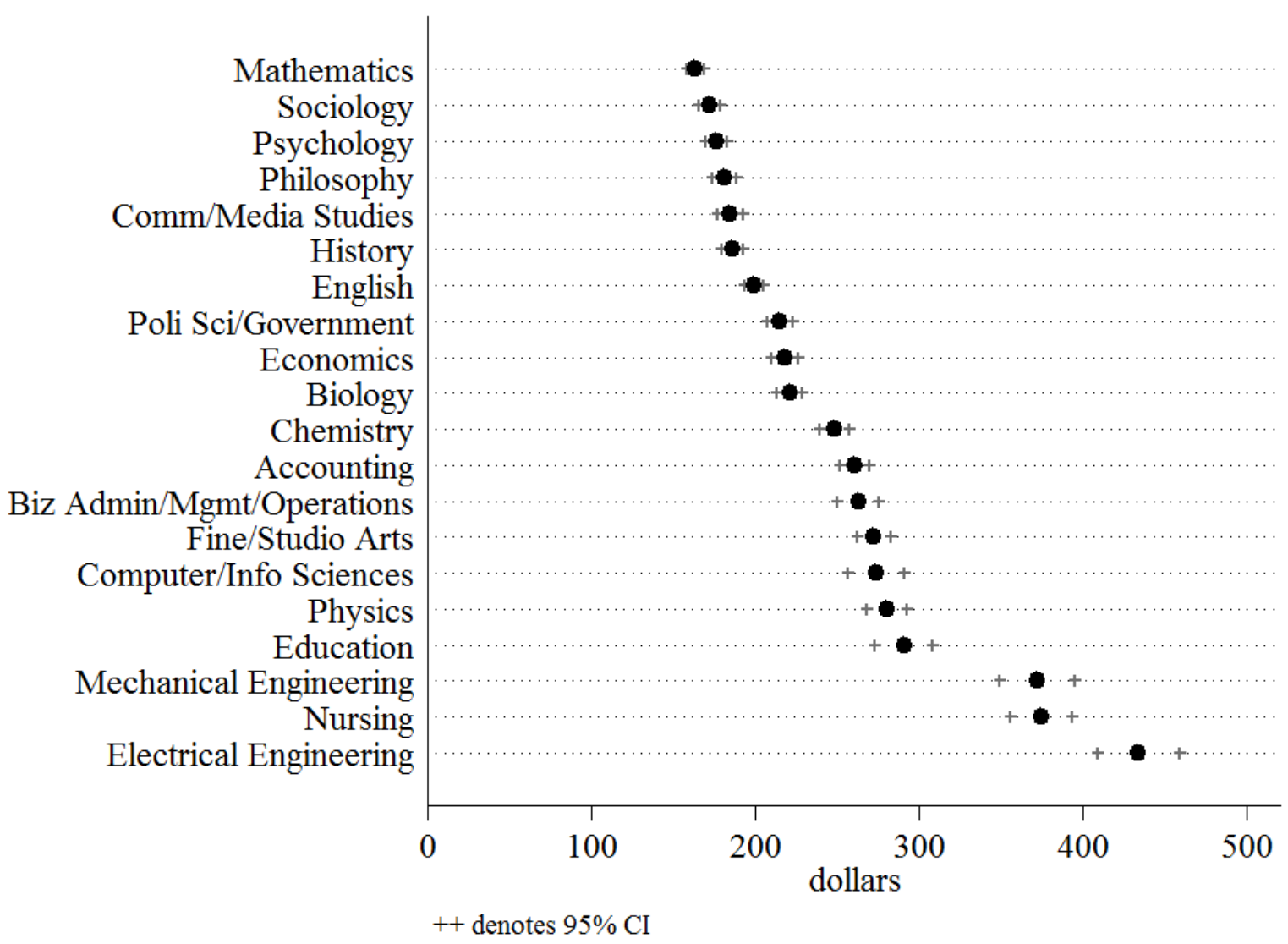

Notes: Sample includes public and private institutions participating in the Delaware Cost Study between 2013-2015. Only departments in the 20 fields listed in Table A1 are included. A small number of observations with missing or outlier data are excluded. Program-level observations are weighted by number of student credit hours multiplied by the inverse of the probability of being included in the sample (estimated at the institution-year level). Costs are in 2015 dollars. 


\section{Figure 3. Differences in Cost Drivers Across Fields}

\section{A. Workload and Class Size}
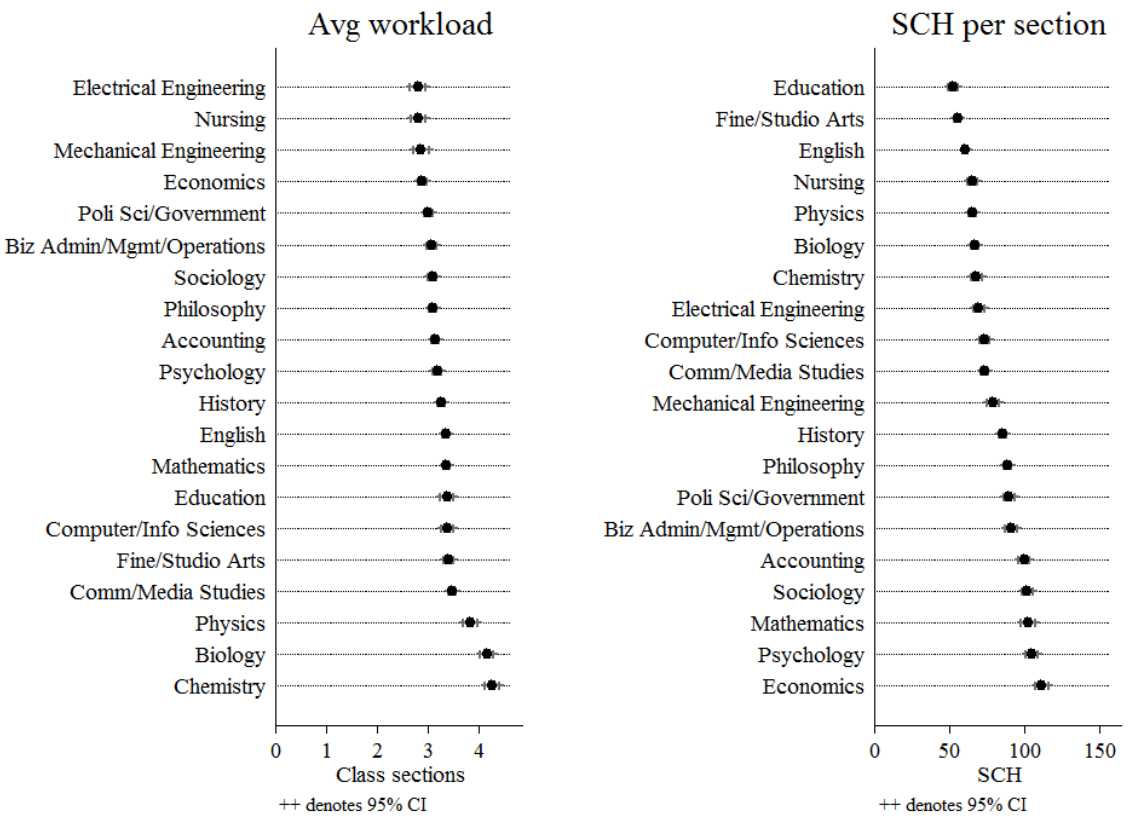

\section{B. Personnel and Non-personnel expenses}
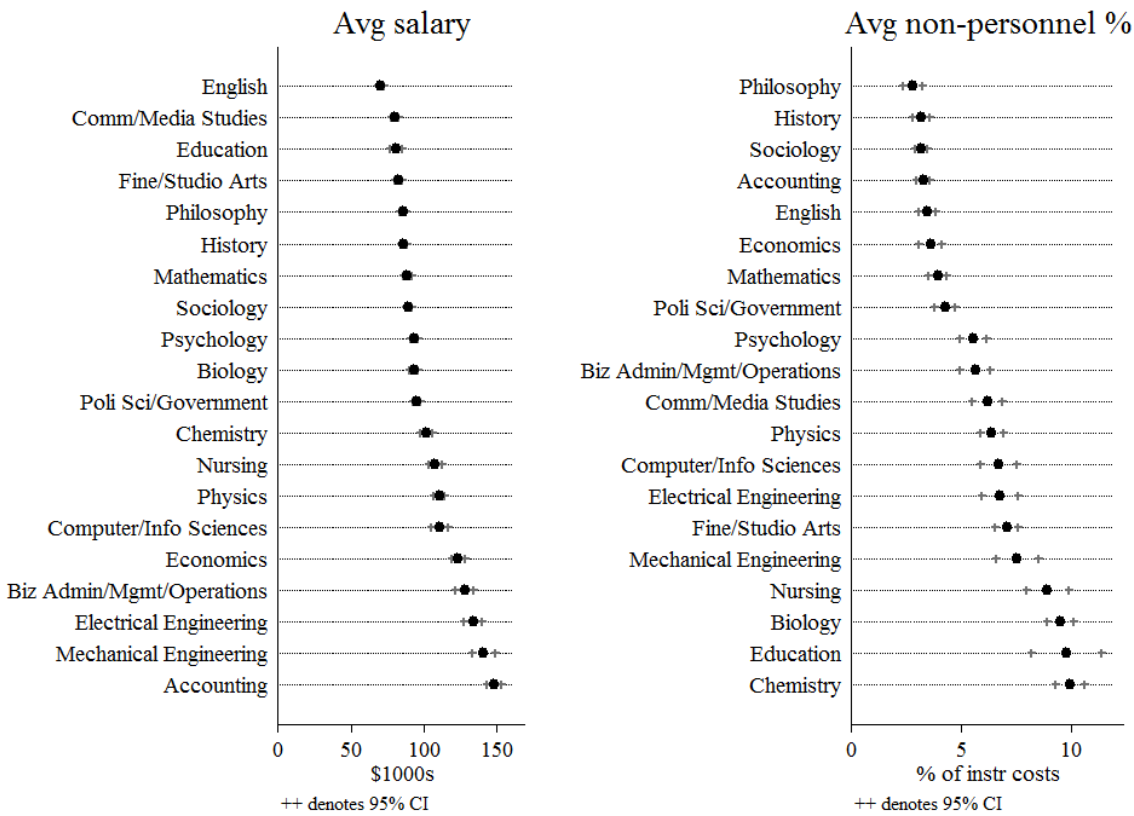

Notes: Sample includes public and private institutions participating in the Delaware Cost Study between 2013-2015. Only departments in the 20 fields listed in Table A1 are included. A small number of observations with missing or outlier data are excluded. Program-level observations are weighted by number of student credit hours multiplied by the inverse of the probability of being included in the sample (estimated at the institution-year level). Costs are in 2015 dollars. 


\section{Figure 4. Baseline Cross-Field Log Cost Differences, relative to English}

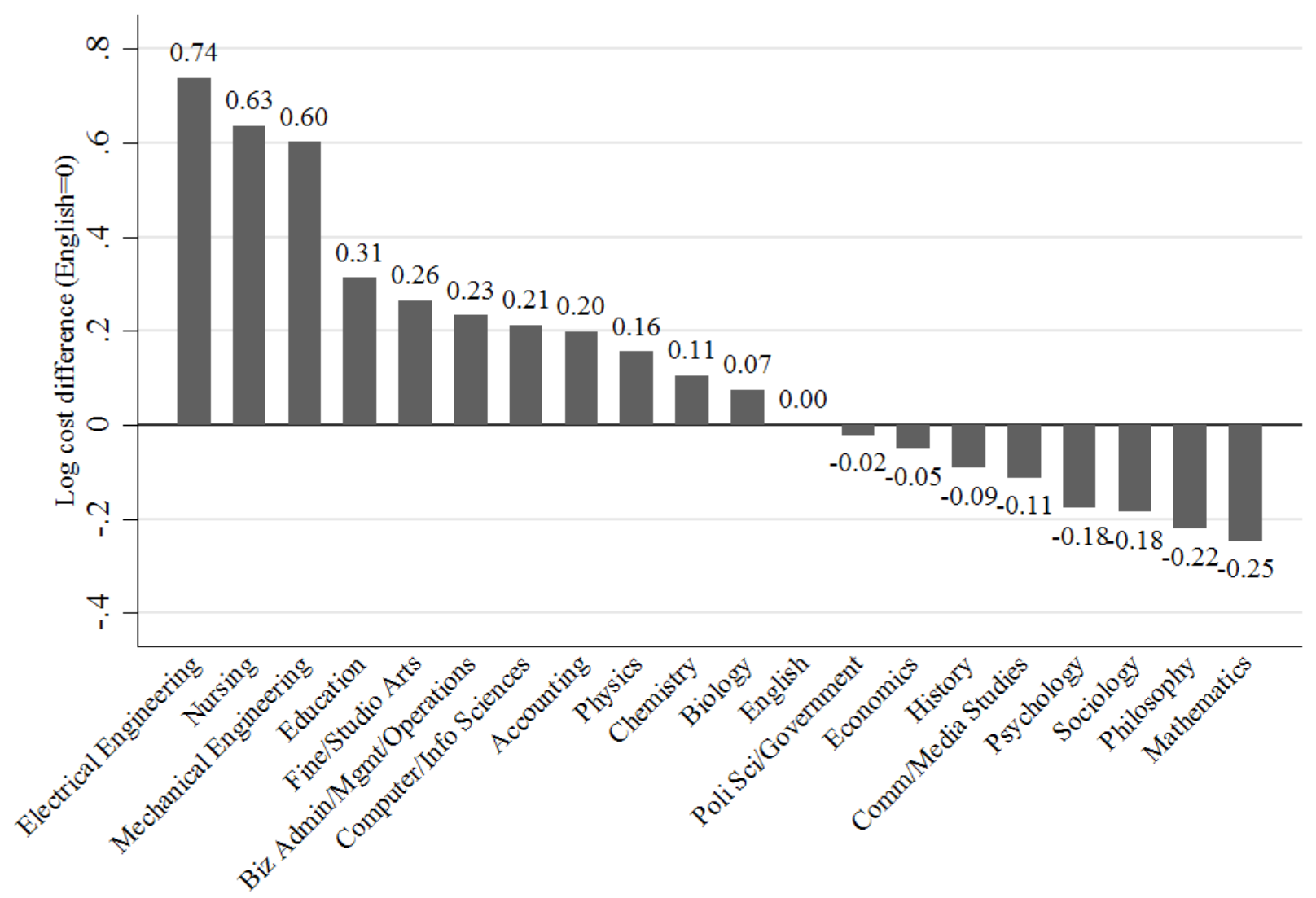

Notes: Each column reports the difference in log of direct instructional cost per SCH between the reported field and English, after controlling for institution and year fixed effects. Positive numbers indicate the field is more expensive than English. Sample includes public and private institutions participating in the Delaware Cost Study between 2013-2015. Only departments in the 20 fields listed in Table A1 are included. A small number of observations with missing or outlier data are excluded. Program-level observations are weighted by number of student credit hours multiplied by the inverse of the probability of being included in the sample (estimated at the institution-year level). Costs are in 2015 dollars. 
Figure 5. Direct Instructional Expenditure per SCH Over Time, by CIP4 $(2000=100)$, 2000-2015

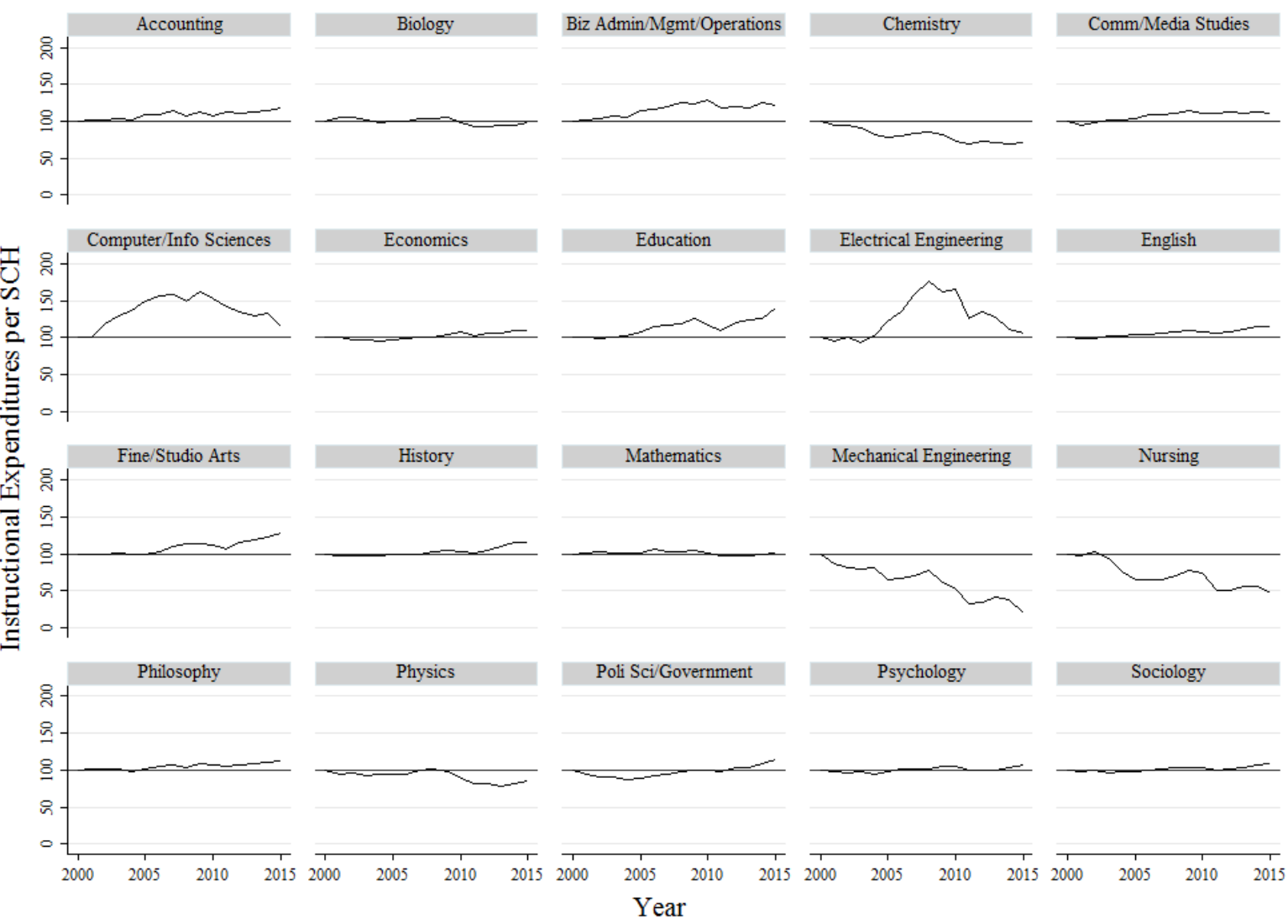

Notes: Sample includes public and private institutions participating in the Delaware Cost Study between 2000-2015. Only departments in the 20 fields listed in Table A1 are included. A small number of observations with missing or outlier data are excluded. Program-level observations are weighted by number of student credit hours multiplied by the inverse of the probability of being included in the sample (estimated at the institution-year level). Trends are normalized to the year 2000 and net of institution-by-field fixed effects. 
Figure 6. Average Annual Percentage Change in Costs and Cost Drivers by Field
A. Instructional Expenditures

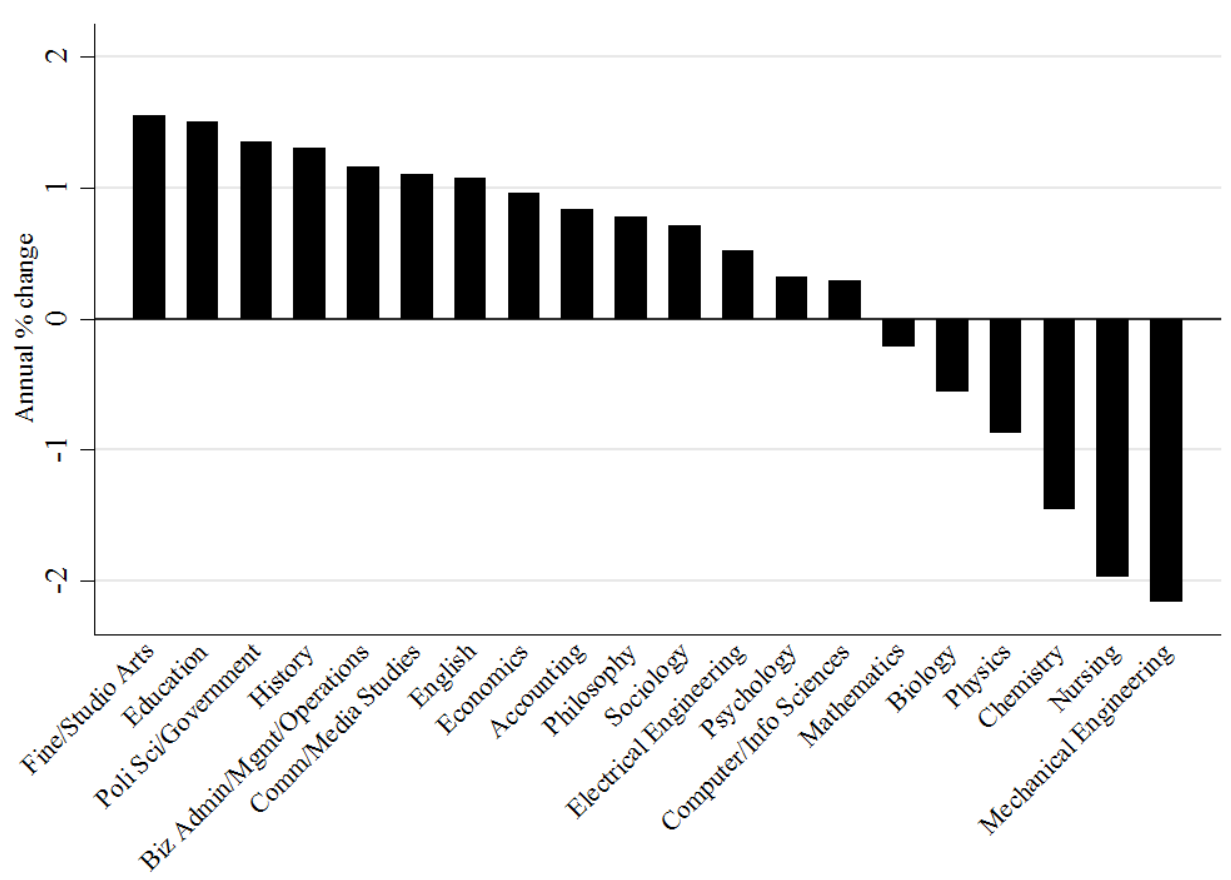

B. Class Size

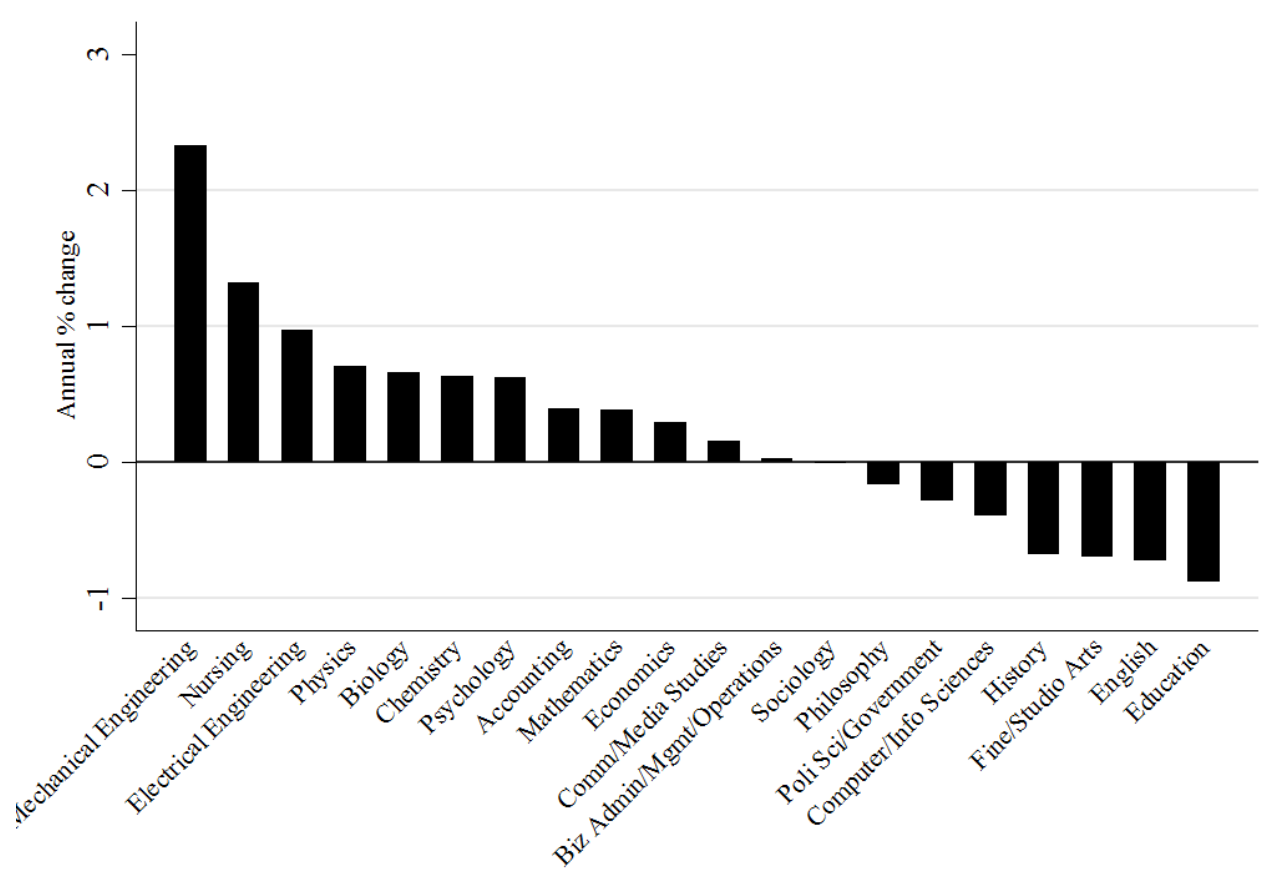




\section{Faculty Salaries}

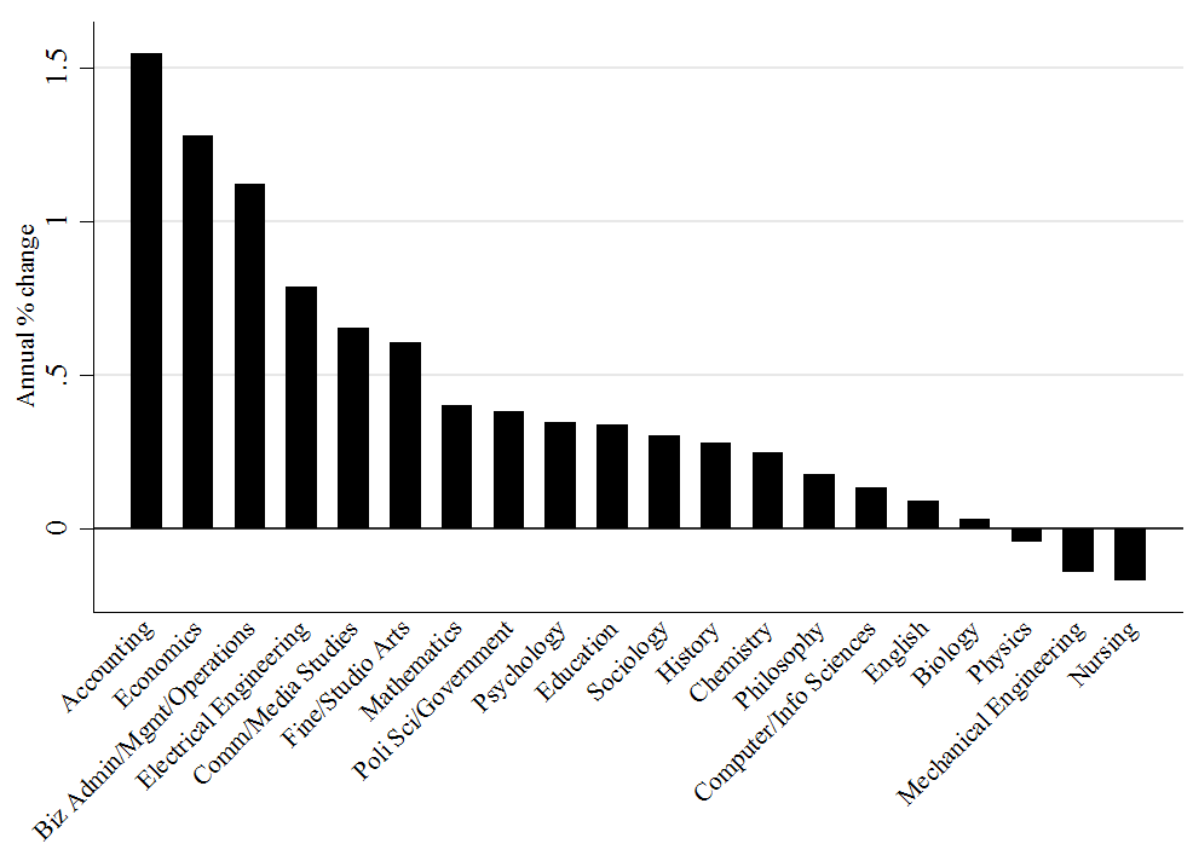

\section{Faculty Workload}

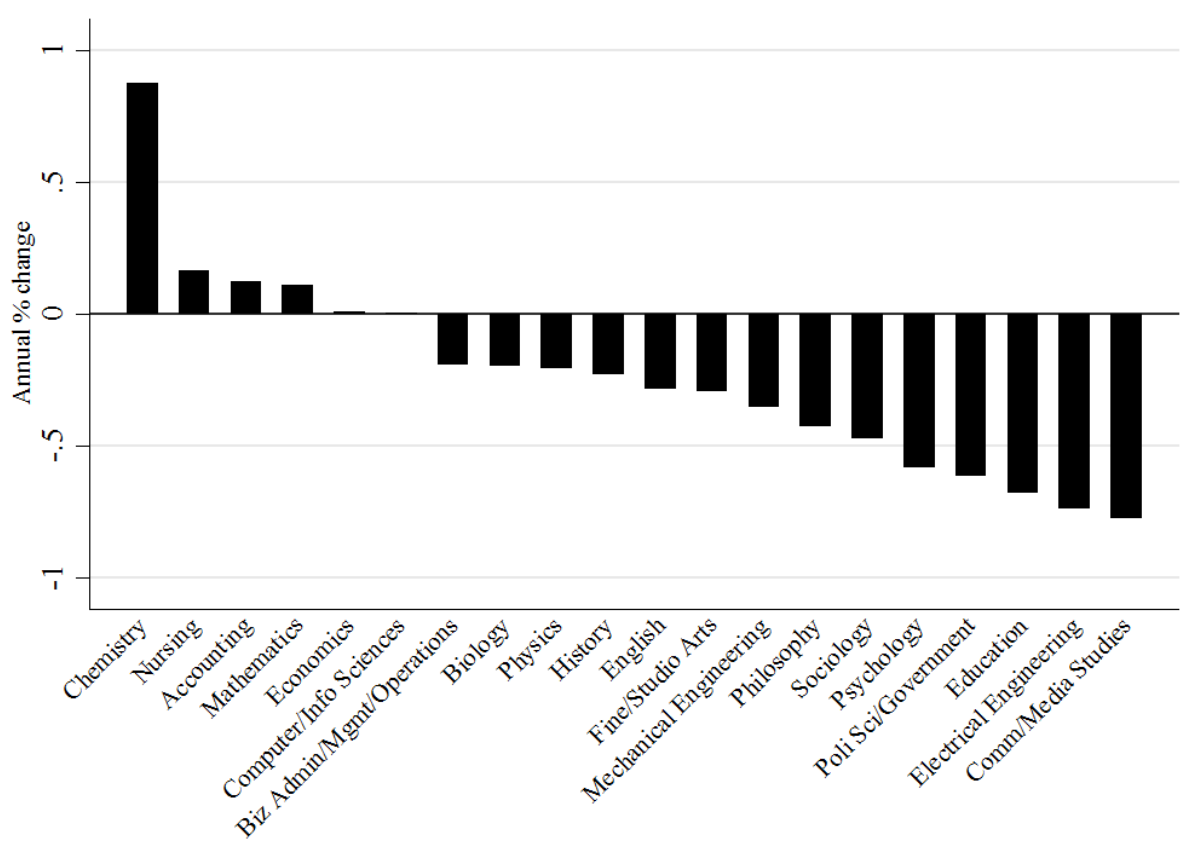

Notes: Bars represent annualized rate of change between 2000 and 2015. Estimates include program fixed-effects. Dollar figures expressed in 2015 dollars. Sample includes public and private institutions participating in the Delaware Cost Study between 2000-2015. Only departments in the 20 fields listed in Table A1 are included. A small number of observations with missing or outlier data are excluded. Program-level observations are weighted by number of student credit hours multiplied by the inverse of the probability of being included in the sample (estimated at the institution-year level). 
Figure 7. Cross-Sectional Differences in Faculty Mix by Field, 2013-2015

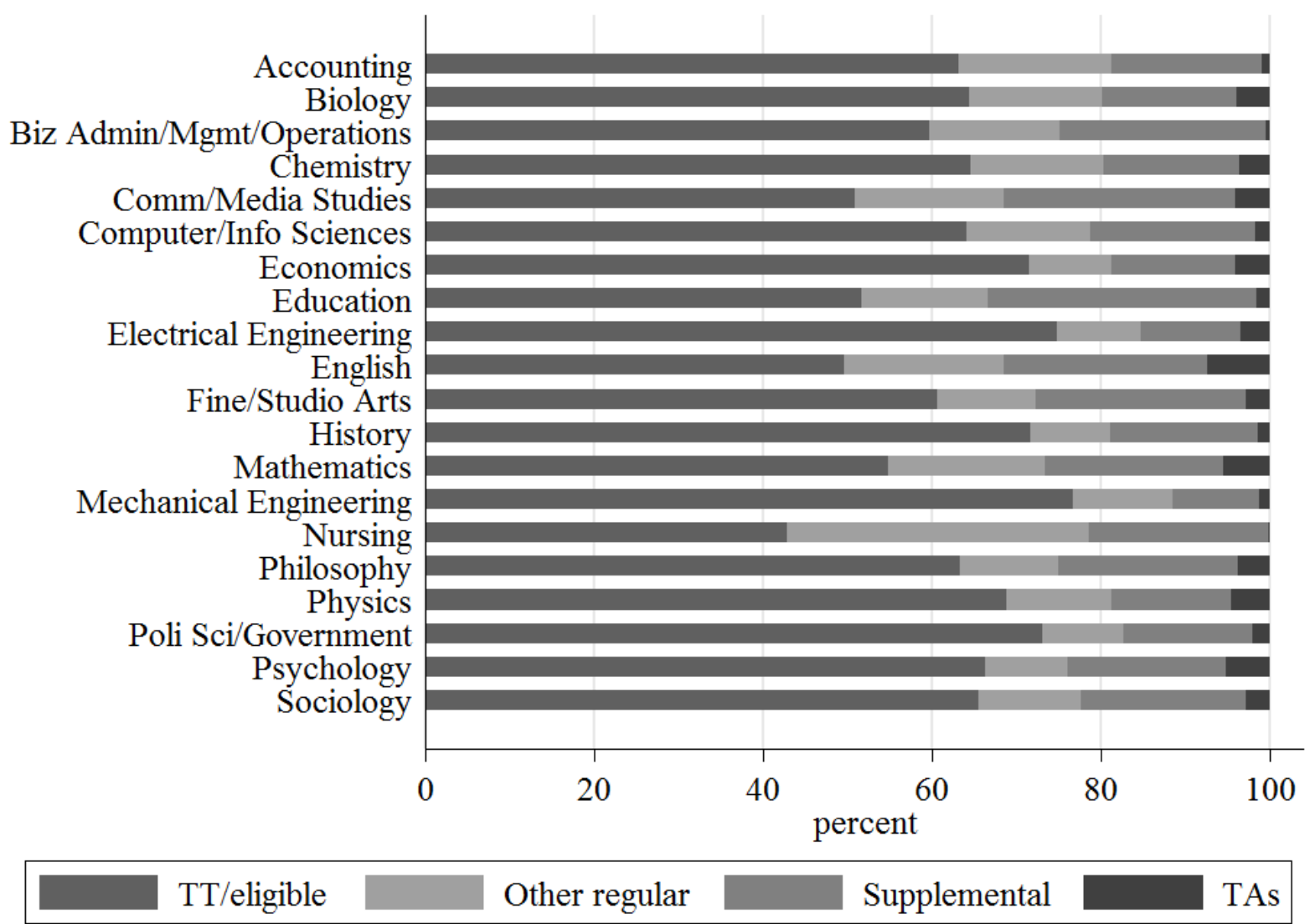

Notes: Bars report proportion of faculty FTE in each rank. Sample includes public and private institutions participating in the Delaware Cost Study between 2013-2015. A small number of observations with missing or outlier data are excluded. Program-level observations are weighted by number of student credit hours multiplied by the inverse of the probability of being included in the sample (estimated at the institution-year level). 
Figure 8. Trends in Faculty Mix by Field, 2000-2015

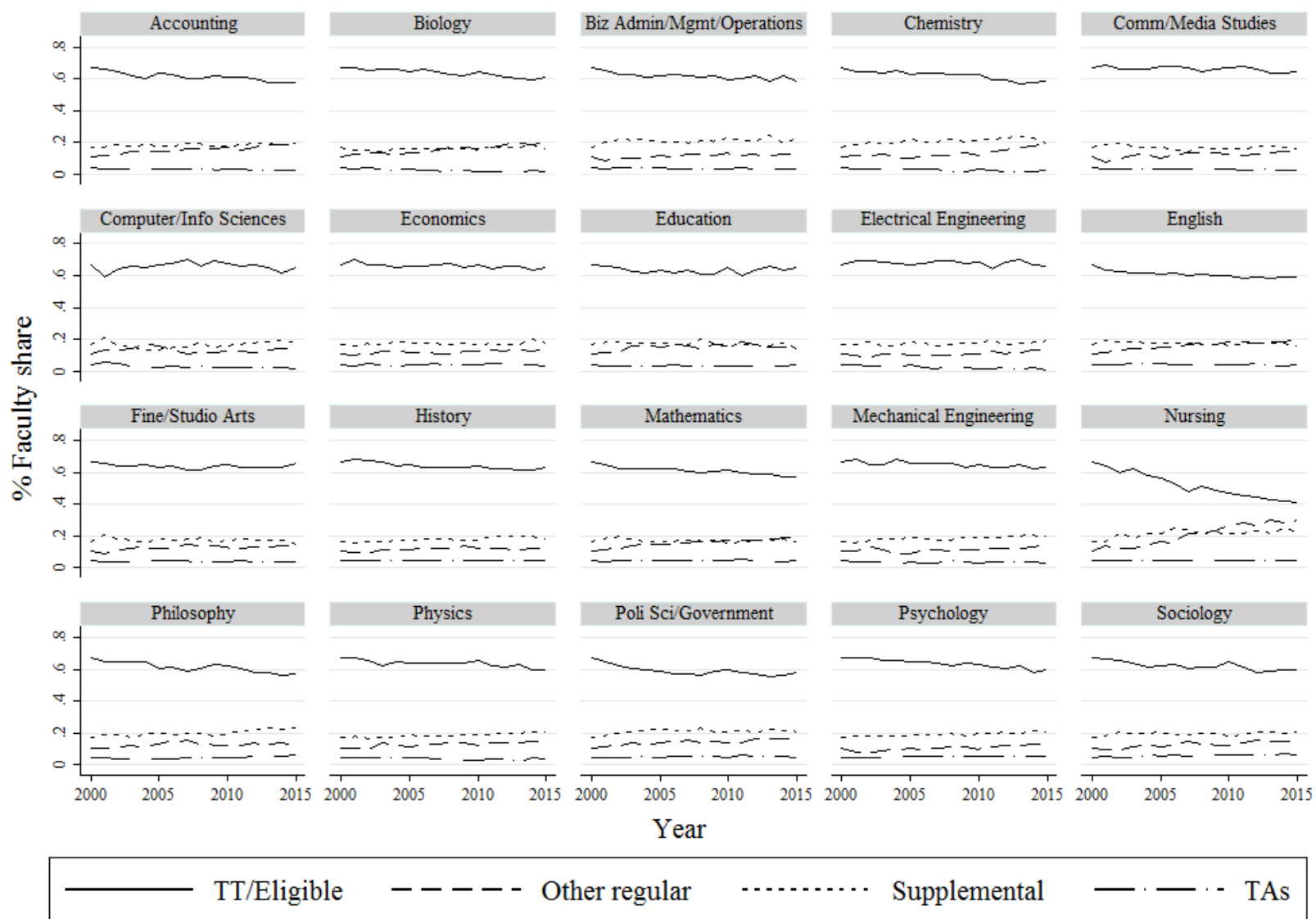

Notes: Lines represent proportion of faculty FTE in each rank over time. Sample includes public and private institutions participating in the Delaware Cost Study between 2000-2015. Only departments in the 20 fields listed in Table A1 are included. A small number of observations with missing or outlier data are excluded. Program-level observations are weighted by number of student credit hours multiplied by the inverse of the probability of being included in the sample (estimated at the institution-year level). 
Figure 9. Cross-Sectional Differences in Credit-Level Mix by Field, 2013-2015

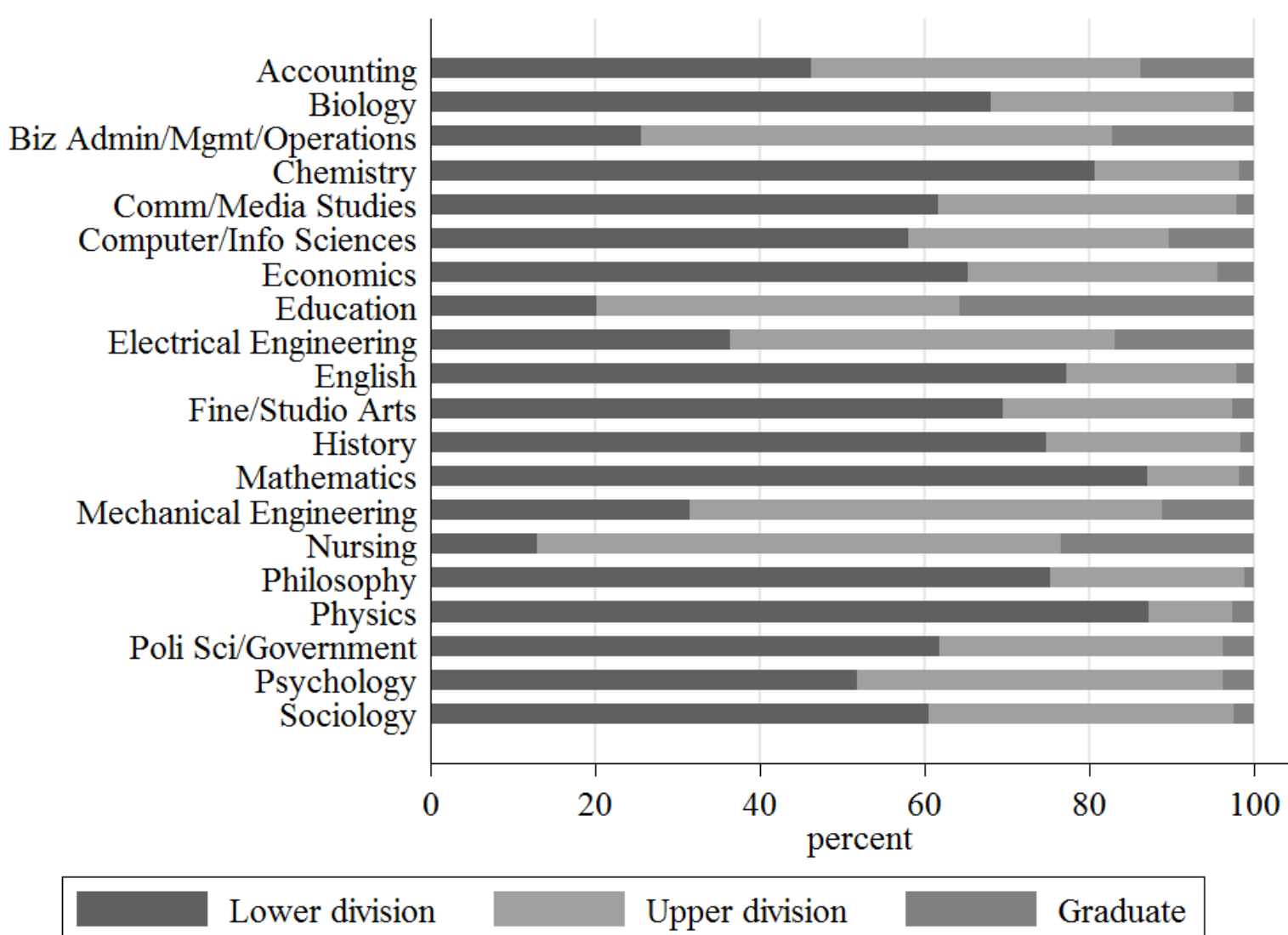

Notes: Bars report proportion of total student credit hours in each division. Sample includes public and private institutions participating in the Delaware Cost Study between 2013-2015. A small number of observations with missing or outlier data are excluded. Program-level observations are weighted by number of student credit hours multiplied by the inverse of the probability of being included in the sample (estimated at the institution-year level). 
Figure 10. Trends in Field-Specific Class Size by Course Type and Credit-Level Mix, 20002015

A. Trends in Class Size by Course Type

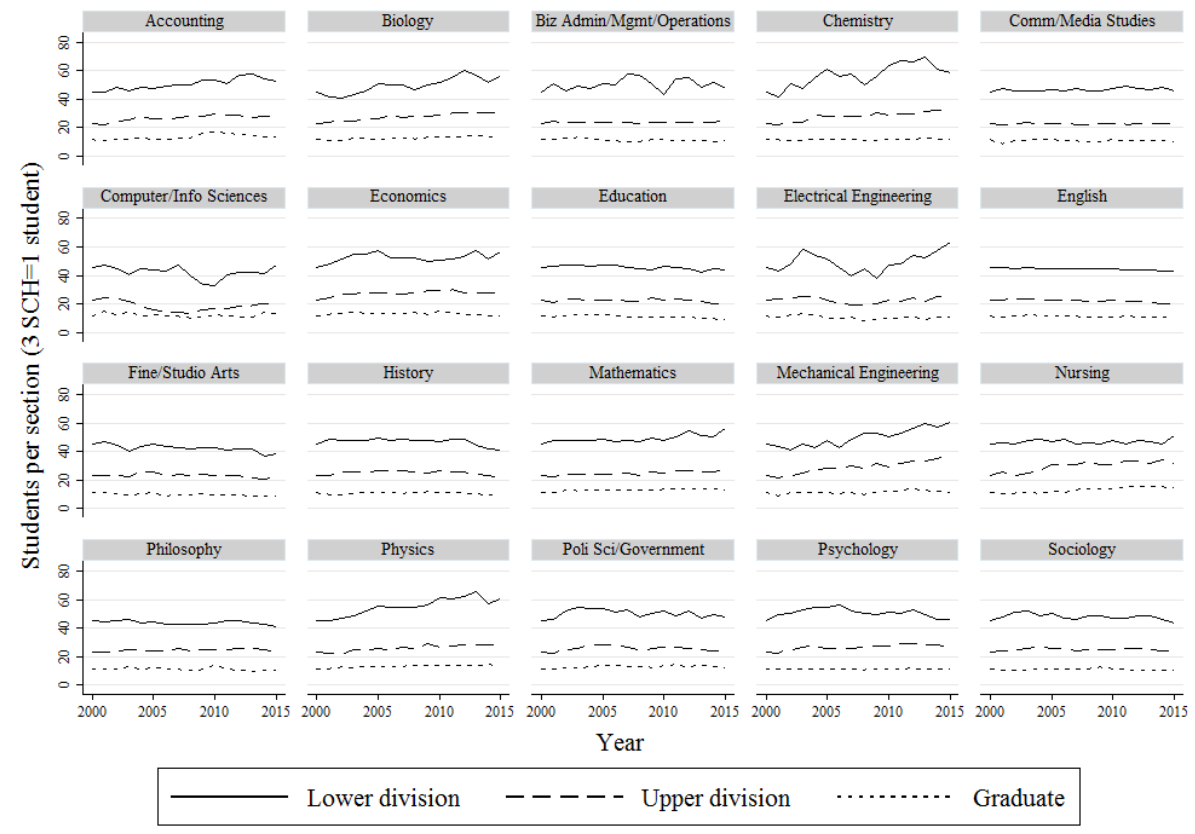

\section{B. Trends in Credit-Level Mix}

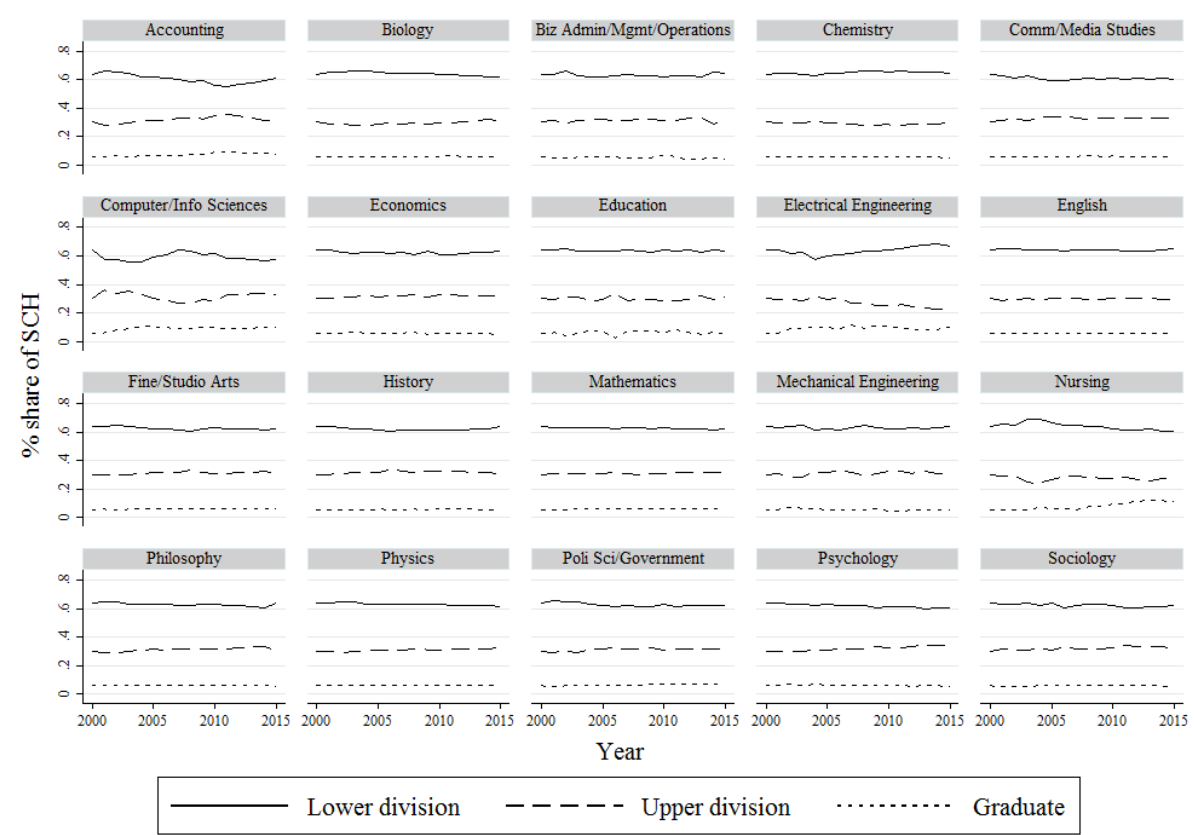

Notes: Class size is calculated as 3 credit hours per student, divided by the number of offered course sections. Mix of credit levels is calculated as the share of total student credit hours in each division. Sample includes public and private institutions participating in the Delaware Cost Study between 2000-2015. Only departments in the 20 fields listed in Table A1 are included. A small number of observations with missing or outlier data are excluded. Programlevel observations are weighted by number of student credit hours multiplied by the inverse of the probability of being included in the sample (estimated at the institution-year level). 


\section{Figure 11. Share of Total Instruction Delivered Online by Field (2015)}

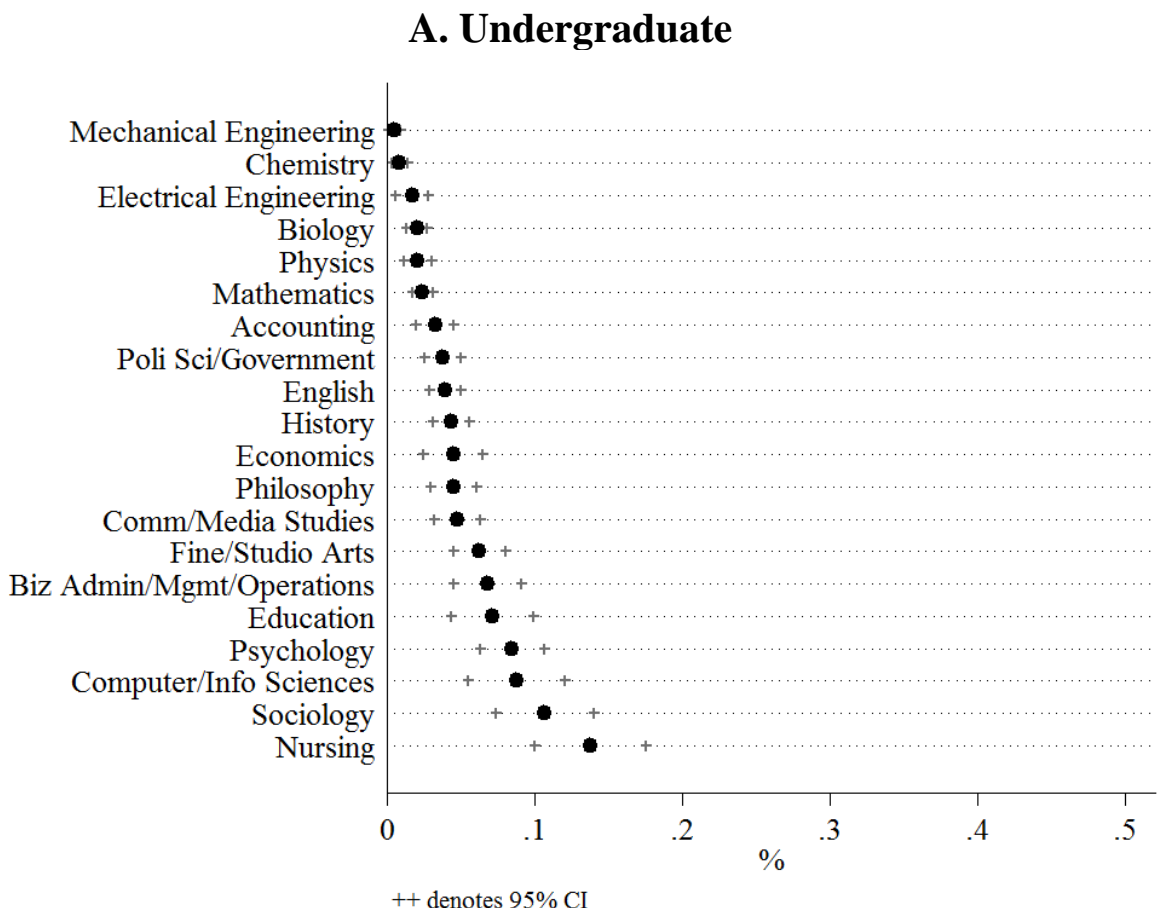

\section{B. Graduate}

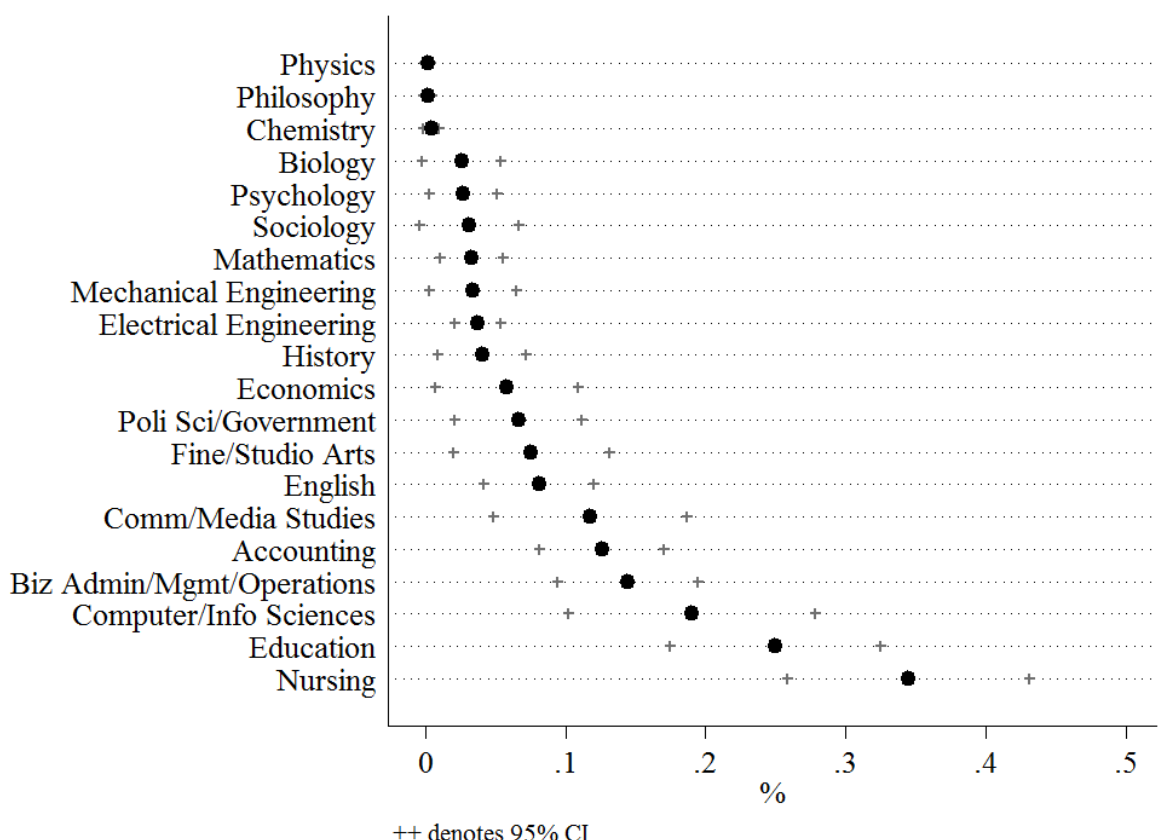

Notes: Sample includes public and private institutions participating in the Delaware Cost Study in 2015. A small number of observations with missing or outlier data are excluded. Program-level observations are weighted by number of student credit hours multiplied by the inverse of the probability of being included in the sample (estimated at the institution-year level). 


\begin{tabular}{|c|c|c|c|c|c|c|c|c|c|c|c|c|}
\hline & \multicolumn{2}{|c|}{ All } & \multicolumn{2}{|c|}{$\begin{array}{l}\text { Research - } \\
\text { High }\end{array}$} & \multicolumn{2}{|c|}{$\begin{array}{l}\text { Research - } \\
\text { Moderate }\end{array}$} & \multicolumn{3}{|c|}{ Masters } & \multicolumn{3}{|c|}{ Baccalaureate } \\
\hline & mean & sd & mean & sd & mean & sd & mean & & & mean & & sd \\
\hline Public Institutions & $66 \%$ & & $89 \%$ & & $53 \%$ & & $65 \%$ & & & $21 \%$ & & \\
\hline Total Degrees Awarded & 112 & & 179 & & 160 & & 77 & & & 33 & & \\
\hline BA as Share of Total Degrees & $84 \%$ & & $76 \%$ & & $75 \%$ & & $87 \%$ & & & $97 \%$ & & \\
\hline MA as Share of Total Degrees & $14 \%$ & & $18 \%$ & & $23 \%$ & & $13 \%$ & & & $3 \%$ & & \\
\hline Prof as Share of Total Degrees & $0 \%$ & & $0 \%$ & & $0 \%$ & & $0 \%$ & & & $0 \%$ & & \\
\hline PhD as Share of Total Degrees & $2 \%$ & & $6 \%$ & & $2 \%$ & & $0 \%$ & & & $0 \%$ & & \\
\hline \multicolumn{13}{|l|}{ Full-Time Equivalents for All Faculty } \\
\hline Fall Semester Total FTE & 32 & 29 & 52 & 34 & 37 & 27 & 22 & & 6 & 10 & & 9 \\
\hline Fall Semester Instructional FTE & 31 & 28 & 51 & 34 & 37 & 27 & 21 & & 6 & 10 & & 9 \\
\hline Tenured Faculty Share of Instructional FTE & $63 \%$ & & $61 \%$ & & $62 \%$ & & $64 \%$ & & & $66 \%$ & & \\
\hline \multicolumn{13}{|l|}{ Student Credit Hours } \\
\hline Fall Semester SCH by All Faculty & 7,712 & 7,115 & 12,602 & 8,442 & 8,877 & 5,922 & 5,535 & & ,352 & 2,203 & & 1,826 \\
\hline Undergrad Share of All SCH & $93 \%$ & & $91 \%$ & & $89 \%$ & & $94 \%$ & & & $98 \%$ & & \\
\hline \multicolumn{13}{|l|}{ Organized Class Sections } \\
\hline Fall Semester OCS - All & 97 & 85 & 143 & 103 & 112 & 80 & 77 & & 1 & 40 & & 32 \\
\hline Undergrad Share of OCS & $87 \%$ & & $79 \%$ & & $81 \%$ & & $90 \%$ & & & $97 \%$ & & \\
\hline Grad Share of OCS & $13 \%$ & & $21 \%$ & & $19 \%$ & & $10 \%$ & & & $3 \%$ & & \\
\hline \multicolumn{13}{|l|}{ Expenditures } \\
\hline $\begin{array}{l}\text { Direct Instructional Expenditures (\$1000) - includes salary, } \\
\text { benefits, and other expenses }\end{array}$ & $\$ 3,223$ & $\$ 3,503$ & $\$ 5,758$ & $\$ 4,314$ & $\$ 4,053$ & $\$ 3,626$ & $\$ 1,895$ & & 459 & $\$ 810$ & & 656 \\
\hline Personnel Spending as a Share of Instructional Spending & $94 \%$ & & $93 \%$ & & $92 \%$ & & $96 \%$ & & & $95 \%$ & & \\
\hline \multicolumn{13}{|l|}{ Analysis Variables } \\
\hline Total Faculty per Student & 0.07 & 0.03 & 0.07 & 0.03 & 0.06 & 0.02 & 0.06 & & 02 & 0.08 & & .03 \\
\hline Average Class Size & 32 & 17 & 43 & 21 & 33 & 14 & 27 & & 0 & 22 & & 7 \\
\hline Undergraduate Class Size & 37 & 24 & 53 & 31 & 38 & 17 & 29 & & 1 & 22 & & 7 \\
\hline Graduate Class Size & 12 & 7 & 12 & 7 & 14 & 8 & 12 & & 7 & 11 & & 6 \\
\hline Instructional Faculty Course Load - All Courses & 3.4 & 1.1 & 2.9 & 1.0 & 3.1 & 0.9 & 3.7 & & .9 & 3.9 & & 1.1 \\
\hline Instructional Spending per SCH & $\$ 222$ & $\$ 114$ & $\$ \quad 259$ & $\$ 140$ & $\$ 236$ & $\$ 102$ & $\$ 196$ & $\$$ & 88 & $\$ 205$ & $\$$ & 94 \\
\hline Instructional Personnel Spending per SCH & 207 & $\$ 101$ & 238 & 123 & 213 & $\$ \quad 88$ & 186 & $\$$ & 81 & 193 & $\$$ & 82 \\
\hline Total Spending per SCH & $\$ 259$ & $\$ 202$ & $\$ \quad 354$ & 292 & $\$ \quad 258$ & \$ 138 & $\$ 201$ & $\$$ & 95 & $\$ 207$ & $\$$ & 95 \\
\hline N (institution-program-year) & 32,496 & & 11,513 & & 2,987 & & 14,218 & & & 3,778 & & \\
\hline Weighted by IPW * SCH & $100 \%$ & & $34 \%$ & & $8 \%$ & & $43 \%$ & & & $15 \%$ & & \\
\hline
\end{tabular}

Note: Observations are weighted by the inverse of the likelihood that a given institution participates in the Delaware Cost Study multiplied by a measure of the program's size (total fall student credit hours). 
Table 2. Characteristics of Fields, Ranked by Cost

\begin{tabular}{|c|c|c|c|c|c|c|}
\hline Field & $\begin{array}{l}\text { Log cost } \\
\text { difference }\end{array}$ & $\begin{array}{l}\text { Median earnings } \\
\text { years } 11-15 \text { ( } \$ 1000 \text {, } \\
\text { relative to English) }\end{array}$ & $\begin{array}{c}\text { Typically } \\
\text { separate school } \\
\text { from Arts \& } \\
\text { Sciences? }\end{array}$ & $\begin{array}{c}\% \text { of schools } \\
\text { with differential } \\
\text { pricing }\end{array}$ & $\begin{array}{l}\text { Diff funding in } \\
\text { TX funding } \\
\text { formula }\end{array}$ & $\begin{array}{c}\text { Tier in NC } \\
\text { funding formula }\end{array}$ \\
\hline Electrical Engineering & 0.74 & 42.0 & Yes & $30 \%$ & Yes & IV \\
\hline Nursing & 0.63 & 12.4 & Yes & $16 \%$ & Yes & IV \\
\hline Mechanical Engineering & 0.60 & 38.7 & Yes & $30 \%$ & Yes & IV \\
\hline Fine/Studio Arts & 0.26 & -7.7 & Yes & $8 \%$ & Yes & III \\
\hline Biz Admin/Mgmt/Operations & 0.23 & 11.1 & Yes & $32 \%$ & & II \\
\hline Computer/Info Sciences & 0.21 & 30.3 & Varies & $8 \%$ & Yes & III \\
\hline Accounting & 0.20 & 17.6 & Yes & $32 \%$ & & II \\
\hline Physics & 0.16 & 31.9 & & $11 \%$ & Yes & III \\
\hline Economics & -0.05 & 32.2 & & $0 \%$ & & I \\
\hline History & -0.09 & 6.5 & & $0 \%$ & & I \\
\hline Comm/Media Studies & -0.11 & 7.9 & Varies & $6 \%$ & & I \\
\hline Psychology & -0.18 & -1.0 & & $0 \%$ & & I \\
\hline Sociology & -0.18 & 1.8 & & $0 \%$ & & I \\
\hline Philosophy & -0.22 & 1.4 & & $0 \%$ & & I \\
\hline Mathematics & -0.25 & 21.4 & & $0 \%$ & & $\mathrm{I}$ \\
\hline
\end{tabular}

Sources: Median earnings come from Hershbein and Kearney (2012) analysis of the ACS, expressed relative to median earnings for English (\$46,000). Separate school refers to whether the field is typically housed in a separate school or college from English, which is traditionally in a School of Arts \& Science. Funding formula difference in Texas refers to difference for upper division courses that is different than that for upper division English courses. Negligible differences for education are ignored. Funding formula in North Carolina splits fields into four tiers. Differential pricing information comes from Nelson (2008) survey of 165 public research universities. 
Table 3. What Drives Cost Differences by Field? Cross-Sectional Decomposition

\begin{tabular}{|c|c|c|c|c|c|}
\hline \multirow[b]{3}{*}{ Field of Study } & \multirow{3}{*}{$\begin{array}{c}\text { Overall } \\
\begin{array}{c}\text { Difference in } \\
\text { Costs }\end{array} \\
(1)\end{array}$} & \multicolumn{4}{|c|}{ Contribution to Difference } \\
\hline & & Salary & Workload & Class size & $\begin{array}{c}\text { Other, Non- } \\
\text { Personnel } \\
\text { Expenses }\end{array}$ \\
\hline & & (2) & (3) & (4) & (5) \\
\hline Electrical Engineering & 0.74 & 0.58 & 0.05 & 0.08 & 0.03 \\
\hline Nursing & 0.63 & 0.38 & 0.21 & -0.01 & 0.06 \\
\hline Mechanical Engineering & 0.60 & 0.55 & 0.09 & -0.08 & 0.04 \\
\hline Education & 0.31 & 0.07 & 0.02 & 0.17 & 0.05 \\
\hline Fine/Studio Arts & 0.26 & 0.11 & -0.01 & 0.13 & 0.04 \\
\hline Biz Admin/Mgmt/Operations & 0.23 & 0.46 & 0.06 & -0.31 & 0.03 \\
\hline Computer/Info Sciences & 0.21 & 0.31 & -0.05 & -0.07 & 0.02 \\
\hline Accounting & 0.20 & 0.59 & 0.01 & -0.39 & 0.00 \\
\hline Physics & 0.16 & 0.28 & -0.18 & 0.03 & 0.03 \\
\hline Chemistry & 0.11 & 0.27 & -0.22 & -0.01 & 0.07 \\
\hline Biology & 0.07 & 0.23 & -0.17 & -0.04 & 0.06 \\
\hline English & & & (base) & & \\
\hline Poli Sci/Government & -0.02 & 0.18 & 0.05 & -0.26 & 0.01 \\
\hline Economics & -0.05 & 0.38 & 0.07 & -0.50 & 0.00 \\
\hline History & -0.09 & 0.16 & 0.02 & -0.27 & 0.00 \\
\hline Comm/Media Studies & -0.11 & 0.06 & -0.06 & -0.13 & 0.02 \\
\hline Psychology & -0.18 & 0.20 & 0.05 & -0.44 & 0.01 \\
\hline Sociology & -0.18 & 0.17 & 0.05 & -0.41 & 0.00 \\
\hline Philosophy & -0.22 & 0.08 & 0.00 & -0.30 & 0.00 \\
\hline Mathematics & -0.25 & 0.15 & -0.03 & -0.37 & 0.00 \\
\hline
\end{tabular}

Notes: Difference in cost measured as log difference from English. We hold 3 of the cost drivers at the values for English and allow the focal cost driver to take the value for the specific field. All models are weighted by total student credit hours*IPW. 


\section{Table 4. What Drives Differences in Field-Specific Cost Trends? Longitudinal Decomposition}

\begin{tabular}{|c|c|c|c|c|c|}
\hline \multirow[b]{3}{*}{ Field of Study } & \multirow{3}{*}{$\begin{array}{c}\begin{array}{c}\text { Annual \% } \\
\text { Change in } \\
\text { Costs }\end{array} \\
(1)\end{array}$} & \multicolumn{4}{|c|}{ Contribution to \% Change in Costs } \\
\hline & & Salary & Workload & Class size & $\begin{array}{c}\text { Other } \\
\text { Expenses }\end{array}$ \\
\hline & & $(2)$ & (3) & $(4)$ & (5) \\
\hline Electrical Engineering & 0.52 & 0.93 & 0.87 & -1.14 & -0.13 \\
\hline Nursing & -1.97 & -0.19 & -0.18 & -1.45 & -0.15 \\
\hline Mechanical Engineering & -2.17 & -0.14 & 0.36 & -2.36 & -0.02 \\
\hline Education & 1.51 & 0.38 & 0.76 & 0.98 & -0.60 \\
\hline Fine/Studio Arts & 1.55 & 0.64 & 0.31 & 0.73 & -0.13 \\
\hline Biz Admin/Mgmt/Operations & 1.17 & 1.06 & 0.18 & -0.03 & -0.04 \\
\hline Computer/Info Sciences & 0.29 & 0.11 & 0.00 & 0.33 & -0.15 \\
\hline Accounting & 0.83 & 1.55 & -0.12 & -0.40 & -0.19 \\
\hline Physics & -0.87 & -0.05 & 0.24 & -0.84 & -0.22 \\
\hline Chemistry & -1.45 & 0.24 & -0.87 & -0.63 & -0.20 \\
\hline Biology & -0.56 & 0.03 & 0.18 & -0.62 & -0.15 \\
\hline English & 1.07 & 0.10 & 0.31 & 0.79 & -0.12 \\
\hline Poli Sci/Government & 1.36 & 0.41 & 0.67 & 0.31 & -0.04 \\
\hline Economics & 0.96 & 1.43 & -0.01 & -0.33 & -0.13 \\
\hline History & 1.30 & 0.32 & 0.26 & 0.78 & -0.06 \\
\hline Comm/Media Studies & 1.11 & 0.66 & 0.79 & -0.16 & -0.18 \\
\hline Psychology & 0.32 & 0.45 & 0.76 & -0.82 & -0.08 \\
\hline Sociology & 0.72 & 0.33 & 0.51 & 0.01 & -0.13 \\
\hline Philosophy & 0.78 & 0.21 & 0.51 & 0.19 & -0.14 \\
\hline Mathematics & -0.22 & 0.44 & -0.12 & -0.43 & -0.11 \\
\hline
\end{tabular}

Notes: Annual percent change in cost measured between 2000 and 2015, inclusive of program fixed effects. We calculate annual percent change for each cost driver and normalize to annual change in instructional costs to estimate contribution of individual drivers. All calculations are weighted by total student credit hours*IPW. 
Table 5. Average vs. Marginal Cost, by Field

\begin{tabular}{|c|c|c|c|c|c|}
\hline \multirow[b]{2}{*}{ Field } & \multirow[b]{2}{*}{$\begin{array}{l}\text { Average } \\
\text { Cost } \\
(1)\end{array}$} & \multicolumn{2}{|c|}{$\begin{array}{c}\text { Marginal Cost } \\
\end{array}$} & \multicolumn{2}{|c|}{ "Marginal Cost (Program FE) } \\
\hline & & $\begin{array}{c}\text { No program } \\
\text { FE } \\
\text { (2) }\end{array}$ & $\begin{array}{l}\text { Program } \\
\text { FE } \\
\text { (3) }\end{array}$ & $\begin{array}{l}\text { Has graduate } \\
\text { education } \\
\text { (4) }\end{array}$ & $\begin{array}{l}\text { No graduate } \\
\text { education } \\
\text { (5) }\end{array}$ \\
\hline Electrical Engineering & 410 & 414 & 228 & 234 & 152 \\
\hline Nursing & 364 & 295 & 118 & 117 & 86 \\
\hline Mechanical Engineering & 342 & 365 & 49 & 39 & 73 \\
\hline Education & 307 & 260 & 221 & 224 & 18 \\
\hline Physics & 283 & 367 & 21 & -5 & 104 \\
\hline Accounting & 277 & 253 & 170 & 169 & 114 \\
\hline Fine/Studio Arts & 276 & 228 & 107 & 112 & 107 \\
\hline Biz Admin/Mgmt/Operations & 256 & 322 & 188 & 191 & 70 \\
\hline Chemistry & 241 & 268 & -72 & -115 & 115 \\
\hline Computer/Info Sciences & 240 & 295 & 5 & 5 & 171 \\
\hline Poli Sci/Government & 231 & 173 & 116 & 112 & 103 \\
\hline Biology & 225 & 184 & 42 & 25 & 93 \\
\hline Economics & 221 & 226 & 113 & 111 & 73 \\
\hline English & 201 & 184 & 88 & 88 & 101 \\
\hline History & 196 & 166 & 84 & 84 & 81 \\
\hline Philosophy & 190 & 180 & 64 & 65 & 47 \\
\hline Psychology & 184 & 160 & 27 & 18 & 114 \\
\hline Comm/Media Studies & 180 & 186 & 172 & 161 & 184 \\
\hline Sociology & 176 & 142 & 76 & 75 & 80 \\
\hline Mathematics & 167 & 171 & 54 & 55 & 52 \\
\hline
\end{tabular}

Notes: All regressions are weighted by total student credit hours*IPW and include year fixed effects. Sample includes 32,496 programyears. Average cost corresponds to the constant from a field-specific regression of direct instructional expenditure per student credit hour on a constant and year fixed effects. Marginal cost corresponds to the coefficient on student credit hours from a field-specific regression of direct instructional expenditure on a constant, the number of student credit hours, year fixed effects, and program fixed effects (for (3) to (5)). 


\begin{tabular}{|c|c|c|c|c|c|c|c|c|c|c|}
\hline & \multicolumn{2}{|c|}{$\begin{array}{l}\text { No Online } \\
\text { Enrollment }\end{array}$} & \multicolumn{2}{|c|}{$\begin{array}{l}\text { 1st Quartile Online } \\
\text { Enrollment } \\
\end{array}$} & \multicolumn{2}{|c|}{$\begin{array}{c}\text { 2nd Quartile } \\
\text { Online Enrollment } \\
\end{array}$} & \multicolumn{2}{|c|}{$\begin{array}{c}\text { 3rd Quartile } \\
\text { Online Enrollment } \\
\end{array}$} & \multicolumn{2}{|c|}{$\begin{array}{c}\text { 4th Quartile } \\
\text { Online Enrollment } \\
\end{array}$} \\
\hline & mean & sd & mean & sd & mean & sd & mean & sd & mean & sd \\
\hline Public Institutions & $55 \%$ & & $77 \%$ & & $79 \%$ & & $84 \%$ & & $88 \%$ & \\
\hline Total Degrees Awarded & 94 & & 136 & & 135 & & 136 & & 290 & \\
\hline BA as Share of Total Degrees & $88 \%$ & & $79 \%$ & & $80 \%$ & & $82 \%$ & & $79 \%$ & \\
\hline MA as Share of Total Degrees & $10 \%$ & & $17 \%$ & & $18 \%$ & & $16 \%$ & & $19 \%$ & \\
\hline Prof as Share of Total Degrees & $0 \%$ & & $0 \%$ & & $0 \%$ & & $0 \%$ & & $0 \%$ & \\
\hline PhD as Share of Total Degrees & $2 \%$ & & $4 \%$ & & $2 \%$ & & $2 \%$ & & $1 \%$ & \\
\hline \multicolumn{11}{|l|}{ Full-Time Equivalents for All Faculty } \\
\hline Fall Semester Total FTE & 24 & 21 & 47 & 33 & 37 & 28 & 38 & 23 & 44 & 43 \\
\hline Fall Semester Instructional FTE & 24 & 20 & 46 & 32 & 36 & 27 & 38 & 23 & 44 & 43 \\
\hline Tenured Faculty Share of Instructional FTE & $64 \%$ & & $55 \%$ & & $58 \%$ & & $55 \%$ & & $52 \%$ & \\
\hline \multicolumn{11}{|l|}{ Student Credit Hours } \\
\hline Fall Semester SCH by All Faculty & 6,421 & 7,051 & 12,104 & 9,481 & 9,446 & 7,293 & 10,424 & 7,286 & 11,580 & 12,374 \\
\hline Undergrad Share of All SCH & $95 \%$ & & $92 \%$ & & $92 \%$ & & $94 \%$ & & $87 \%$ & \\
\hline Total Online Credit Share & 0.00 & 0.00 & 0.01 & 0.01 & 0.04 & 0.01 & 0.10 & 0.02 & 0.28 & 0.15 \\
\hline UG Online Credit Share in 2015 & 0.00 & 0.00 & 0.01 & 0.01 & 0.04 & 0.02 & 0.09 & 0.03 & 0.24 & 0.15 \\
\hline GR Online Credit Share in 2015 & 0.00 & 0.00 & 0.04 & 0.11 & 0.06 & 0.13 & 0.11 & 0.21 & 0.33 & 0.34 \\
\hline \multicolumn{11}{|l|}{ Organized Class Sections } \\
\hline Fall Semester OCS - All & 76 & 63 & 147 & 111 & 125 & 116 & 120 & 72 & 129 & 116 \\
\hline \multicolumn{11}{|l|}{ Expenditures } \\
\hline $\begin{array}{l}\text { Direct Instructional Expenditures (\$1000) - includes salary, } \\
\text { benefits, and other expenses }\end{array}$ & $\$ 2,852$ & $\$ 2,920$ & $\$ 4,933$ & $\$ 4,305$ & $\$ 3,660$ & $\$ 3,026$ & $\$ 3,524$ & $\$ 2,505$ & $\$ 4,410$ & $\$ 5,631$ \\
\hline Personnel Spending as a Share of Instructional Spending & $94 \%$ & & $94 \%$ & & $95 \%$ & & $93 \%$ & & $90 \%$ & \\
\hline \multicolumn{11}{|l|}{ Analysis Variables } \\
\hline Total Faculty per Student & 0.07 & 0.02 & 0.06 & 0.02 & 0.06 & 0.02 & 0.06 & 0.02 & 0.07 & 0.03 \\
\hline Estimated Class Size & 34 & 22 & 38 & 22 & 32 & 16 & 32 & 14 & 30 & 19 \\
\hline Instructional Faculty Course Load - All Courses & 3.4 & 1.1 & 3.3 & 1.0 & 3.5 & 1.2 & 3.3 & 0.9 & 3.3 & 0.9 \\
\hline Instructional Spending per SCH & $\$ 239$ & $\$ \quad 99$ & $\$ 234$ & $\$ 133$ & $\$ 218$ & $\$ 103$ & $\$ 201$ & $\$ 105$ & $\$ 206$ & $\$ \quad 114$ \\
\hline Instructional Personnel Spending per SCH & $\$ 225$ & 92 & 218 & 121 & 205 & 95 & 188 & 100 & 186 & 105 \\
\hline Total Spending per SCH & $\$ 277$ & 171 & 285 & 236 & 244 & 167 & 220 & 126 & 222 & 132 \\
\hline N (institution-program-year) & 989 & & 266 & & 265 & & 266 & & 265 & \\
\hline Weighted by IPW * SCH & $48 \%$ & & $13 \%$ & & $13 \%$ & & $13 \%$ & & $13 \%$ & \\
\hline
\end{tabular}

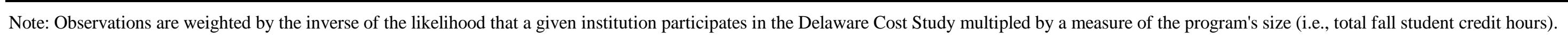


Table 7. Online Courses and Instructional Costs

Outcome $=$ Log instructional cost per student credit hour

Independent variable

A. Presence of Online Instruction

Any online credits in 2015

Any online UG credits in 2015

Any online GR credits in 2015

B. Intensity of Online Instruction

Online as a share of total credits 2015

Online share of undergraduate credits 2015

Online share of graduate credits 2015

By Quartile (ref: no online credits)

1 st quartile of online credits

2nd quartile of online credits

3rd quartile of online credits

4th quartile of online credits

1st quartile of undergraduate online credits

2nd quartile of undergraduate online credits

3rd quartile of undergraduate online credits

4th quartile of undergraduate online credits
(2)

(3)

$-0.0182$

$-0.0354$

(0.0349)

$-0.0502 \sim$

(0.0278)

$-0.0128$

$(0.0229)$

$(0.0343)$

$-0.0413$

(0.0264)

0.00780

$-0.0312$
(4)

(5)

(6)
$-0.290 *$

(0.133)
$-0.141$

(0.120)

$-0.0806$

(0.0890)
$-0.0255$

(0.0399)

$-0.0463$

(0.0417)

$-0.00834$

(0.0295)

$-0.0918 \sim$

(0.0508)

\begin{tabular}{lllllll}
\hline Observations & 2,037 & 2,037 & 2,037 & 2,037 & 2,037 & 2,037 \\
R-squared & 0.662 & 0.652 & 0.664 & 0.653 & 0.664 & 0.665 \\
\hline \hline
\end{tabular}

Notes: All models include institution fixed effects, field fixed effects, and a lagged measure of the outcome variable. Specifically, the lagged measure is the log of the average instructional cost per student credit hour by program data from 2000-2005. When such data are missing, we include an indicator variable to maintain the full sample. Standard errors clustered on institution appear in parentheses and all models are weighted by total student credit hours*IPW . ${ }^{* * *} \mathrm{p}<.001 ; * * \mathrm{p}<.01 ;{ }^{*} \mathrm{p}<.05 ; \sim \mathrm{p}<0.1$ 


\section{Appendix A. Additional Figures and Tables}

\section{Appendix Figure A1. Data Collection Template for Delaware Cost Study}

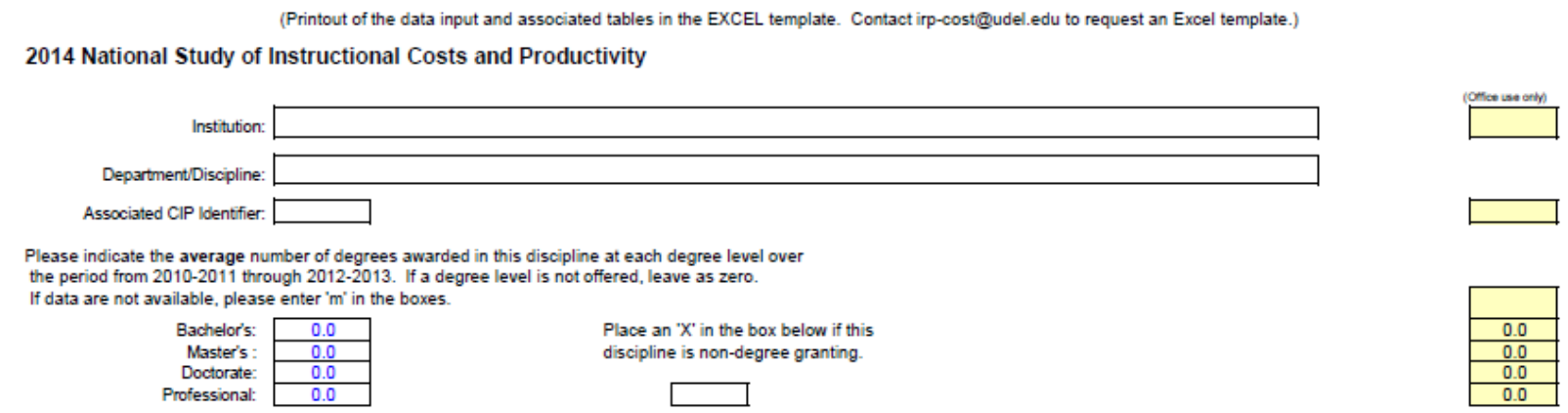

A. INSTRUCTIONAL COURSELOAD: FALL SEMESTER, 2013

Please complete the following matrix, displiaying student credit hours and organized class sections taught, by type of facuity, and by level of instruction.

Be sure to consut defntilons before proceeoling. Do not input data in shaded cells except for those mentioned in the important note below that pertains to (G) and (J).

\begin{tabular}{|c|c|c|c|c|c|c|c|c|c|c|c|c|c|c|c|c|}
\hline \multicolumn{4}{|c|}{ Faculty } & \multicolumn{2}{|c|}{ Enver Undengreas Deeals } & \multirow{3}{*}{\begin{tabular}{|c|}
\multicolumn{1}{|c|}{} \\
$\begin{array}{c}\text { (F) } \\
\text { Underpros } \\
\text { intov. } \\
\text { natrust. }\end{array}$ \\
\end{tabular}} & \multicolumn{2}{|c|}{ Student Credit Hours } & \multicolumn{3}{|c|}{ 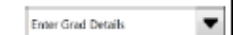 } & \multicolumn{5}{|c|}{ Organized Class Sections } \\
\hline \multirow[b]{2}{*}{ Classification } & \multicolumn{3}{|c|}{ FTE Faculty } & \multirow{2}{*}{$\begin{array}{l}\text { (D) } \\
\text { Lower } \\
\text { Dlv. OC" }\end{array}$} & \multirow{2}{*}{$\begin{array}{c}\text { (E) } \\
\text { Upper } \\
\text { Dlv. OC. } \\
\end{array}$} & & \multirow{2}{*}{$\begin{array}{c}\text { (G) } \\
\text { Total } \\
\text { Underprad } \\
\text { OCH }\end{array}$} & \multirow{2}{*}{$\begin{array}{l}(H) \\
\text { Grad } \\
\infty C^{*}\end{array}$} & \multirow{2}{*}{$\begin{array}{c}\text { (1) } \\
\text { Groduste } \\
\text { Indve. } \\
\text { Instruct. }\end{array}$} & \multirow{2}{*}{$\begin{array}{c}\text { (J) } \\
\text { Total } \\
\text { Grasuaste } \\
{ }_{0} \mathrm{CH} \\
\end{array}$} & \multirow{2}{*}{$\begin{array}{c}(\kappa) \\
\text { Total } \\
\text { Student } \\
\text { Crosit Hours } \\
\end{array}$} & \multirow{2}{*}{$\begin{array}{c}\text { (L) } \\
\text { LabiDad } \\
\text { Rece } \\
\text { Sectiona }\end{array}$} & \multicolumn{3}{|c|}{$\begin{array}{l}\text { Ocher section Types } \\
\text { (Lecture, Seminar, etc.) }\end{array}$} & \multirow[b]{2}{*}{ Total } \\
\hline & $\begin{array}{l}\text { (A) } \\
\text { Total }\end{array}$ & $\begin{array}{c}\text { (B) } \\
\text { Sep. Budg. }\end{array}$ & $\begin{array}{c}\text { (C) } \\
\text { intruc- } \\
\text { tional }\end{array}$ & & & & & & & & & & $\begin{array}{l}\text { (Lect) } \\
\text { (II) } \\
\text { Lower DN. }\end{array}$ & $\begin{array}{l}\text { yre, Oeminar } \\
\text { (N) } \\
\text { Upper Div. }\end{array}$ & $\begin{array}{l}\text { etc.) } \\
\text { (o) } \\
\text { Graduaste }\end{array}$ & \\
\hline $\begin{array}{l}\text { Regular facuity: } \\
\text { - Tenured/Tenure Eligble }\end{array}$ & 0.00 & 0.00 & 0.00 & 0 & 0 & 0 & 0 & 0 & 0 & 0 & 0 & 0.0 & 0.0 & 0.0 & 0.0 & 0.0 \\
\hline - Other Regular Faculty & 0.00 & 0.00 & 0.00 & 0 & 0 & 0 & 0 & 0 & 0 & 0 & 0 & 0.0 & 0.0 & 0.0 & 0.0 & 0.0 \\
\hline Supplemental Faculty & 0.00 & Na & 0.00 & 0 & 0 & 0 & 0 & 0 & 0 & 0 & 0 & 0.0 & 0.0 & 0.0 & 0.0 & 0.0 \\
\hline $\begin{array}{l}\text { Teaching Assistants: } \\
\text { - Credit Bearing Courses }\end{array}$ & 0.00 & Na & 0.00 & 0 & 0 & 0 & 0 & 0 & 0 & 0 & 0 & 0.0 & 0.0 & 0.0 & 0.0 & 0.0 \\
\hline - Non-Credit Bearing Activity & 0.00 & Na & 0.00 & $\mathrm{Ma}$ & Na & Na & Na & na & na & Na & Na & 0.0 & 0.0 & 0.0 & 0.0 & 0.0 \\
\hline TOTAL & 0.00 & 0.00 & 0.00 & 0 & 0 & 0 & 0 & 0 & 0 & 0 & 0 & 0.0 & 0.0 & 0.0 & 0.0 & 0.0 \\
\hline
\end{tabular}

Reminder: Use Fall 2013 semester data as of your official census date.

Important note: If you cannot differentiate between "Organized Class" and "Individualized Instruction" student credit hours, assign all credit hours to the appropriate "Organized Class" column. Similarly, if you cannot differentiate between "Lower Division" and "Upper Division" undergraduate student credit hours, report all those hours under "Total Undergraduate SCH."

B. COST DATA: ACADEMIC AND FISCAL YEAR 2013-2014

1. Total student credit hours generated during Academic Year 2013-2014, that were supported by the department/discipline instructional budget. (NOTE: Semester calendar institutions will typically report fall and spring student credit hours: quarter calendar institutions will report fall, winter, and spring student credit hours.)

0 A. Undergraduate

0 B. Graduate

2. Total direct expenditures for instruction in Fiscal Year 2013-2014

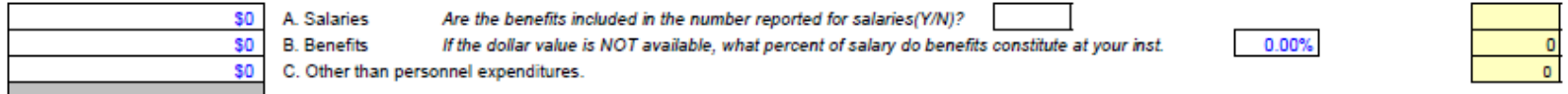

so D. Total (including benefits if it was calculated)

3. Total direct expenditures for separately budgeted research activities in Fiscal Year 2013-2014

\section{so}

4. Total direct expenditures for separately budgeted public service activities in Fiscal Year 2013-2014

2014 University of Delaware. The National Study of Instructional Costs and Productivity (Delaware Cost Study) is solely intended for unit and institutional improvement. Unauthorized use without the express writt 


\section{Appendix Figure A2. Cross-Field Cost Differences, by Institution Type}

\section{A. Research Institutions}

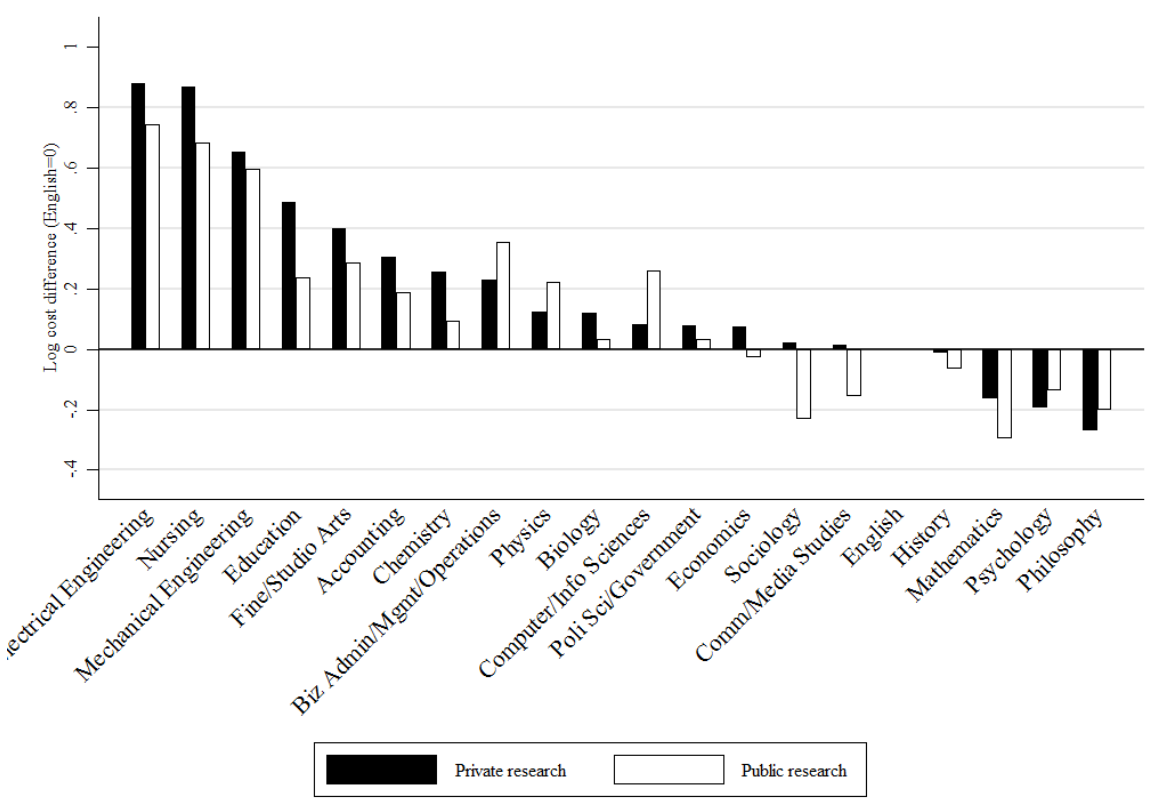

\section{B. Comprehensive Institutions}

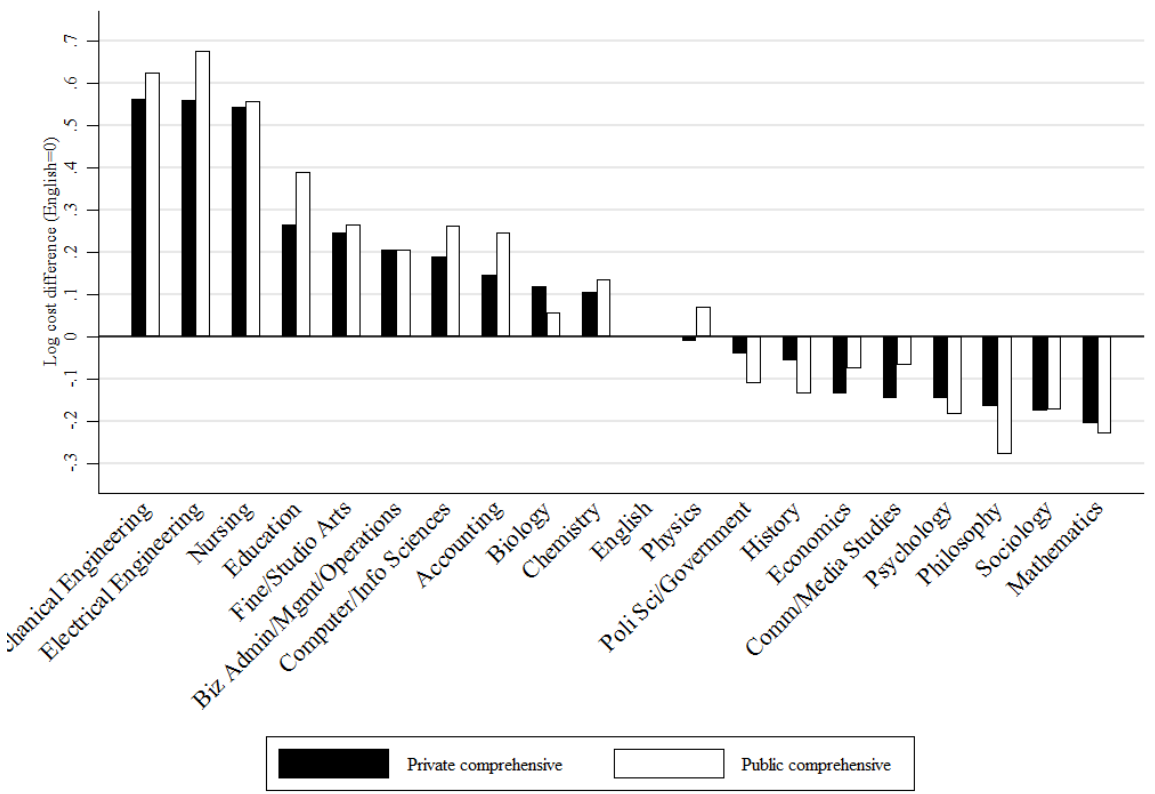

Notes: Each column reports the difference in log of direct instructional cost per SCH between the reported field and English, after controlling for institution and year fixed effects. Positive numbers indicate the field is more expensive than English. Sample includes public and private institutions participating in the Delaware Cost Study between 2013-2015. Only departments in the 20 fields listed in Table A1 are included. A small number of observations with missing or outlier data are excluded. Program-level observations are weighted by number of student credit hours multiplied by the inverse of the probability of being included in the sample (estimated at the institution-year level). Costs are expressed in 2015 dollars. 


\section{Appendix Figure A3. Cross-Field Cost Differences, by Institutional Selectivity}

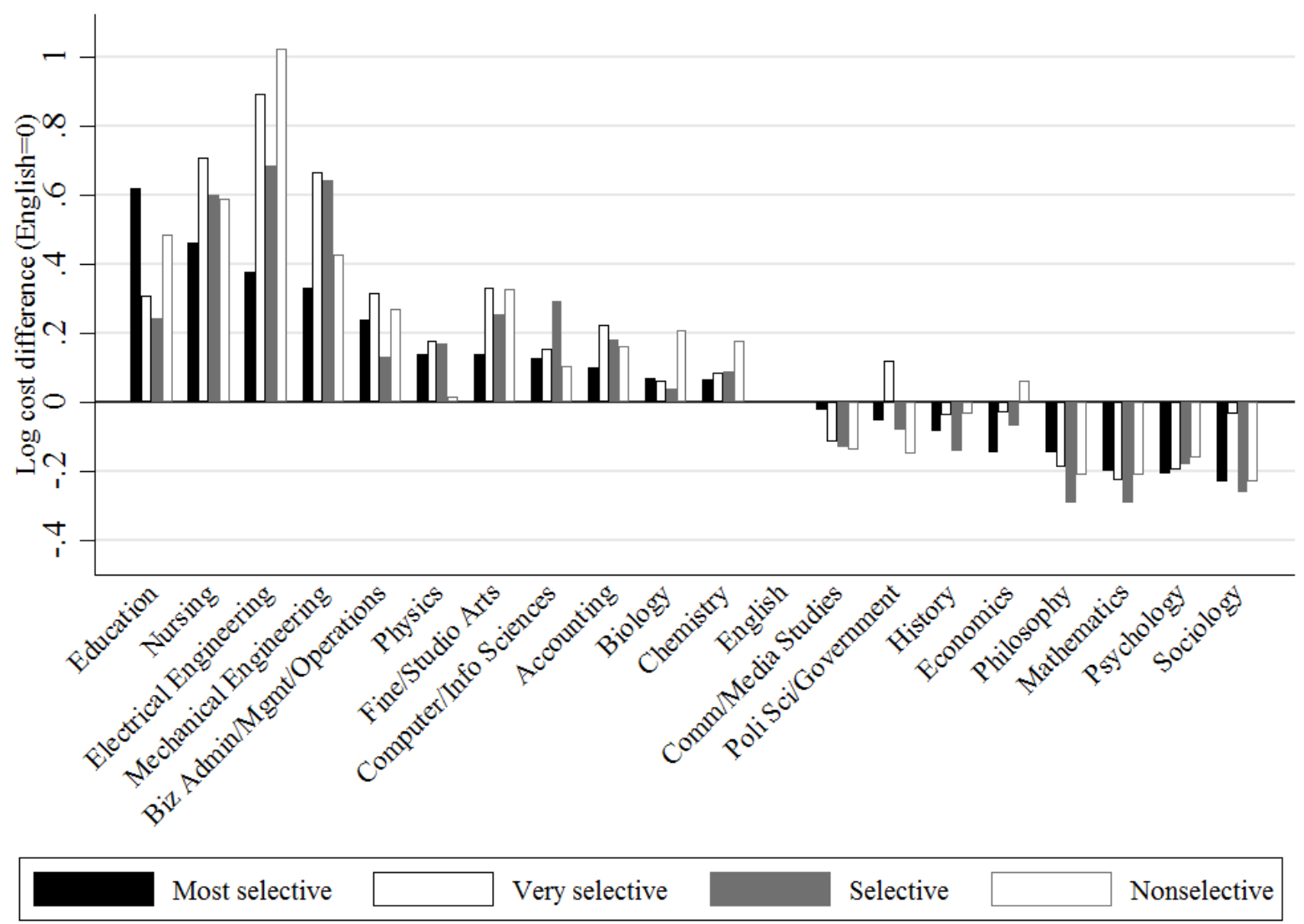

Notes: Each column reports the difference in log of direct instructional cost per SCH between the reported field and English, after controlling for institution and year fixed effects. Positive numbers indicate the field is more expensive than English. Sample includes public and private institutions participating in the Delaware Cost Study between 2013-2015. Only departments in the 20 fields listed in Table A1 are included. A small number of observations with missing or outlier data are excluded. Program-level observations are weighted by number of student credit hours multiplied by the inverse of the probability of being included in the sample (estimated at the institution-year level). Costs are expressed in 2015 dollars. 


\section{Appendix Figure A4. Class Size Trends Over Time, by CIP4 $(2000=100), 2000-2015$}

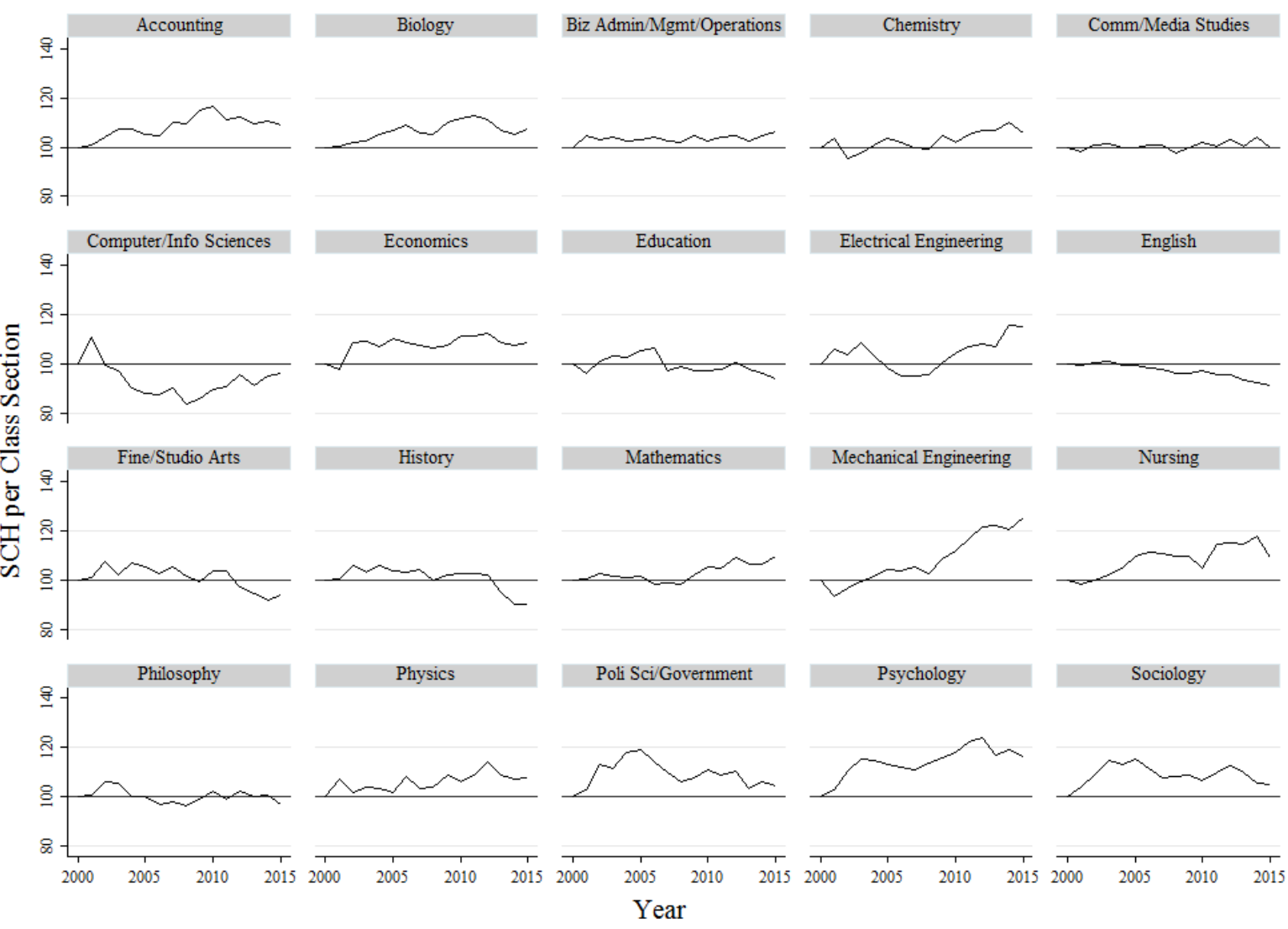

Notes: Class size is measured by the number of student credit hours ( $\mathrm{SCH}$ ) per organized class section (OCS). Sample includes public and private institutions participating in the Delaware Cost Study between 2000-2015. Only departments in the 20 fields listed in Table A1 are included. A small number of observations with missing or outlier data are excluded. Program-level observations are weighted by number of student credit hours multiplied by the inverse of the probability of being included in the sample (estimated at the institution-year level). Trends are normalized to the year 2000 and net of institution-by-field fixed effects. 


\section{Appendix Figure A5. Faculty Salary Trends Over Time, by CIP4 $(2000=100), 2000-2015$}
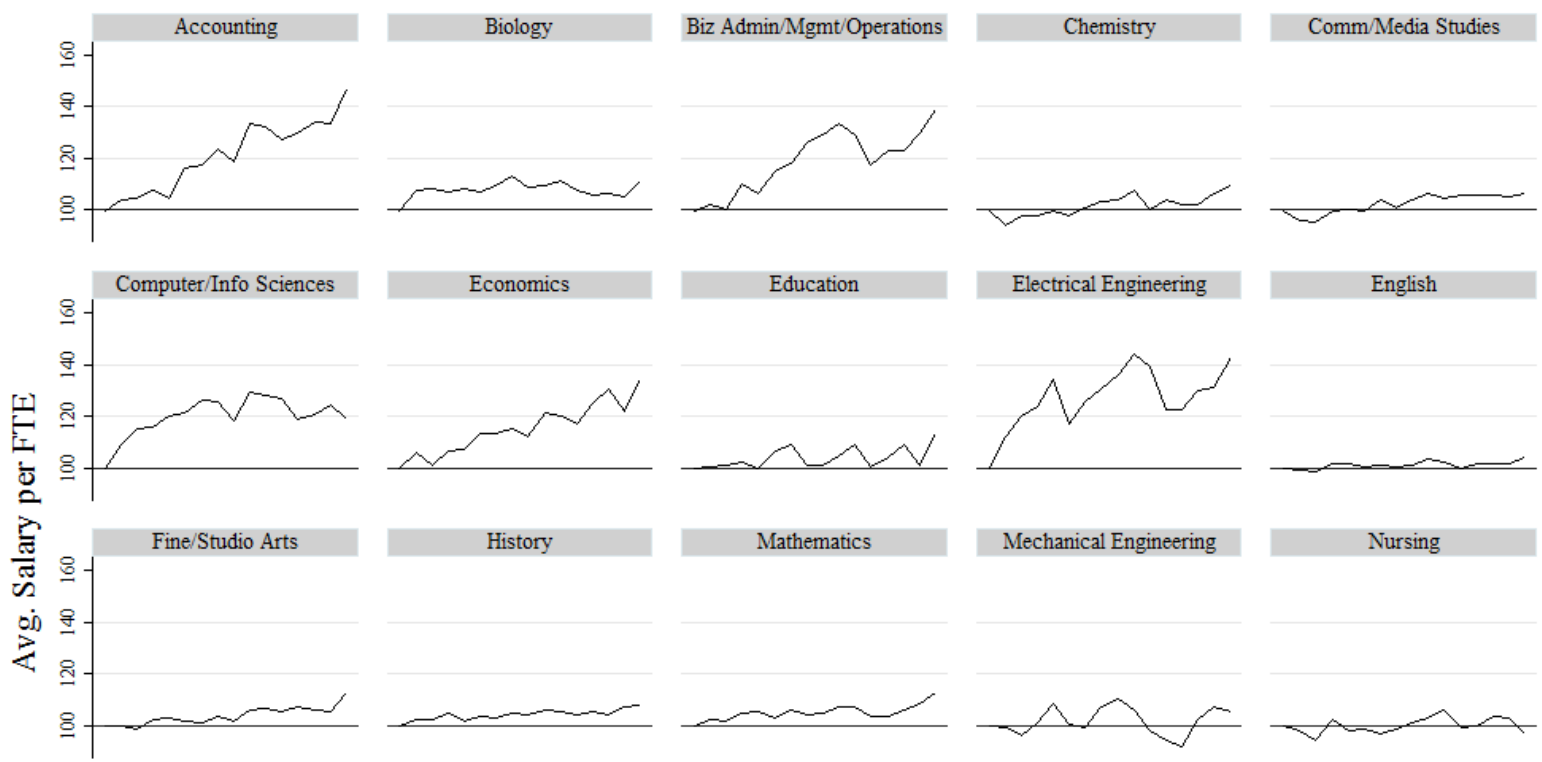

History
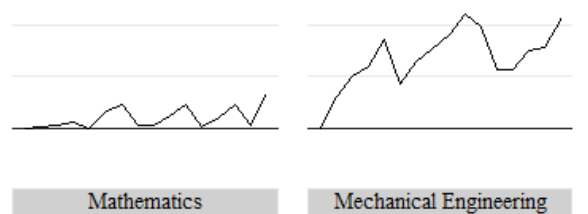

Comm/Media Studies
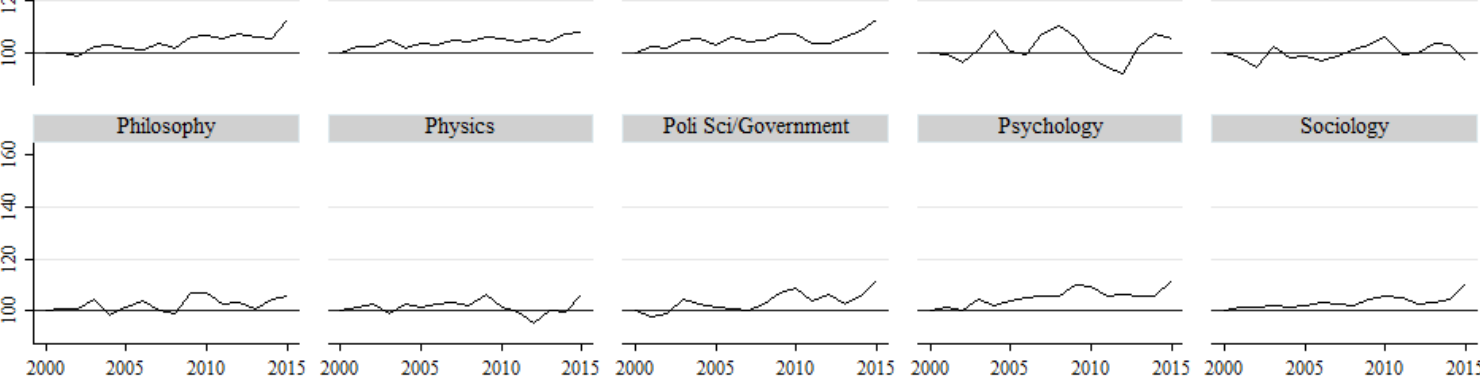

Poli Sci/Government

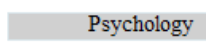

Sociology

Physics
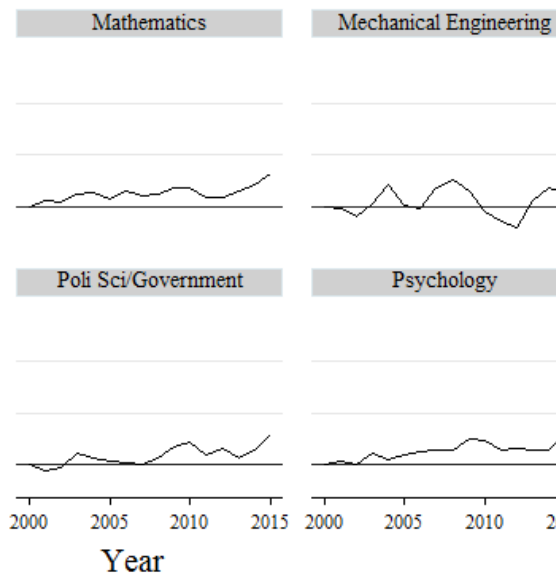

Nursing

English
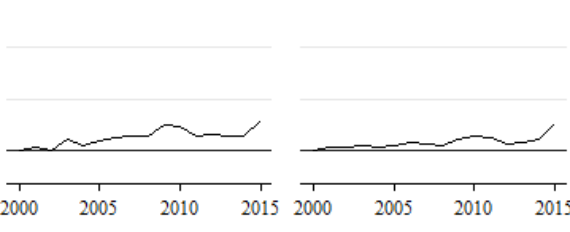

Notes: Faculty salary is measured by total faculty personnel expenditures per FTE. Sample includes public and private institutions participating in the Delaware Cost Study between 2000-2015. Only departments in the 20 fields listed in Table A1 are included. A small number of observations with missing or outlier data are excluded. Programlevel observations are weighted by number of student credit hours multiplied by the inverse of the probability of being included in the sample (estimated at the institution-year level). Trends are normalized to the year 2000 and net of institution-by-field fixed effects. 


\section{Appendix Figure A6. Teaching Load Trends Over Time, by CIP4 (2000 = 100). 2000-2015}
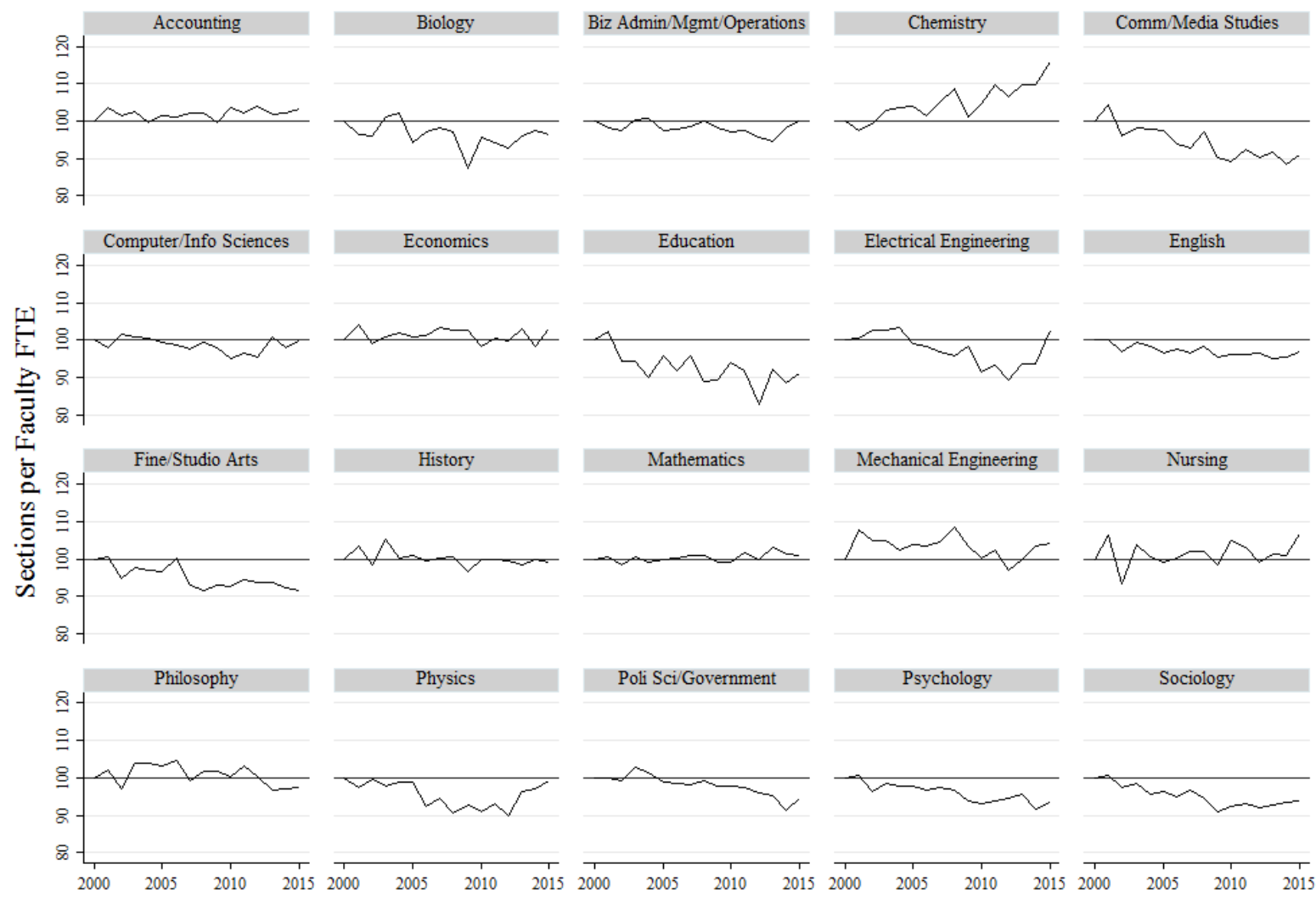

Poli Sci/Government
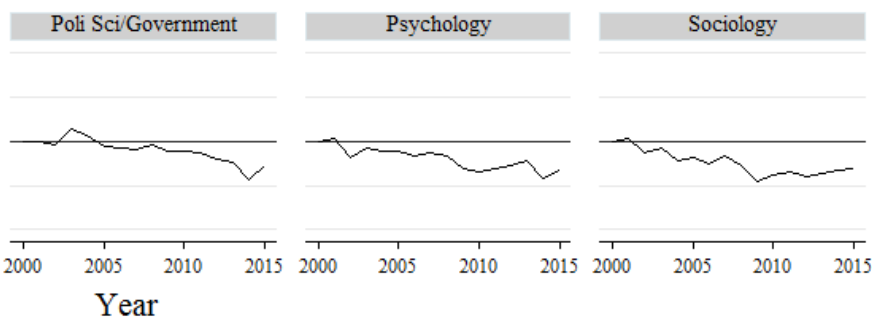

Notes: Teaching load is measured by the number of course sections taught by FTE. Sample includes public and private institutions participating in the Delaware Cost Study between 2000-2015. Only departments in the 20 fields listed in Table A1 are included. A small number of observations with missing or outlier data are excluded. Programlevel observations are weighted by number of student credit hours multiplied by the inverse of the probability of being included in the sample (estimated at the institution-year level). Trends are normalized to the year 2000 and net of institution-by-field fixed effects. 


\section{Appendix Figure A7. Non-Personnel Trends Over Time, by CIP4 (2000 = 100). 2000-2015}

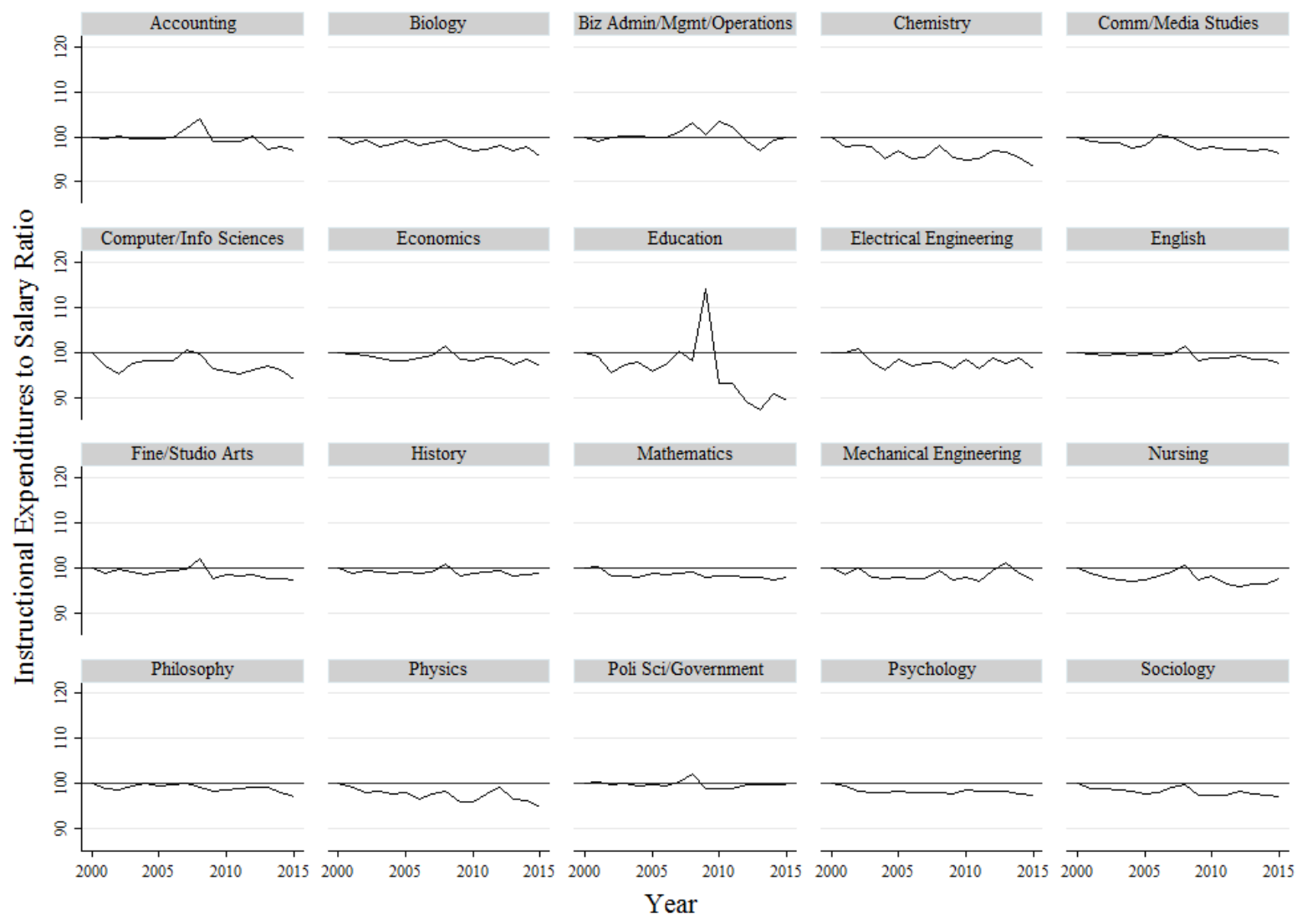

Notes: Non-personnel expenditures measured as the ratio of direct instructional expenditures to personnel expenditures. Sample includes public and private institutions participating in the Delaware Cost Study between 2000-2015. Only departments in the 20 fields listed in Table A1 are included. A small number of observations with missing or outlier data are excluded. Program-level observations are weighted by number of student credit hours multiplied by the inverse of the probability of being included in the sample (estimated at the institution-year level). Trends are normalized to the year 2000 and net of institution-by-field fixed effects. 


\section{Appendix Table A1. List of Participating Institutions}

Note: Over 700 institutions have participated in the study. Below we only list the 148 institutions that participated in the study for at least 8 years between 1998 and 2015, though our analysis includes all institutions. Parentheses indicate the number of years that the institution participated over this period.

Appalachian State University (NC) (19)

Arizona State University (AZ) (13)

Auburn University - Montgomery (AL) (14)

Austin Peay State University (TN) (12)

Baylor University (TX) (16)

Belmont University (TN) (14)

Bowling Green State University $(\mathrm{OH})(16)$

California State University - San Marcos (CA) (10)

Catholic University of America (DC) (9)

Central Connecticut State University (CT) (14)

Central Michigan University (MI) (17)

Clarkson University (NY) (11)

Clemson University (SC) (18)

Cleveland State University (OH) (11)

College of Charleston (SC) (13)

College of Notre Dame of Maryland (MD) (8)

College of St. Elizabeth (NJ) (9)

College of St. Scholastica (MN) (10)

Columbia College, SC (SC) (9)

Delaware Valley College (PA) (8)

DePaul University (IL) (15)

Drew University (NJ) (11)

East Carolina University (NC) (19)

East Tennessee State University (TN) (10)

Eastern Washington University (WA) (8)

Edinboro University of Pennsylvania (PA) (9)

Elizabeth City State University (NC) (18)

Fayetteville State University (NC) (16)

Ferrum College (VA) (9)

Florida International University (FL) (16)

Florida State University (FL) (15)

Gannon University (PA) (9)

Geneva College (PA) (11)

Georgia Institute of Technology (GA) (8)

Georgia Southern University (GA) (8)

Georgia State University (GA) (11)

Gonzaga University (WA) (13)

Goshen College (IN) (12)

Grand Valley State University (MI) (13)

Hartwick College (NY) (11)

Indiana State University (IN) (11)

Indiana University - South Bend (IN) (12)

Iowa State University (IA) (10)

Ithaca College (NY) (12)

James Madison University (VA) (15)
Seattle University (WA) (8)

Shepherd University (WV) (10)

Slippery Rock University (PA) (15)

South Dakota State University (SD) (10)

Southeastern Louisiana University (LA) (14)

Southern Univ and A\&M College - Baton Rouge (LA) (8)

Stonehill College (MA) (8)

SUNY - Stony Brook (NY) (9)

SUNY - University at Buffalo (NY) (12)

Tennessee Technological University (TN) (18)

Union University (TN) (15)

University of Alabama - Birmingham (AL) (9)

University of Alabama - Huntsville (AL) (11)

University of Alabama - Tuscaloosa (AL) (15)

University of Arizona (AZ) (14)

University of Arkansas - Fayetteville (AR) (13)

University of Central Florida (FL) (13)

University of Colorado at Boulder (CO) (11)

University of Colorado at Colorado Springs (CO) (11)

University of Connecticut (CT) (16)

University of Delaware (DE) (17)

University of Houston (TX) (11)

University of Idaho (ID) (14)

University of Kansas (KS) (18)

University of Maine (ME) (11)

University of Mary Washington (VA) (8)

University of Massachusetts - Amherst (MA) (16)

University of Massachusetts - Dartmouth (MA) (11)

University of Memphis (TN) (11)

University of Minnesota - Morris (MN) (8)

University of Mississippi (MS) (15)

University of Missouri - Columbia (MO) (16)

University of Missouri - Kansas City (MO) (16)

University of Missouri - St. Louis (MO) (19)

University of Montevallo (AL) (9)

University of Nebraska - Lincoln (NE) (12)

University of Nebraska at Kearney (NE) (11)

University of Nebraska at Omaha (NE) (11)

University of New Hampshire (NH) (14)

University of North Carolina - Asheville (NC) (15)

University of North Carolina - Chapel Hill (NC) (14)

University of North Carolina - Charlotte (NC) (14)

University of North Carolina - Greensboro (NC) (15)

University of North Carolina - Pembroke (NC) (14)

University of North Carolina - Wilmington (NC) (10) 
John Carroll University (OH) (8)

Kansas State University (KS) (10)

Kent State University (OH) (14)

Lander University (SC) (9)

Louisiana State University (LA) (15)

Loyola University of Chicago (IL) (8)

Lynchburg College (VA) (12)

McMurry University (TX) (8)

Mercer University (GA) (11)

Middle Tennessee State University (TN) (9)

Mississippi State University (MS) (18)

Missouri State University (MO) (11)

Missouri University of Science and Technology (MO) (10)

Montana State University-Billings (MT) (15)

Montana State University-Bozeman (MT) (15)

North Carolina A\&T State University (NC) (16)

North Carolina Central University (NC) (18)

North Carolina State University (NC) (15)

Northeastern University (MA) (13)

Northern Arizona University (AZ) (15)

Northwestern State University of Louisiana (LA) (12)

Oakland University (MI) (18)

Ohio Northern University $(\mathrm{OH})(8)$

Oklahoma State University (OK) (9)

Radford University (VA) (11)

Ramapo College of New Jersey (NJ) (11)

Rowan University (NJ) (12)

Saint Francis University (PA) (10)

Schreiner University (TX) (11)
University of North Dakota (ND) (9)

University of Northern Iowa (IA) (16)

University of Notre Dame (IN) (8)

University of Oregon (OR) (14)

University of Rhode Island (RI) (8)

University of South Carolina - Columbia (SC) (17)

University of South Carolina - Upstate (SC) (9)

University of South Florida (FL) (11)

University of Southern Mississippi (MS) (10)

University of Tennessee - Chattanooga (TN) (12)

University of Tennessee - Knoxville (TN) (16)

University of Tennessee - Martin (TN) (13)

University of Texas at Austin (TX) (8)

University of Toledo $(\mathrm{OH})(8)$

University of Utah (UT) (19)

University of Vermont (VT) (11)

University of Virginia - Charlottesville (VA) (10)

University of West Florida (FL) (12)

University of West Georgia (GA) (11)

University of Wisconsin - Madison (WI) (10)

Virginia Polytechnic Inst. \& State Univ. (VA) (14)

Washington State University (WA) (8)

West Virginia University (WV) (18)

Western Carolina University (NC) (19)

Wichita State University (KS) (14)

Wilkes University (PA) (14)

Winston-Salem State University (NC) (18)

Wright State University $(\mathrm{OH})(11)$

Youngstown State University (OH) (9) 


\section{Appendix Table A2. Fields of Study in Sample, by Four-Digit CIP Classification}

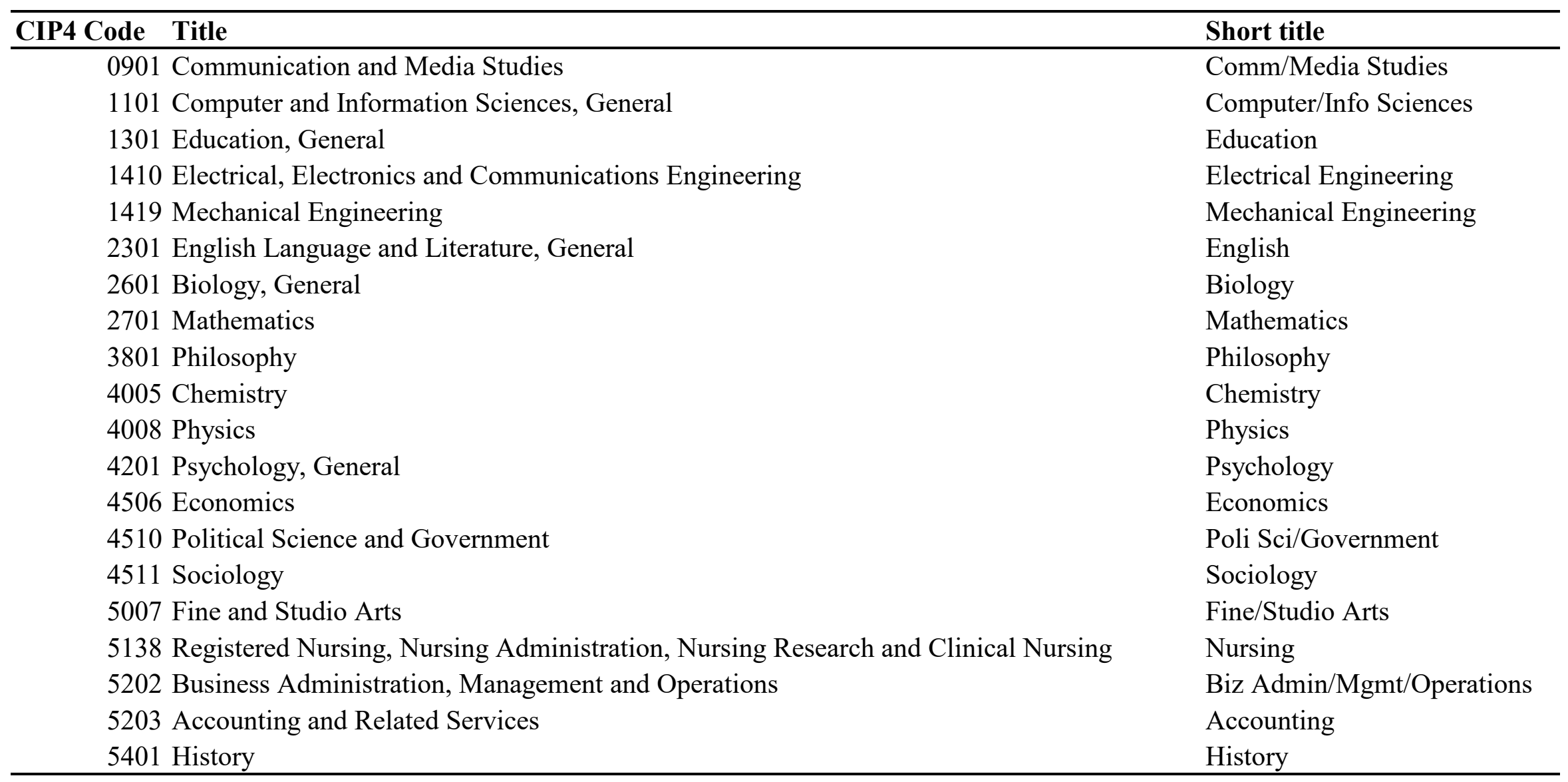




\begin{tabular}{|c|c|c|c|c|c|c|c|c|c|c|c|c|}
\hline & \multicolumn{2}{|c|}{ All } & \multicolumn{2}{|c|}{ Research - High } & \multicolumn{2}{|c|}{$\begin{array}{l}\text { Research - } \\
\text { Moderate }\end{array}$} & \multicolumn{3}{|c|}{ Masters } & \multicolumn{3}{|c|}{ Baccalaureate } \\
\hline & mean & sd & mean & sd & mean & sd & mean & & sd & mean & & sd \\
\hline Public Institutions & $64 \%$ & & $91 \%$ & & $37 \%$ & & $62 \%$ & & & $21 \%$ & & \\
\hline Total Degrees Awarded & 132 & & 207 & & 216 & & 77 & & & 31 & & \\
\hline BA as Share of Total Degrees & $84 \%$ & & $77 \%$ & & $78 \%$ & & $88 \%$ & & & $97 \%$ & & \\
\hline MA as Share of Total Degrees & $14 \%$ & & $17 \%$ & & $21 \%$ & & $12 \%$ & & & $3 \%$ & & \\
\hline Prof as Share of Total Degrees & $0 \%$ & & $0 \%$ & & $0 \%$ & & $0 \%$ & & & $0 \%$ & & \\
\hline PhD as Share of Total Degrees & $2 \%$ & & $6 \%$ & & $1 \%$ & & $0 \%$ & & & $0 \%$ & & \\
\hline \multicolumn{13}{|l|}{ Full-Time Equivalents for All Faculty } \\
\hline Fall Semester Total FTE & 33 & 28 & 54 & 33 & 36 & 24 & 22 & & 16 & 9 & & 9 \\
\hline Fall Semester Instructional FTE & 33 & 28 & 52 & 32 & 36 & 24 & 22 & & 16 & 9 & & 9 \\
\hline Tenured Faculty Share of Instructional FTE & $61 \%$ & & $58 \%$ & & $59 \%$ & & $62 \%$ & & & $66 \%$ & & \\
\hline \multicolumn{13}{|l|}{ Student Credit Hours } \\
\hline Fall Semester SCH by All Faculty & 8,323 & 7,898 & 14,035 & 9,664 & 8,430 & 5,316 & 5,481 & & 4,274 & 1,869 & & 1,846 \\
\hline Undergrad Share of All SCH & $93 \%$ & & $91 \%$ & & $89 \%$ & & $94 \%$ & & & $98 \%$ & & \\
\hline \multicolumn{13}{|l|}{ Organized Class Sections } \\
\hline Fall Semester OCS - All & 102 & 87 & 152 & 106 & 112 & 70 & 78 & & 59 & 34 & & 30 \\
\hline Undergrad Share of OCS & $86 \%$ & & $79 \%$ & & $82 \%$ & & $91 \%$ & & & $98 \%$ & & \\
\hline Grad Share of OCS & $14 \%$ & & $21 \%$ & & $18 \%$ & & $9 \%$ & & & $2 \%$ & & \\
\hline \multicolumn{13}{|l|}{ Expenditures } \\
\hline $\begin{array}{l}\text { Direct Instructional Expenditures }(\$ 1000) \text { - includes salary, } \\
\text { benefits, and other expenses }\end{array}$ & $\$ 3,443$ & $\$ 3,625$ & $\$ 5,921$ & $\$ 4,483$ & $\$ 4,261$ & $\$ 3,515$ & $\$ 1,992$ & & $\$ 1,453$ & $\$ 672$ & & $\$ 670$ \\
\hline Personnel Spending as a Share of Instructional Spending & $94 \%$ & & $92 \%$ & & $94 \%$ & & $96 \%$ & & & $95 \%$ & & \\
\hline \multicolumn{13}{|l|}{ Analysis Variables } \\
\hline Total Faculty per Student & 0.07 & 0.03 & 0.06 & 0.03 & 0.07 & 0.02 & 0.07 & & 0.02 & 0.08 & & 0.03 \\
\hline Estimated Class Size & 33 & 19 & 45 & 23 & 32 & 15 & 27 & & 10 & 21 & & 7 \\
\hline Undergraduate Class Size & 38 & 26 & 56 & 33 & 37 & 19 & 28 & & 12 & 22 & & 8 \\
\hline Graduate Class Size & 12 & 7 & 12 & 7 & 14 & 7 & 12 & & 7 & 10 & & 6 \\
\hline $\begin{array}{l}\text { Instructional Faculty Course Load including } \\
\text { Labs/Discussions/Recitations }\end{array}$ & 3.4 & 1.0 & 2.9 & 1.1 & 3.2 & 0.9 & 3.6 & & 0.9 & 4.0 & & 1.1 \\
\hline Instructional Spending per SCH & 225 & 111 & 246 & 138 & 251 & 106 & 209 & $\$$ & 90 & 195 & $\$$ & 82 \\
\hline Instructional Personnel Spending per SCH & 211 & 101 & 227 & 125 & 235 & 94 & 199 & $\$$ & 84 & 184 & $\$$ & 74 \\
\hline Total Spending per SCH & $\$ \quad 257$ & 181 & 325 & 258 & 277 & 149 & $\$ 213$ & $\$$ & 94 & 195 & $\$$ & 82 \\
\hline N (institution-program-year) & 7,245 & & 2,425 & & 673 & & 3,428 & & & 719 & & \\
\hline Weighted by IPW $*$ SCH & $100 \%$ & & $34 \%$ & & $12 \%$ & & $43 \%$ & & & $11 \%$ & & \\
\hline
\end{tabular}

Note: Observations are weighted by the inverse of the likelihood that a given institution participates in the Delaware Cost Study multiplied by a measure of the program's size ( total fall student credit hours). 


\section{Appendix Table A4. Approximation of the Accounting Identify}

\begin{tabular}{lcc}
\hline & Outcome $=$ Log Instructional costs per SCH \\
& $(1)$ & $(2)$ \\
\hline DIE/Personnel & $0.944^{* * *}$ & $0.931^{* * *}$ \\
Personnel/FTE (salaries) & $(0.039)$ & $(0.039)$ \\
& $0.927^{* * *}$ & $0.939 * * *$ \\
Faculty FTE/Class sections (workload) & $(0.014)$ & $(0.006)$ \\
& $0.898^{* * *}$ & $0.909^{* * *}$ \\
Class sections/SCH (class size) & $(0.015)$ & $(0.006)$ \\
& $0.928^{* * *}$ & $0.941^{* * *}$ \\
\hline Observations & $(0.009)$ & $(0.004)$ \\
R-squared & 7,191 & 32,422 \\
Fixed effects & 0.971 & 0.970 \\
\hline
\end{tabular}

Notes: Column 1 reports results for cross-section (2013-2015); column 2 reports results for full panel (2000-2015). All independent variables are entered as logs. Robust standard errors are clustered at the institution (column 1) or program (column 2 ) level. All models are weighted by total student credit hours ${ }^{*}$ IPW. ${ }^{* * *} \mathrm{p}<.001 ;{ }^{* *} \mathrm{p}<.01 ;{ }^{*} \mathrm{p}<.05 ; \sim \mathrm{p}<0.1$ 


\section{Appendix B. Detailed Data Overview}

In this appendix, we provide more information about the National Study of Instructional Cost and Productivity, explore coverage of the data, and detail our weighting approach.

\section{The Delaware Cost Study Data}

We use data from the National Study of Instructional Cost and Productivity from the University of Delaware (referred to as the Delaware Cost Study). Since 1998, the study has collected program-level data from over 700 four-year public and private non-profit higher education institutions. We provide a list of participating institutions in Appendix Table A1.

Each year, institutions report degrees awarded, fall semester instructional activity, and annual expenditure data for each of their academic programs, which are identified at the fourdigit Classification of Instructional Program (CIP) code level. Degrees awarded are reported in rolling three-year averages by level: bachelors, master's, professional, and doctorate. Measures of fall term instructional activity include total faculty FTEs, total student credit hours, and total organized class sections. These measures are disaggregated in various ways. Faculty FTEs are categorized by rank: tenured and tenure eligible, other regular, supplemental, credit-bearing teaching assistants, and non-credit-bearing teaching assistants. ${ }^{1}$ Student credit hours and organized class sections are broken out by course level (undergraduate lower division, undergraduate upper division, and graduate) and are also associated with a specific faculty rank. Finally, institutions report total direct expenditures for instruction, research, and public service and total undergraduate and graduate student credit hours for the entire academic year. We construct quarterly rescaled measures for some of our analyses to preserve consistency in numerators and denominators when possible.

\footnotetext{
${ }^{1}$ The distinction between "other regular" and "supplemental" faculty relates to length of contracts and the sources of funds. Other regular faculty have a recurring relationship with the institution and have a recurring appointment. Supplemental faculty are paid from temporary funds for non-recurring teaching assignments. Detailed definitions for each survey item are available online at https://ire.udel.edu/definitions/.

APPENDIX - 13
} 
The institutional research department at the University of Delaware uses these data to develop national cost benchmarks and peer analyses for participating institutions, which may use the information for their own budgeting and strategic planning.

\section{Coverage of U.S. Institutions}

Because participation in the Delaware Cost Study (DCS) is optional, we analyzed the representativeness of our sample against the universe of public and private non-profit institutions that are US-based and that report information to the Integrated Postsecondary Education Data System (IPEDS). ${ }^{2}$ The final universe includes 1,786 institutions and 34.9 million degrees. While the majority of schools were private institutions (67.4\%), public schools produced the most graduates $(64.2 \%$ of all degrees).

Using the IPEDS Completions survey, we analyze how nationally representative the DCS is at the two-digit CIP code level. Over one-third of all institutions reported to the Delaware Cost Study at least once (34.2\%), accounting for 60.1 percent of all the degrees awarded between 1998 and 2015. However, institutions do not participate every year and some fail to report data for all of their departments (CIP2). When participating, institutions report most their departments to the study (82\%) and these departments represent more than 90 percent of the degrees they award (92.3\%). Taking these gaps into account, we estimate that our sample represents 23.3 percent of all degrees awarded over this period. Coverage is significantly higher for public degrees than for private degrees ( $32.2 \%$ versus $7.8 \%$, respectively), and among public institutions, those rated very competitive or competitive by Barron's have the highest participation rates. The relationship between selectivity and participation reverses among private

\footnotetext{
${ }^{2}$ We also dropped institutions identified by Carnegie Classification as tribal, special focus (mostly private faithrelated institutions, medical and health professional schools, and schools of art, music, and design), and unclassified (mostly unaccredited schools). A small number of international and special focus institutions report to the Delaware Cost Study ( $\mathrm{n}=15)$, but we decided to drop these institutions because the sample of similar institutions would be too small to draw meaningful comparisons. We also dropped a small number of institution-year-CIP2 records that were observed in the Delaware Cost Study, but not in the Completions survey $(<1 \%)$.
} 
colleges: most competitive and highly competitive institutions are less likely to participate, compared to noncompetitive private colleges (35.4 and 17.6 percentage points, respectively). Larger public institutions, as well as private institutions with higher tuition prices, are more likely to participate. Finally, expenditures per FTE and state and local appropriations are uncorrelated with participation.

Because certain types of institutions are overrepresented in the data, we construct analytic weights that improve the representativeness of the sample. For each institution, we estimate a probability of participating in the DCS for each year. We weight observations by the inverse of the probability of participation, giving more weight to programs that were underrepresented that year. Since our analyses are at the CIP-4 level, we then interact that inverse probability weight with the total student credit hours for each institution at each CIP-4, giving more weight to larger programs. We model DCS participation by institution $(i)$ and year $(t)$ using the variables considered in the sampling frame of the National Postsecondary Student Aid Study (NPSAS). The NPSAS is a survey that is nationally representative at the institution and student level, and provided a reasonable guide to choosing observable characteristics for inclusion in our model of DCS participation. We estimate the following model:

$$
\operatorname{Pr}\left(\text { Participate }_{i t}=\Phi\left(\alpha+\beta \text { Inst }_{i}+\text { renroll }_{i t}+\text { Sexpend }_{i t}+\varepsilon_{i t}\right)\right.
$$

Where Inst $t_{i}$ is a set of indicator variables for unique combinations of institutional control (public or private), Carnegie Classification (research, master's, or baccalaureate), Barron's selectivity rating (most/highly competitive, very competitive, or other) ${ }^{3}$, and region. We also include 12-month unduplicated enrollment and expenditures per FTE. The model includes

\footnotetext{
${ }^{3}$ For master's and baccalaureate institutions, we created two selectivity groups (instead of three) to achieve large enough cell sizes. Specifically, we grouped together very, most, and highly competitive institutions to compare against "other" institutions. "Other" includes less competitive, noncompetitive, and special institutions. To deal with missingness in the Barron's and Carnegie Classification variables (as described in the Coverage section), institutions missing Barron's data are grouped with "other" institutions and institutions missing Carnegie Classification data are grouped with baccalaureate institutions.
} 
polynomials of the latter two variables (quadratic and cubic) and interactions of all terms with institutional control (public or private). Appendix Table B1 reports some descriptive statistics for the unweighted and weighted samples across all years, and Appendix Table B2 reports the average weight given to each observation in an institutional category for select years. 
Appendix Table B1. Descriptive Statistics for IPEDS, DCS Sample, and Weighted Sampl

\begin{tabular}{|c|c|c|c|}
\hline & IPEDS & $\begin{array}{c}\text { Sample } \\
\text { (unweighted) }\end{array}$ & $\begin{array}{c}\text { Sample } \\
\text { (weighted) }\end{array}$ \\
\hline \multicolumn{4}{|l|}{ Institution Group } \\
\hline Research Univ, Most/High Comp, Public & $1.8 \%$ & $5.1 \%$ & $1.9 \%$ \\
\hline Research Univ, Most/High Comp, Private & $3.4 \%$ & $2.4 \%$ & $3.2 \%$ \\
\hline Research Univ, Very Comp, Public & $3.1 \%$ & $13.4 \%$ & $3.1 \%$ \\
\hline Research Univ, Very Comp, Private & $1.2 \%$ & $2.0 \%$ & $1.5 \%$ \\
\hline Research Univ, Comp, Public & $5.8 \%$ & $20.9 \%$ & $6.2 \%$ \\
\hline Research Univ, Comp, Private & $2.1 \%$ & $0.8 \%$ & $1.5 \%$ \\
\hline Masters Univ, Most/High/Very Comp, Publ & $2.4 \%$ & $5.9 \%$ & $2.4 \%$ \\
\hline Masters Univ, Most/High/Very Comp, Priv & $5.1 \%$ & $5.0 \%$ & $5.6 \%$ \\
\hline Masters Univ, Comp, Public & $14.5 \%$ & $20.3 \%$ & $13.8 \%$ \\
\hline Masters Univ, Comp, Private & $16.7 \%$ & $10.0 \%$ & $17.5 \%$ \\
\hline Bach Univ, Most/High/Very Comp, Public & $0.7 \%$ & $0.9 \%$ & $0.4 \%$ \\
\hline Bach Univ, Most/High/Very Comp, Private & $11.3 \%$ & $3.4 \%$ & $13.8 \%$ \\
\hline Bach Univ, Comp, Public & $7.3 \%$ & $4.0 \%$ & $5.5 \%$ \\
\hline Bach Univ, Comp, Private & $24.4 \%$ & $5.9 \%$ & $23.7 \%$ \\
\hline \multicolumn{4}{|l|}{ Region } \\
\hline New England & $9.1 \%$ & $6.2 \%$ & $6.2 \%$ \\
\hline MidEast & $19.9 \%$ & $17.4 \%$ & $23.9 \%$ \\
\hline Great Lakes & $15.6 \%$ & $14.2 \%$ & $18.8 \%$ \\
\hline Plains & $10.3 \%$ & $11.6 \%$ & $9.3 \%$ \\
\hline Southeast & $24.8 \%$ & $34.9 \%$ & $20.4 \%$ \\
\hline Southwest & $7.4 \%$ & $6.2 \%$ & $9.5 \%$ \\
\hline Rocky Mountains & $3.1 \%$ & $5.0 \%$ & $2.6 \%$ \\
\hline Far West & $9.8 \%$ & $4.5 \%$ & $9.4 \%$ \\
\hline Enrollment (12-month, unduplicated) & 7,939 & 15,704 & 7,496 \\
\hline Total Expenses per FTE & 21,035 & 20,857 & 20,438 \\
\hline
\end{tabular}

Notes: Table reports summary statistics for IPEDS Completions survey. The second and third columns report the same characteristics for the DCS sample and then characteristics weighted by the inverse probability of participating in the DCS times student credit hours. 
Appendix Table B2. Average Weights by Institution Group for Select Years

\begin{tabular}{lrrrrrr}
\hline & \multicolumn{3}{c}{ IPW only } & \multicolumn{4}{c}{ IPW*SCH } \\
& 2000 & 2007 & 2015 & 2000 & 2007 & 2015 \\
\hline Research Univ, Most/High Comp, Public & 1.8 & 3.9 & 3.0 & 12,878 & 25,899 & 26,086 \\
Research Univ, Most/High Comp, Private & 5.2 & 3.2 & 30.0 & 22,301 & 15,148 & 179,245 \\
Research Univ, Very Comp, Public & 2.1 & 1.6 & 2.1 & 11,490 & 10,129 & 17,665 \\
Research Univ, Very Comp, Private & 27.2 & 5.5 & 10.1 & 65,122 & 29,362 & 46,887 \\
Research Univ, Comp, Public & 2.2 & 2.1 & 2.2 & 10,098 & 11,263 & 11,533 \\
Research Univ, Comp, Private & 9.5 & 13.8 & 5.6 & 24,515 & 48,616 & 18,869 \\
Masters Univ, Most/High/Very Comp, Public & 6.2 & 2.5 & 2.2 & 24,405 & 11,383 & 9,721 \\
Masters Univ, Most/High/Very Comp, Private & 12.9 & 5.3 & 12.2 & 23,373 & 9,604 & 25,260 \\
Masters Univ, Comp, Public & 5.3 & 6.2 & 5.2 & 17,938 & 20,829 & 18,480 \\
Masters Univ, Comp, Private & 56.2 & 12.7 & 12.8 & 65,282 & 18,642 & 21,067 \\
Bach Univ, Most/High/Very Comp, Public & 4.9 & 2.5 & 5.6 & 7,611 & 4,210 & 10,172 \\
Bach Univ, Most/High/Very Comp, Private & 75.5 & 40.7 & 40.7 & 52,800 & 55,812 & 49,108 \\
Bach Univ, Comp, Public & 13.2 & 9.6 & 14.7 & 17,354 & 23,774 & 51,844 \\
Bach Univ, Comp, Private & 287.2 & 22.3 & 50.2 & 393,495 & 25,366 & 37,073 \\
\hline Nos: Averag
\end{tabular}

Notes: Average weights by institution group indicate the analytic weight given to observations in each category under two weighting schemes: the inverse of the probability of participating in the DCS, and the IPW interacted with number of student credit hours for each CIP4. 


\section{Appendix C. Details on Measurement of Costs and Cost Drivers}

Our goal is to understand the relative importance of each cost driver in generating acrossfield cost differences. We begin with the accounting identity:

$$
\frac{D I E}{S C H}=\left(\frac{D I E}{\text { PERSONNEL }}\right)\left(\frac{\text { PERSONNEL }}{\# F A C U L T Y F T E}\right)\left(\frac{\# F A C U L T Y F T E}{\text { CLASS SECTIONS }}\right)\left(\frac{\text { CLASS SECTIONS }}{\text { SCH }}\right)
$$

This would exactly hold for each program if we were able to measure all variables on the same time scale. However, some variables are measured in only the fall semester while others are measured for the full year. Whenever possible, we construct our drivers so that the numerator and denominator of each driver are measured for the same period. Given our units for the dependent variable, we want to convert all cost drivers to those units using appropriate scaling factors, $\gamma_{d}$, for cost driver element $d$. Then, letting $f$ denote that the variable was measured for the fall semester only and $y$ the full year, we can rewrite our accounting identity as:

$$
\frac{\text { DIE }_{y}}{\text { SCH }_{y}}=\left(\frac{\text { DIE }_{y}}{\text { PERSONNEL }_{y}}\right)\left(\frac{P E R S O N N E L_{y}}{\gamma_{1} \# \text { FACULTY FTE }}\right)\left(\frac{\gamma_{1} \# F A C U L T Y F T E_{f}}{\gamma_{2} \text { CLASS SECTIONS }_{f}}\right)\left(\frac{\gamma_{2} \text { CLASS SECTIONS }_{f}}{\gamma_{3} \text { SCH }_{f}}\right)
$$

If fall and spring semesters were identical across all drivers, then the $\gamma_{d}$ would not enter the equation. However, these semesters may be different and the difference may vary by program. If fall-to-spring differences were identical across programs, then the constant from equation (2) would be non-zero, but the coefficients on the drivers would be one.

Taking logs, we have:

$$
\ln \left(\frac{D I E_{y}}{S C H_{y}}\right)=\ln \left(\frac{D I E_{y}}{\text { pers }_{y}}\right)_{c i}+\ln \left(\frac{\text { pers }_{y}}{\text { facFTE }_{f}}\right)_{c i}+\ln \left(\frac{\text { facFTE }_{f}}{\text { sections }_{f}}\right)_{c i}+\ln \left(\frac{\text { sections }_{f}}{S C H_{f}}\right)_{c i}-\gamma_{3}
$$

If we knew $\gamma_{3}$, we could exactly fit this equation. Instead, we appropriate them using field (i.e., CIP-4) and institution fixed effects. Some fields may spend relatively more in one semester (i.e., fall or spring) than the other - for example, many math and science fields may have higher costs in the fall than in the spring due to tight course sequences. Since we cannot directly observe such 
field-specific scaling factors, our model is an approximation of the underlying accounting identity and the coefficients on the four cost drivers in equation (2) will not exactly equal one. Indeed, the magnitude of the bias is a function of (a) the inverse covariance matrix of the log cost drivers and the proxies; (b) the covariance of $\gamma_{3}$ with each logged cost driver and the proxies; (c) and the magnitudes of $\gamma_{3}$. We use institution and field fixed effects to control for such unobserved differences and find that the coefficients are very close to one (see Appendix Table A4). 